\title{
Paradigm Shift: an Overview on Nutrigenetics and
}

\section{Nutrigenomics}

Stefano Ciaurelli (1), Caterina Origlia (2), Ariela Adamo (3), Silvia Giannattasio (4), Michael J. Gonzales (5), Liborio Quinto (6), Pier Mario Biava (7)

1) CMNS, Via G. Oberdan 8, Latina (Italy)

2) Molecular Pathways In Life Sciences. Via Don Carlo Gnocchi 7F, Bari (Italy)

3) CMNS, Via G. Oberdan 8, Latina (Italy)

4) University of Rome Tor Vergata, Via Montpellier 1, Rome (Italy)

5) University of Puerto Rico, GPO Box 365067, San Juan, PR 00936-5067

6) Basilicata University, Via Nazario Sauro, Potenza (Italy)

7) Scientific Institute of Research and Care Multimedica Milano (Italy)

Corresponding Author: Pier Mario Biava Phon Number: + 393477823894

Keywords: Nutrigenomics, nutrigenentics, microbiota, nutraceutics, chrononutrition.

Abstract

Nutrigenetics concerns individual differences in the reaction to food based on the genetic factors. Nutrigenomics analyses direct influences of nutrients on gene expression. Both terms are explained in our review article. Nutrigenetics and nutrigenomics require a deep understanding of nutrition, genetics and biochemistry and of new 'omic' technologies. It is often difficult to appreciate their relevance in the practice of preventive approaches for optimizing health, delaying onset of disease and diminishing its severity. This paper represents a review about the current research on Nutrigenomics and Nutrigenetics, and provide scientific data for a new integrated clinical approach. 


\section{Introduction}

In the last years a new concept about nutrition and dietotherapies has arised, also because there are new evidence about the impact of some nutrients on gene expressions and transcriptions. In this scenario new areas of research were born: nutrigenomic and nutrigenetic.

In this scenario we have to consider the kinetics of the digestive process which involves the processing of nutrients by the microbiota.

Nutrigenomic investigates about nutrients actions and reactions on some important genes, and it has been seen that these aspects could influence human health in some individuals and under some circumstances.

Following nutrigenomic and nutrigenetic studies, other omic sciences help researchers to understand and comprehend several metabolic processes operated by nutrients on human genome. For instance, genomics is responsible to discover the whole expressions of complete genomes on the health of population, in combination with the environment.

Transcriptomics analyzes in a very precise manner gene transcription to understand the exact place, form of the generated transcripts, under particular conditions. Proteomics and metabolomics, also called "the future sciences" analyze proteins and metabolites derived from metabolic processes and pattern [1]. Nutrigenetics, on the other hand, characterizes nutritional needs linked to the genetic individual profile and studies the risk of developing pathologies (e.g. obesity, type 2 diabetes, or homocysteine increased blood levels). Nutrigenetics therefore has the task to identify corrective measures and strategies to prevent the diseases in relationship with the individual genetic profile (Figure 1). 


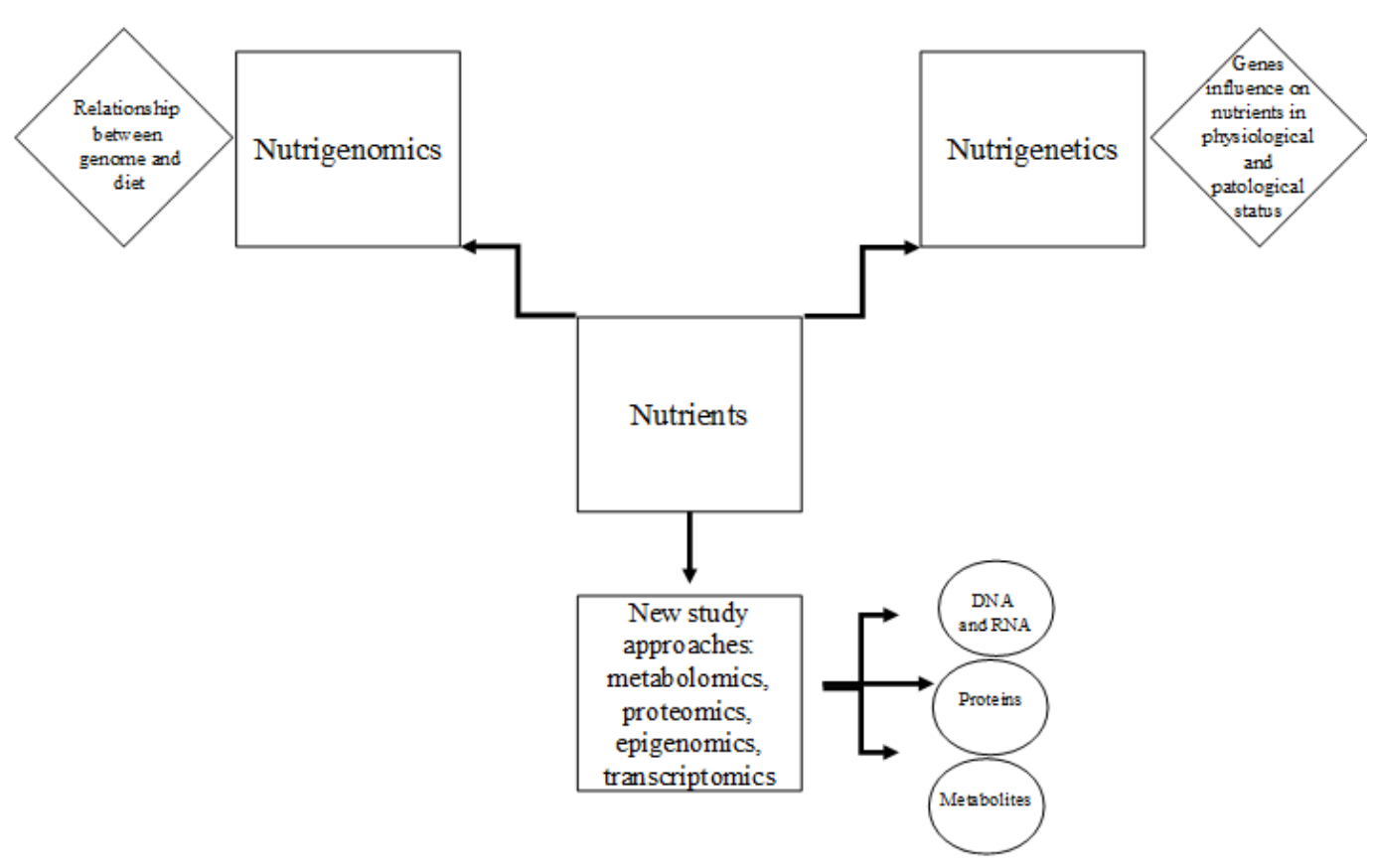

Figure 1: How nutrients interfere in several human health processes and different study methods used to investigate them.

Nutraceuticals and Nutrients and their role in Modulating Epigenome.

The identification of molecular biodiversity, increasingly detailed in particular biochemicals and biophysics, is currently proceeding at high speed in a well-defined direction: the integrated assessment of ecosystems, complex, intelligent, ordered and teleonomic units, evolving for flexible interaction between individual parts and the surrounding environment.

The valuation of biological super-organisms such as the Holobiont-Hologenome (1), the validation of the quantum theory of the Unified Field (2), the overcoming of the "Central Dogma of Molecular Biology" (3) with the development of Epigenetics (4), changed in substantial way the scientific approach by supporting the epistemology of complexity (5).

Epigenetics (6) initiated a circular research method, overcoming reductionist sequential linearity. 
New therapeutic perspective have appeared at the horizon: epigenetic therapy $[2,3,4]$, or epigenetic modulation of gene expression through epigenetic drugs (7), begins to be a well-defined reality. The search for epigenetically active agents is expanding with in vitro and in vivo trials.

The commitment also in the field of nutraceutical and nutrition is considerable.

Particular attention is paid to phytochemicals and phytonutrients (8), molecules of plant origin, secondary metabolites of plants, naturally aimed at specific functions in the interaction of plant ecosystems with the environment, such as communication with other plants, as in the phenomenon of allelopathy (9), the defense against biological or physical pathogens, the attraction of animal disseminators-pollinators, the activation and maintenance of symbiotic interaction with various microorganisms, etc. Many phytochemicals and phytonutrients, at appropriate dosages, are biologically active in maintaining well-being and protection from pathological conditions [5.6.7].

Phytochemicals, phytonutrients and epigenetics

In this paragraph we describe the role of different phytochemicals and phytonutrients for which scientific data confirm an epigenetic regulation $[8,9]$.

\section{Curcumin}

The curcumin is a component of the phytocomplex of the Curcuma longa, perennial plant, of the family of the Zingiberaceae, native to the Indian subcontinent, in particular of India and Pakistan, widely used in the Ayurvedic medicine [10,11,12].

It is extracted from the primary, oval, and secondary rhizomes, elongated.

It's a polyphenol, diferuloilmethane, soluble in ethanol, alkali, acetone, acetic acid, and chloroform. 
The overall action is anti-free radicals, anti-oxidant, anti-inflammatory, neuro-protective, chemopreventive [7], modulating angiogenesis.

It interacts on different signalling pathways and on epigenetic modulation $[3,8,13,14,15,16,17]$, at different levels, as evidenced by numerous experiments, in vitro and in vivo, carried out on different tumoral cell lines and in patients suffering from chronic degenerative diseases, like diabetic nephropathy, heart hypertrophy, congenital heart disease. It has demethylating action. It inhibits DNA-methyltransferase [13,14,16], DNMTs, especially DNMT1 [15,16]. It modulates the expression of promoter methylated genes and induces demethylation of partially methylated genes. It reduces the p-300/HAT activity [13]. It inhibits histone acetyltransferase [13], HATs, causing hypoacetylation of histones H3, H4 by p300/CREB-1 binding protein [15,16], CBP. It reduces the expression of several histones deacetylase [13], HDACs, including 1, 3 and 8 [15]. It increases phosphorylation of histone H3 [15]. It inhibits BRCA1 gene expression by inhibition of histone acetylation [15]. Curcumina exerts down-regulation of histone methylation [14]. It modulates miRNAs [13], activating tumor suppressor genes and inhibiting oncogenic genes and up-regulates the miRNAs with onco-suppressive action, such as miR-9, miR-15a, miR-16, miR-22, miR-26a, miR-34a, miR-145, miR-146a, miR-200b,c, miR-203, regulating downstream target genes such as Er-1 and Sp-1 [13]. It down-regulates miRNAs oncogenicic, as miR-19a,b, miR-21, miR-27a, miR130a, miR-186, favoring the arrest of the cellular cycle and the apoptosis [13]. It activates caspase by delaying cell growth and proliferation via $\beta$-catenin pathway [13]. Curcumin modulates estrogen receptor, ER, and HER2, human epidermal growth factor of receptor 2; it activates p53, with transcriptional regulation of p21, GADD45, APO-1, BAI1, and modulation of the cell cycle, DNArepair, apoptosis and angiogenesis and interacts on different signaling pathways: COX-2, STAT, NF-кB, MAPK, Jak/STAT, Akt, p53, p38, mTOR, Notch-1, Erk1/2, androgen receptors (AR), estrogen receptors (ER), Ras and on different kinases $[13,14,15]$. On the tumor cell lines it plays inhibition and contrast effect by stimulation of apoptosis, reduction of proliferation by modulation of Akt expression, Bax Activity, ERK, MKK4, JNK activity, Bcl-2, Cell viability [13,14]. It 
inhibits the expression of anti-apoptosis factors such as cl-1 and the family Bcl-2 and increases the expression of apoptosic factors such as Bax, pro-caspase-3, 7 and 9, mitochondrial release of cytochrome $\mathrm{C}$ and apoptotic activation produced by TNF, inhibits P13/AKT signalling pathway $[14,15]$. Target genes examined in experimental oncology include: CDKN2B, NEUROG1, NFE2L2, Nrf2, Neurog1, RASSF1A, p16, SPARC, SOCS1, SOCS3, p53, p21, GAS5, HOTAIR, H19, AFO86415, AKO95147, RP1-17916.3, MUDENG, AK056098, AK29400 [14]. The effective dose is variable in the achievement of epigenetic modulations, for a maximum value of $160 \mu \mathrm{M}$ at decreasing doses, depending on the action examined, in vitro, on breast cancer cells, prostate, colon-rectum, stomach, and ovary [14]. The epigenetic effects are integrated with the already known actions of curcumin: anti-inflammatory, anti-oxidant, hepato-protective, neuro-protective, anti-bacterial, anti-viral, anti-mycotic, modulating cortisol bioavailability $[10,11,12]$. Curcumin selectively inhibits 113 -HSD1, reducing the bioavailability of cortisol; it also inhibits the synthesis of cortisol activated by ACTH and angiotensin II at the level of aCYP11 steroid-hydroxylase, mRNA coding the acute regulatory protein of steroids and ionic channels $\mathrm{Ca}_{\mathrm{v}} 3.2 \mathrm{Ca}^{2}[10,11,12]$. Long-term administration of $10 \mathrm{mg} / \mathrm{kg}$ of curcumin, in some studies seven $100 \mathrm{mg} / \mathrm{kg}$, stimulates adrenal secretion of cortisol, by inhibition of bTREK-1 K+ channels [11].

Curcumin inhibits the following $[10,11,12,15]$ :

-5-lipo-oxygenase, 12-lipo-oxygenase and oxygenase cycle, especially 2, with transcriptional and post-transcriptional mechanisms;

-production of IL-1 and macrophages TNF;

-activation of the nuclear factor NF $\kappa \mathrm{B}$;

-PGE2 synthetase 1;

-NO synthesis induced by gamma interferon by suppression of iNOS;

-the action of hepatic stellate cells of synthesis and collagen deposit;

-phosphorylation and leptin receptor expression;

-glutathione S-transferase; 
-the activation of NLP3 Inflammasoma;

-the VEGF

-the production of macrophage inflammatory protein-2, MIP-2, at the level of the brain;

-the synthesis of matrix metalloproteinas produced by mononucleate blood-cells;

-the activity of multidrug-resistance-linked ATP Binding Cassette, ABCG2, carrier of certain drugs such as sulfasalazine;

-the growth of Helicobacter pylori.

- parasitic growth by modulating histone acetylation levels;

and $[10,12]$

-it reduces the biological activity of TNF and the levels of microsomal and mitochondrial hydroperoxides;

-it reduces the activity of the p300.

;it activates Peroxisome Proliferator-Activated Receptor $\gamma, \operatorname{PPAR} \gamma$;

-it increases glutathione and superoxydodismutase levels;

-it crosses the blood-brain barrier;

-experimentally it reduces the density of amyloid plaques, prevents the formation of new deposits and promotes the functional recovery of damaged neurons with antioxidant action;

-it's a direct-acting antioxidant;

-it has antispasmodic action on the smooth muscle cells of the digestive tract;

-t chelates the heavy metals.

It has a low bioavailability: about $20-60 \%$ of the oral dose is metabolized by the intestinal mucosa and the liver.

The association with black pepper piperine or long pepper piperine, excellent bioenanchers $[10,11,12]$, increases blood concentration and half-life, favoring intestinal absorption and slowing down liver catabolism. 
The half-life may also be favored by association with lipid molecole such as oils, even the same essential oil of turmeric, or with bromelain, epigallo-catechin-gallate, resveratrol, to bioenachers action, or carrier like nanoparticles, curcumin-phospholipid, in the form of liposomes and phytosomes.

Currently potential toxic action is reported in the course of liver diseases or gallbladder and biliary tract [18]. It interacts with drugs. The daily therapeutic dosage of pure dry extract of curcuma longa titrated at $95 \%$ curcuminoids varies between 500-1000 mg, with 475-950 mg of curcuminoids divided into two or three doses/day, of phytosom or liposome of purified curcumin $150 \mathrm{mg}$ twothree times a day, even $100 \mathrm{mg}$ in nanoparticles.

\section{Resveratrol}

It's a polyphenol, 3.5.4' trihydroxy-trans-stylbene, phytoalexin (10) synthesized by plants of the Vitaceae family, Poligonaceae, various bryophytes and higher plants, as a protective agent in reaction to parasitic invasions, fungi and bacteria or to physical agents such as UV rays.

Particularly concentrated in the phytocomplex of the Polygonum Cuspidatum, perennial herbaceous plant of the family of the Polygonaceae, native to eastern Asia, it is well represented also in the skin of the grapes, infructescence of the Vitis Vinifera. in the red variety, rather than white, in red wine more than white, in peanuts, pistachios, almonds, walnuts, raw cocoa and bitter cocoa beans, strawberries, cranberries, currants, fresh mulberries and various berries. It's absorbed in the gut. It has particolar organotropism for the liver. Bioavailability increases from the intake during meals and is reduced by glucuronation in cis and trans forms, by hepatocytes. It aroused the first interest in the anti-free radicals, antii-oxidant general, anti-peroxidant lipid, anti-inflammatory, antiaggregant platelet, vasodilator, cardio-vascular protective, so much to be held responsible for the "French Paradox" as a factor of protection of cardiovascular diseases in diets rich in saturated fats such as that typically French. Research data [19], subsequently confirmed its detoxifying, anti- 
allergic, hormonal modulating, epigenetic [3,8,9,14,16,17], chemo-preventive and anti-aging effects, even for topical use. The benefits are mediated by complex regulation and modulation of different signaling pathways and key enzymes. It reduces oxidation catalyzed by copper and performs action mercury-protective. It stimulates tetrahydrobiopterin-GPT-cyclohydrolase and modulates the gene expression of enzymes related to oxidative processes. It promotes the synthesis of SOD1 and GPX1 and inhibits NADPH oxidase [8]. It inhibits COX1 and COX2. It inhibits the pathway of factor NF- $\kappa B[8,16]$ with anti-inflammatory and anti-proliferative action. It turns on the iNOS [17]. It inhibits the oxidation of LDL inhibiting the COX-2 and scavengerr receptor expression (SR-A) and stimulating the vessel dilatation activity of eNOS [17]. It inhibits the proliferation of VSMC, smooth vascular muscle cells, blocking the G1-S transcription of the cell cycle. It activates the transcription mediated by PPARs, Peroxisome Proliferator-Activated Receptors, with expression of genes active in the control of lipid and glucidic metabolism, of particolar interest also in anti-inflammatory modulation, cardio-protective vascular, metabolic atherosclerosis, diabetes mellitus and neoplastic diseases. Stimulation of the transcription factor PPAR $\alpha$ optimizes the lipid metabolism, phosphorying the receptor, thus protecting it from oxidative stress. The anti-oxidant action, inhibiting both platelet aggregation and lipid accumulation, monocyte and lymphocytic infiltrations well as the migration of smooth muscle cells, motivates the preventive anti-atherosclerotic, arteriosclerotic and protective cardio-vascular action. Resveratrol stimulates phosphorylation of ERK 1/2, which in turn phosphorylates PPAR $\alpha$. At low concentrations it is a partial agonist of ER (estrogen receptors). At high doses it antagonizes 17 beta estradiol and its proliferative action. It reduces levels of PSA, Specific Prostate Antigen. It has cancer preventive [9] modulating enzymes involved in carcinogenesis and inhibiting the activation of growth factors and cell proliferation [14]. It induces cell cycle arrest in neoplastic cells by decreasing D1 and D2 cyclines and Cdk2, 4, 6 kinases, inhibits "amyloid-like" aggregation of mutant p53. It induces expression, phosphorylation and acetylation of proteins p53 and p21 with unexpected. The regulation on p53 is mediated by MAPKs [16], Mitogen-Activated Protein 
Kinase, particularly ERKs and p38. It reduces phosphorylation of AKT [14] (and Akt/PBK) with pro-apoptotic action. It inhibits cellular adhesion. It activates, phosphorylating, the p66shc (of the Shc protein family), active in the control of mitochondrial metabolism, inhibiting cell proliferation and "signal survival". It modulates DNA polymerase, proteinkinase D, cPKCs, ribonucleasi reductase. It induces apoptosis. It induces autophagy by inhibition of the mTOR [14] and mTORC1 pathway [8].

At the epigenetic level it:

-inhibits DNMT3a, DNMT3b and HAT [14]

-inhibits methylation of BRAC1 gene [17]

-activates SIRTS, Sirtuine, Silencing Information Regulator, class of NAD-dependent deacetylase, transcriptional modulators of the silencing of genes responsible for cell aging and survival, especially SIRT-1 but also SIRT-2, SIRT-3 [14,17] and SIRT-4 and up-regulation of mir-let-7f-1 prostatic level [8].

It determines the change of the mevalonate and the activation of the protein Ras.

It reduces oxidative damage of DNA and acts on DNA with demethylation and antioxidant.

It demethylates partially the glutathione gene $S$ transferase P1, GSTP, and increases its mRNA expression regulating the phosphorylation and acetylation of histones.

It sub-rules the trans-forming growth-factor, TGF and over-rules mirRNA-21 [17].

The action is stabilized by the intake of melatonin.

It is also used in topical preparations.

The daily dosage is between 250 and $500 \mathrm{mg}$.

\section{Lycopene}

Lycopene is a red pigment of lipid nature, a tetraterpenoid, carotenoid linear, acyclic, non provitaminic A, particularly susceptible to the action of light and oxygen with the formation of successive oxidated degradation products, toxic, mutagenic. 
It is present as a "trans" isomer, thermally more stable, in fresh coloured fruits and vegetables, such as watermelon, apricot, papaya, pink grapefruit, pink guava, mango, grape rosehip. It is found in higher concentrations in the outer part of the mesocarp of the ripe red tomato, berry of the plant Solanum lycopersicum L., or Lycopersicum esculentum (ICBN, International Code of Botanical Nomenclature), belonging to the family of the Solanaceae. The concentration is different in relation to the vegetative period and the variety of the plant, being maximum at the veraison, that is at the beginning of the acquisition of the colour of maturation. The cooking temperature also favors the release of lycopene from protein molecules and dispersion. The cooking with oil favors the isomerization in"cis", to minor steric encumbrance, greater solubility in the micelles of absorption, greater bioavailability and nutraceutic alactivity. The isomer "cis" is distributed in human tissues, accumulating in the lipophilic territories, especially in the adipose tissue, but also in the liver, skin, breasts, testicles, adrenals and prostate, especially at the level of the cell membrane of androgenicsensitive prostatic cells. The bioavailability is enhanced by the intake at meals and in association with other carotenoids, especially beta carotene, while it is reduced by the consensual introduction of plant sterols, hypolipemic drugs and foods high in cholesterol. The synergy with the polyphenols and other carotenoids contained in the plant phyto-complex of the berry, the raw material of extraction, enhances numerous biological effects [20,21]. Lycopene has antifungal, antibacterial and antitoxic action towards monopodic-glutamate and, experimental on rat, cadmium, aflatoxins and cyclosporine, anti-free radicals, anti-oxidant, anti-aging and anti-inflammatory, detoxifying, cardioprotective vascular, chemopreventive and photo-aging, also modulating cellular communication, immune activity, hormonal responses and the epigenome $[3,8,16]$ :

-it induces the enzymes of I and II phase of liver detoxification, in particular of cytochrome P450 (possible interference with other biological molecules and drugs such as cyclosporine), and quinone reductase; 
-it inhibits the expression of adhesion cells and leukocytes and prevents the migration of endothelial cells supporting vascular barrier integrity;

-it inhibits the expression of HMG-Coa reductase and by ACAT, acilCoA-cholesterol acyltransferase, reducing the synthesis of cholesterol and the blood concentration of LDL:

-it protects lipid molecules, such as LDL, from lipoperoxidation: this effect is favored by the presence of vitamin E. It inhibits the COX;

-it promotes the antioxidant activity of Glutathione-S-Transferase, Superoxydodismutase (SOD) and catalase (CAT). It performs scavenger, anti-oxidant, action of DNA and T lymphocytes;

-it promotes the production of IL-2 and IL-4. It prevents and reduces the incidence of free radical fractures on bone tissue. It improves urinary flow, reduces PSA values and chronic pelvic pain during prostatitis and prostatic hypertrophy;

-it contains inflammatory manifestations, such as pancreatitis, reducing neutrophilic infiltration, lipid oxidation, activation of NF- $\mathrm{BB}$ expression of inflammatory cytokines by ROS.

Lycopene taken through foods in which it is naturally contained at high concentrations, plays interesting effects of modulation and reduction of the incidence of prostate cancer, digestive system, including the oral cavity and pancreas, breast. Lycopene inhibits growth-induced proliferation and cell cycle progression, reducing cell growth and promoting cancer cell apoptosis [8]. On animal cancer models it reduces the growth of mammary, prostatic and pulmonary tumors. The action is particularly studied at the level of prostatic and mammary cancer cells. Lycopene modulates the expression of active genes on the control of the cell cycle, for the repair of DNA and apoptosis and reduces the frequency of micronuclei, regulates cell growth by inhibiting the expression of cyclines involved in the progression of the cell cycle, inhibits the activity of the growth-factor IGF-1, which accentuate the predisposition to prostatic cancer and breast cancer in premenopausal. It demethylates partially induced harpin 1 genes in non cancer breast cells and TSG glutathione S transferase $\mathrm{P} 1$ in breast cancer cells. It modulates the expression and activity of $\mathrm{Wnt} / \beta$-catenin and androgens and reduces the expression of 5-alpha reductase. It promotes apoptosis of prostatic cells 
in IPB, benign prostatic hypertrophy. It inhibits DNA synthesis, and the expression and activity of the androgen receptor gene in prostate cancer cells. It determines down-regulation of AKT2 expression in MDA-MB-468 breast cancer cells line, and of RARbeta 2 gene and harpin induced 1, HIN-1 genes, possible early markers of cancer, in non tumorigenic MCF10A fibrocystic breast cells [16]. It regulates the expression of the connexin 43 gene, protein of the junctions, increasing its miRNA by improving cellular communications at the junctions level [8]. It supports GJC, Gap Junction Communication at intercellular junction level. It inhibits the epidermal ornithine decarboxylase activity by protecting the skin from photo-aging: topical use prevents and reduces damage from even carcinogenic UV radiation [16]. It is used in the food industryas a dye, additive, indicated by the acronym E 160d. Beneficial effects are reported in the literature at daily dosages of $30-60 \mathrm{mg}$ up to $100 \mathrm{mg}$. The maximum daily dosage of one-component lycopene, for Italy is 15 mg, as an administration in supplements and foods added only with notification procedure (Italian Ministry of Health 2018-Other nutrients and other substances with nutritional or physiological effect-September Review) [18]. High dosage can produces lycopenemia, yellow-orange skin coloring, reversible with suspension.

\section{Uncaria Tomentosa}

Uncaria tomentosa $[5,8]$, or Cat's claw or Uña de gato in spanish, is a climbing liana native to the Amazon forest. The drug is represented by the root of plants between 3 and 8 years, dried, by the bark of the root and by the caul. The phytocomplex includes, among the active ingredients, predominantly alkaloids, oxyndolics, depending on the chemotype, pentacyclics, (uncarine B, E, F, D, mitraphylline), and tetracyclics, pentacyclic and tetracyclic indoles. It also contains quinoic acid glycosides, triterpene saponins, sterols, polyphenols, pyrquinovic acid glycosides. It has antiinflammatory, immunomodulating-immunostimulating, anti-oxidant, anti-hypertensive, antiaggressive, adaptogenic, DNA-repair [8], antiapoptic, anti-aging, neurotrophic, neuro-protective, 
chemo-protective. Experimentally it induces the expression of IL-1 $\beta$, IL-1 and IL-6 in macrophages, of IL-1 $\beta$ and simultaneous reduction of TNF- $\alpha$ expression [8] in THP-1 monocytes stimulated with LPS, promotes the increase of immune-related cells, especially neutrophiles, CD2 and CD4 $\mathrm{T}$ cells and a decrease in eicosanoid concentration PGE2, PGF2, TXB2. It plays chemo-protective action on immuno-competent cells. It inhibits CYP3A4 [8] by interfering with several medications such as cyclosporine, some benzodiazepines, protease inhibitors, non nucleoside reverse transcriptase inhibitors, for example. At high dosage it can cause diarrhea and intestinal spasms. The dosage reported in the literature varies between 300 and $750-1000 \mathrm{mg} / \mathrm{day}$ of extract with $3 \%$ titration in pentacyclic oxyndolic alkaloids and $6 \%$ in triterpene glucosides, divided into two to three daily doses.

\section{Capsaicin}

Capsicum [5,8], commonly Capsicum from "capsa", in Latin container, is an herbaceous plant of the family of the Solanaceae, native to Central America. It includes several species, such as the Capsicum annuum minimum variety, the common chili pepper, and the Capsicum frutescens, the paprika. The drug is represented by ripe dried fruits and contains up to $1 \%$ capsaicinoids, such as capsaicin, as well as vanillilammides of caprylicacid and nonilic acid, carotenoids, vitamins A and C. The capsaicin is endowed with action pain killer, analgesic, anti-inflammatory, immunostimulating, thermogenic, stimulating the metabolism and the physical resistance, anti-obesity, vascular protective, chemo-preventive $[8,22]$, in topical and trophic revulsive oleoresin for the scalp. Capsaicin, 8-methyl-N-vanillil-6-nonenamide, is an agonist molecule of vanilloid receptors type 1 or TRPV1, of non-selective TRPV1 cationic channels. The TRPV1 protein, transient receptor potential cation channel subfamily $\mathrm{Y}$ member I, is distributed in the central nervous system and Ctype polymodal fibers endings of sensitive neurons: receptor activation first causes urent 
perception-pungent, with a subsequent long period refractory to the neuronal transmission of stimuli and anagesic-pain killer effect. Endothelium-dependent vasodilation is associated.

The TRPV1 receptor is also present at the gastric level, where activation causes vasodilation, endothelial permeability and stimulation of the duodenal peristalsis, and prolonged stimulation leads to reduction of acid secretion. The TRPV1 receptor is also abundantly expressed in the nerve fibers of the nasal mucosa. Capsaicin inhibits the secretion of substance $\mathrm{P}$ and promotes the expression of eNOS, COX-2, anti-oxidant enzymes Nrf2-reactive and thrombomodulin. It subregulates the expression of VEGF, vascular endothelium growth factor, EGFR, PI3K/Akt/mTOR signalling pathways, inhibits MMP-2, MMP-9, Bcl-2, mesenchymal markers vimentin and Ncadherin, tNOX expression, NADH oxidase tumor-associated, actives on different tumor cell lines apoptosis from mitochondrial damage by ROS and Jun kinase, JNKs, intervening experimentally in vitro and in vivo on the development, growth and spread of different tumor forms, also by interference with angiogenesis. The secondary metabolites of capsaicin, not spicy, capsiate, dihydrocapsiate and nordhydrocapsiate, stimulate the thermogenesis of brown adipose tissue activating mitochondrial decoupling proteins, UCPs, uncoupling proteins, or thermogenin, the orthosympathetic system at the level of $\beta 2$-adrenergic receptors, favoring the appearance of beige adipocytes in white adipose tissue and inducing satiety [8]. The daily dosage of capsaicin, as a dry extract titrated at $2 \%$, varies from 6 to $10 \mathrm{mg} /$ day, divided into several doses. It can give gastric pyrosis.

\section{Bacopa monnieri}

Bacopa monnieri [5,8] or Herpestis monniera or, in Sanskrit, Brāhmī or Sarasvatī, is a herbaceous plant widely used by traditional Ayurvedic medicine. Native to Asia, species of the humid zones of India, it is present in brackish and marshy regions also in other areas as well as in the southern ones of the United States. It belongs to the family Scrophulariaceae. Its phytocomplex contains several 
active ingredients: triterpenic saponins, called bacosides, such as the bacoside A (containing in higher concentration the bacogenine A3, and in lower quantity the A1 and A2), alkaloids (brahmin, herpestine, monnierine), flavonoids. It has a particolar tropism for the nervous system, in particular for the amygdala, the hippocampus, the striatum and the frontal cortex. It has a nootropic, neuroprotective, neuro-restorative, psycho-stimulating action. It manifests adaptogenic functions supporting stress resilience processes. It supports attention, cognitive processes, mnesicability, learning, discriminatory ability, speed and efficiency of reflexes. It optimizes mood tone, has anticonvulsivante effect, relaxing, anxiolytic and sedative. It reduces the formation and accumulation of $\beta$-amyloid and improbe cerebral perfusion. It contracted experimentally, especially at amygdala level, reports related to pre-natal stress induced in rats [23], such as increased corticosterone concentration, ACTH, glucocorticoid receptors, pro-apoptotic Caspase-receptors 3, of receptora 5HT 2c, reduction of 5-HT1A receptor, synaptophysin and synaptotagmin-1, synaptic proteins, post synaptic density protein 95 , anti-apoptotic Bcl-2, phosphorylation of calmodulin-dependent protein kinase II/neurogranin, $\mathrm{N}$-methyl-D-aspartate receptors $(2 \mathrm{~A}, 2 \mathrm{~B})$, inhibition of pro-BDNF conversion to mature BDNF. It attenuates the manifestations of ADHD (Attention Deficit and Hyperactivity Syndrome), neuro degeneration, in particular senile degeneration, and reduces intellectual fatigue. It inhibits the enzymes MAO-A and B. It inhibits acetylcholinesterase and activates choline acetyltransferase. It interacts with serotoninergic and adrenergic receptors. It intervenes in the modulation of dopamine and Gabaergic pathways. It's an epigenetic modulator. It demethylates the reelin and BDNF DNA-promoter regions of DNA [24]. It's also an excellent antioxidant, anti-free radicals, anti-inflammatory, digestive, bronchodilator, emmenagogue. The daily dosage is $100-400 \mathrm{mg}$ of dry extract titrated at $20 \%$ Bacosides A and B. The association with other neurotrophic plants, such as Centella asiatica, Whitania somnifera, Griffonia simplicifolia, Asparagus racemosus, Ginkgo biloba, Triphala and Ginseng is good. At the dosage of $300 \mathrm{mg} /$ day it manifests antidepressant action. 
Fisetin

It's a flavonol, flavonoid polyphenol found in several plant products, especially apples, strawberries, water melons, persimmons, cucumbers and onions. It's an anti-oxidant [25], anti-free radicals, anti-aging, senolithic [26]. It has a neuro-protective effect [27], supports long-term memory, cognitive ability and mood with anti depressant effect. It carries out chemo-preventive action $[8,25,28,29]$, experimentally demonstrated on different cell lines, intervening on the cell cycle phases, favoring apoptosis [30] and reducing cell migration. The effects are mediated by epigenetic modulation and different cell signaling pathways. It reduces meyhylglyoxal dependent protein glycation [31] and the production of pro-inflammatory cytokines induced by hyperglycemia [32], countering radical carbonyl stress, glycation and insulin resistance. It inhibits the transformation of preadipocytes into adipocytes, hepatic and adipocyte fibrosis. It activates the sirtuins. It inhibits $\mathrm{PI} 3 \mathrm{~K} / \mathrm{AKT} / \mathrm{mTOR}$ signaling pathways and Bcl-xL protein. It induces oxidative stress and stimulation of caspase expression, subregulating the expression JAK1 and STAT3 in TPC-1 cells, inducing apoptosis [33]. It inhibits PAK4 signaling pathway in oral squamous carcinoma cells by inhibiting cell proliferation and migration and favoring apoptosis [34]. It's a topoisomerase inhibitor. It promotes the expression of proteins p53 and of p21, p53 inducible. It inhibits TNF-alfa and IL-6 and NF-kB, deacylated by sirtuin 1. It up-regulates the glutathione. It is direct antioxidant and protects from lipoperoxidation. It contains skin damage from UVB rays [35] by inhibiting the expression of MMPs, COX-2, IL-6, NK-kB, PI3K, phosphorylation of AKT [8], increasing the expression of cutaneous Nrf2 [35], inhibiting the damage of aquaporin and filaggrin. It has an antibacterial action. It enhances the action of quercitin, resveratrol, vitamin D and other epigenetic modulators. The average daily dosage in dry extract is $100 \mathrm{mg}$. 


\section{Ziziphus jujuba}

The Ziziphus jujuba, commonly called jujube or Chinese date, is a small fruit tree of the family of the Rhamnaceae, native to south-east Asia and diffused also in Australia and Europe. The edible fruits, the jujubes, are rich in vitamins, in particular the $\mathrm{C}$, saponosids, tannins, anthraquinones, alkaloids (the zuzufusin), cyclopeptides, flavonoids (quercetin and catechin), pectin and mucilages, carbohydrates.

The drug is represented by the seeds, rich in triterpenic saponins: betulin, betulinic acid, jujubosids. It has anti-oxidant, anti-inflammatory, anti-obesity, protective of the digestive tract, tonic, adaptogenic, anxiolytic, hypno-inducer, and, in vitro, chemo-preventive, anti-proliferative and proapoptotic $[8,36,37]$. It reduces the action of the monoamine system. In vitro it induces apoptosis, dose-dependentcy to toxicity, on some tumor cell lines [38]. It modulates the gene expression of proapoptotic Bax and antiapoptotic Bcl-2 proteins. The optimal effect is obtained with the aqueous extract. The indicated daily dosage is $200-400 \mathrm{mg}$. Possible interference with venlafaxine is described.

\section{Ellagic Acid}

The Pomegranate, Punica granatum, is a fruit tree, the pomegranate, native to Asia Minor, of the family of the Punicaceae. It produces at the level of the fruit, the seeds, but also of the bark, the leaves and the flowers, various compounds of polyphenolic nature, hydrolyzable tannins, the punicalagins or ellagitannines, besides ellagic acid and its conjugated glycosides. Ellagic acid [8] is a polyphenol produced by hydrolysis of ellagitannines, and in some plants, of the geraniin. After ingestion, the punicalagins, by action of the intestinal microbiota, are transformed into ellagic acid and then into urolithine, with variability of expression in relation to the enterotype. Urolithines, especially A, have anti-free radicals, anti-oxidant, anti-inflammatory, anti-dysmetabolic, antihypertensive, neuro-protective epigenetic $[14,16]$ and chemo-preventive action on some tumor cell 
lines (prostate cancer, hepatocellular, cutaneous , pulmonary, esophageal p. e.) [14]. In several experimental studies they manifest inhibitory effect the enzyme ACE, the alpha-gucosidases, the lipases and anti-atherosclerotic activities. Ellagitannines have protective action on the gastric mucosa, anti-free radicals, anti-oxidant, anti-inflammatory, anti-microbial, anti-viral, anti-mycotic immuno-stimulating, protective cardio-vascular [39] and chemo-preventive. In experimental works they also manifest the role of ACE inhibitors. Ellagitannins act on different signalling pathways and different transcription factors in neoplastic cell lines. They determine up-regulation of miR-let-Te, miR-370, miR-373, miR-526b and down-regulation of let-7a, let-7c, let-7d [16], interfering on proliferation and cellular differentiation. Ellagitannines have been identified also in the nuts, in the strawberries, blackberries, raspberries, cranberries, almonds, walnuts, grapes, Goji berries, peaches, pecans, but also in the oak, Quercus albus and Quercus robur, in the macrophyte Myriophyllum spicatum, in the Balanophora japonica and the mushroom Phellinus linteus. Ellagic acid has antifree radical activities, anti-oxidant, iron chelating, anti-inflammatory, immuno-modulating, antiangiogenetic, photo-protective skin damage from ultraviolet radiation [40], UV, chemo preventive, pro-apoptosica and anti-proliferative neoplasty. It inhibits the binding of $\mathrm{N}$-nitrosamines to polycyclic aromatic hydrocarbons and DNA. It carries out neuro-protective effects acting as antioxidant and inhibiting NLRP3 inflammasoma signalling pathway [41]. It also inhibits DNMT1, DBNT3b and HDAC. It induces the expression of p53/p21 [42]. It modulates the regulatory kinases of angiogenetic signalling. It acts on the gene expression of caspase $3 / \mathrm{Bcl}-2 / \mathrm{Nrf}-2 / \mathrm{NF}-\mathrm{kB} / \mathrm{TNF}$ alpha/COX-2 [43]: it inhibits the signaling Bcl-2 and Cox-2 and favors the Nrf-2, caspase 3 and 9. It increases the activity of catalase and glutathione. It reduces the production of MDA, malonyaldehyde. It reduces, in experimental models, the expression of MCP-1, IL-1 $\beta$, IL-6, IL-8, IL-10. It inhibits signalling pathways induced by hypoxia-inducible factor $1 \alpha$, HIF-1 $\alpha$, VEGF/VEGFR and PI3K/Akt/mTOR, MAPK [44]. The daily dosage is between 70 and $600 \mathrm{mg}$ of ellagic acid (in products with titration between 40 and $70 \%$ ) divided into two to three doses. The 
action is enhanced by the simultaneous administration of other phytochemicals such as curcumin, rosmarinic ac

\section{Ginger}

Ginger, or Zingiber officinale [5], is a plant of the Ayurvedic therapeutic tradition belonging to the family of Zingiberaceae, native to south-east Asia. The drug is represented by the deprived rhizomes of cork, fresh, dried or powdered, containing a rich phytocomplex with essential oil, terpenoids, gingerols, these in turn transformed in the dry product in shogaoli. Ginger is used for its effective anti-inflammatory action, anti-pain article-muscle, anti-migraine, anti-dysmenorrhic, digestive, anti-free radicals, anti-oxidant, anti stress-carbonyl with inhibition of the formation of AGES, Advanced Glycation End Products, and therefore anti-glycating. It reduces the duration and intensity of menstrual flow and inhibits the growth of Helicobacter pylori. Gingerols and shogaols are inhibitors of peripheral 5-HT3 receptors, TRPV1 receptors activators, transient receptor potential V1. They inhibit COX1-COX2 and LOX-5 [45]. The 6-shogaol has neuroprotective action, with enhancement of mnesic function. Ginger extracts in toto and 6-gingerol intervene on different reporting pathways, Bax/Bcl2, p38/MAPK, Nrf2, p65/NF-kB, TNF- $\alpha$, ERK 1/2, SAPK/JNK, ROS/NF-kB/COX-2, caspase-3, caspase-9, p53, as confirmed in vivo and vitro on different tumor cell lines, by promoting apoptosis, inhibiting growth, proliferation and tumor dissemination $[8,46]$. The epigenetic action in anti-inflammatory direction is reinforced by the Alpinia galanga [8], also of the family of the Zingiberaceae. Zerumbet ginger, or Alpinia zerumbet, of the Zingiberaceae family, also has epigenetic activity with inhibition of HDAC, histone deacetylase. The daily dry extract dosage is $300-600 \mathrm{mg} /$ day titrated in $5 \%$ gingerols. 


\section{Rhodiola rosea}

Rhodiola rosea [5] is a small shrub of the family of the Crassulaceae, native to the cold and mountainous zones of the Caucasus. The name rosea comes from the smell that emanates when cutting the roots. It is particularly rich in active ingredients, especially present in the autumn in the roots and rhizome of plants of at least 3 years. Its phytocomplex has phenylpropanoids derivatives of cinnamic acid, rosavine rosin, rosavin and rosarine, and derivatives of phenylethanol, such as salidroside and p-tyrosol. Rhodiola in phytotherapy is indicated as an adaptogenic, anti-astenic, anxiolytic, anti-depressive remedy. It enhances attention, concentration and short-term memory, physical endurance, mood, even in mild forms of eating disorders, reduces fatigue, promotes sleep [8]. It's anti-free radicals, anti-oxidant, anti-inflammatory, anti-arrhythmic, cardioprotective. It manifests immuno-stimulating and chemo-preventive action [47]. It inhibits IL-6 and IL-1 $\beta$, the TNF- $\alpha$, by interfering with the NF-kB and MAPK signalling pathways and activating the inflammasoma NPLRF3. It inhibits JAK2-STAT3 pathways by suppressing STAT3's nuclear localization. It overrides the SIRT1 expression.It stimulates the production of IgG immunoglobulins and CD3+ and CD4+ Th1 T cells. It inhibits mTOR signaling pathway, antagonizing angiogenesis, by subregulation of HIV-1 $\alpha / \mathrm{HIF}-2 \alpha$ expression. It supports neurogenesis, with anti-inflammatory action, reducing the synthesis of $\mathrm{PCR}$, reactive $\mathrm{C}$ protein, stimulating the synthesis of ATP, protecting the hippocampus neurons under stress and promoting their proliferation and differentiation. The neuroprotective action is mediated by the activation of the complex I through the antioxidant pathway DJ/Nrf2 [48]: the rhodiola increases the nuclear trans location of DJ-1 and Nrf2 and mitochondrial of DJ-1, enhances the action of the enzymes glutathione-peroxidase, GSHPx, superoxydodismutase, SOD, catalase, CAT, and reduces reactive oxygen species, ROS. It's a MAO, Monoamine Oxidase Inhibitor, MAOI. It increases levels of serotonin, norepinephrine and opioid peptides, such as $\beta$-endorphins, in the brain and modulates the hypothalamus-pituitarycorticosurrene axis. It's a potential inhibitor of CYP3A4 and glycoprotein P. The most commonly effective daily dosage is $150-200 \mathrm{mg}$, with rosavina and salidroside in $3: 1$ ratio (standardized 
extracts in rosavina $3 \%$ and salidroside $1 \%$ ) to be divided into two doses between morning and afternoon. Efficacy and tolerance between 100 and $600 \mathrm{mg}$ is also descrive [8]. The administration over two weeks should be carried out with careful evaluation and clinical surveillance.

\section{Panax Ginseng}

Panax ginseng [5] or Ginseng or Asian or Korean ginseng, is a plant of the family of the Araliaceae, native to Manchuria and Korea. The phytocomplex is contained in the roots of plants aged between 4 and 6 years, present on the market as white ginseng, dried, and red ginseng, treated with steam before drying, richer in active ingredients. The roots are rich in ginsenosides, or panaxosids, tetracyclic triterpenic saponins of the dammaran series, metabolized by the gut microbiota in active molecole such as phytochemicals, in particolar ginsenoside K. Ginseng has adaptogenic action, anti-free radicals, anti-oxidant, anti-inflammatory [5,8]. It stimulates learning and cognitive abilities. It supports recovery from convalescence. It finds indications for fatigue syndrome and erectile dysfunction. It stimulates the hypothalamic-pituitary-adrenal axis. It inhibits the reuptake of GABA and other neurotransmitters such as norepinephrine, dopamine, serotonin. It stimulates the synthesis of acetylcholine, over-regulating choline-O-acetyltransferase, ChAT. It activates transcription of the cytoprotective transcriptional factor Nrf2, with neurotrophic and neuroprotective effect. The neuroactive action is prevalent in the hippocampus and cerebral cortex. It activates NK cells, Natural Killer, macrophage function with ROS production, IL-1 $\beta$, IL-2, TNF$\alpha, \operatorname{IgG}, \operatorname{IgM}$ and IgA production. It inhibits the NK-kB [49] pathway and the production of IL-6 and TNF- $\alpha$ at the $\beta$ cell level of the Langerhans Islands. Panax ginseng (but also Panax quinquefolius, or American Ginseng) has a hypoglycemic effect, with reduced glycemic values, insulin fasting and glycated hemoglobin. It inhibits carboxy-kinase, glucose-6-phosphate kinase. It sub-rules the PPAR $\gamma$. It stimulates the endothelial production of nitric oxide, NO, at the level of the heart, lungs, kidneys and corpora cavernosa. It protects spermatogenesis from oxidative process, reduces blood 
levels of prolactin, increases testosteronemia, libido, male fertility. On different tumor cell lines $[8,49,50]$ it is chemo-preventive, activates apoptosis, reduces migration and metastatic invasion. It inhibits demethylation enzymes DNMT1, DNMT3a, DNMT3b. It increases acetyl-H3 K14/K9 and acetyl-H4 K12/K5/K16. It promotes p53, p16 and hMLH1 in ovarian tumor cell lines [50]. It modulates the action of metalloproteases [51], the expression of anti-inflammatory cytokines, the Met/miR-222 axis in LLC cells of lung cancer [52]. It reduces myelosuppression by chemotherapy. It's hepatic and gastroprotective. It can enhance the action of various hypoglycemic preparations, cardiokinetics, central nervous system stimulants, anticoagulants (phenelzine, caffeine, dipyridamol, warfarin etc...). The daily dosage ranges from $0.1 \mathrm{~g}$ two to three times a day for the standardized dry extract with titration in ginsenosides of 10 to $15 \%$ and $1,000 \mathrm{mg}$, in some cases $1,500 \mathrm{mg}$ die, in two to three dosings for the dried root pulverized. The intake beyond the three months must be followed by careful clinical monitoring. The $\alpha$-Lipoic acid and the dihydrolipoic acid

Alpha-lipoic acid is lipoic acid, or 6.8 dithioctanoic acid, or thioctic acid, or vitamin N. It occurs in the double structure: open, reduced or dihydrolipoicacid, DHLA, and cyclic, oxidized, ALA, with formation of disulfide bridges between two oxidized molecules. It is amphipathic, therefore active in both lipophilic and hydrophilic environments. A conditionally essential nutrient, it is synthesized by our body from caprylic acid or octanoic acid and cysteine from mitochondria lipoic acid synthase, LASY. It's well represented in broccoli, spinach, tomatoes, meat, especially the entrails. It's an interesting thiol, reversibile redox system, electron transporter and acetyl groups, mitochondrial enzyme cofactor of oxidative metabolism, pyruvatedehydrogenase and $\alpha$ ketoglutarate dehydrogenase. It has anti-free radicals, anti-oxidant, anti-inflammatory, anti-aging, neurotrophic, neuro-protective, regulator of glycidy [53] and anti-glycant metabolism, antiosteoporotic, anti-endothelial dysfunction and protective cardio-vascular. It crosses the blood-brain barrier with good bioavailability in the tissue of the central nervous system. It is scavenger of ROS such as singlet oxygen, peroxynitrite and peroxides, it has reducing effect of the oxidized forms of 
vitamin C, E, glutathione and coenzyme Q 10. It reduces levels of osteopontin and TNF- $\alpha$. It modulates NF-kB, the nuclear factor-light chain-enhancer of activated B cells, and Nrf2, the nuclear factor erythroid 2-related factor 2, containing the inflammatory reaction in chronic inflammatory diseases, neuro-degenerative, metabolic, cardiovascular. It promotes translocation of GLUT1 and GLUT 4, intracellular, with recruitment at the level of the plasma membrane of adipocytes and skeletal muscle fibrocells, boosts insulin cell signalling at the level of the insulin receptor, IR, and insulin receptor substrates 1 , IRS1, Phosphatidylinositide 3-kinase, PI3K, and protein kinase B, AKT. It activates the expression of 5'-adenosine monophosphate-activated protein kinase, AMPK, at the level of the central nervous system and peripheral tissues. It activates caspace proteins induced by the stress of the endoplasmic reticulum [54], reduces the formation of lactate in neoplastic cells favoring apoptosis. The cofactor action of pyruvate deydrogenase promotes the inhibition of glycolysis. It inhibits the mTOR signaling pathway. It shows chelating activity on copper, zinc, cadmium, manganese, lead, arsenic, iron and mercury. It protects the central nervous system from damage of excitous toxins such as glutamate. It's a transcriptional regulator, epigenetic level. It subrules IL-1 $\beta$ and IL-6 [55] by hypermethylating DNA in IL-1 $\beta$ and IL-6 5'-flanking regions and locating ubiquinoning Nrf2 in SK-N-BE Neuroblastoma Cells. It favors at the gene level the expression of enzymes of the antioxidant barrier [56] such as superoxydodismutase, catalase, glutathione-peroxidase, glutathione reductase, glutathione transferase. It enhances the antiinflammatory action of omega 3. The minimum daily dose is $50-100 \mathrm{mg}$. Efficacy as an antiglicant is achieved with doses ranging from 200 to $600 \mathrm{mg}$ per day, and, as an epigenetic agent, between 300 and $900 \mathrm{mg}$ die and sometimes even $1800 \mathrm{mg}$.

The Indole 3 carbinol

Indole-3-carbinol, or 3-(hydroxymethyl)indole, I3C, is a metabolite derived from glucosinolates, sulfur glucosides [5] found in plants of the Brassicaceae family, or Crucifereae, such as broccoli, 
cabbage, cauliflower, Brussels sprouts, savoy cabbage, mustard, radicchio, arugula. Along with glucosinolates, Brassicaceae contains thioglucosidase, or myrosinase, an enzyme activated by chewing or breaking plant cells, and inactivated by cooking. Myrosinase turns glucosinolates into thiocyanates, isothiocyanates, indoles and nitriles. Indole-3-carbinol is a derivative of glucosinolate glucobrassicin. Indole-3-carbinol is subsequently processed in the gastric lumen, with varying intensity depending on the degree of acidity of the environment, in its metabolites diindolylmethane, DIM, 5, 11-dihydroindole-(3,2-b)carbazole, ICZ, and triindole, CT. Diindolylmethane, DIM, is the predominant molecule responsible for the biological activity of indole-3-carbinol. The action of $\mathrm{I} 3 \mathrm{C}$ and its derivatives is anti-free radicals, anti-oxidant, antiinflammatory, neuro-protective, hormone-modulating, chemo-preventive [8] toward the development and migration of hormone-sensitive tumor cell lines, anti-angiogenic, protective anti human papilloma virus, HPV, also directly anti-viral. I3C activates the erythrod nuclear transcription factor, Nrf2, increases Muc2 expression and Paneth cell lysozyme, increases the level of active $\beta$-catenin nonphosphorylated, inhibits the signalling pathways Notch and NF-kB. I3C, and its metabolites, bind to aryl hydrocarbon receptor, Ahr, cytoplasmic protein, and reach the nucleus, where they activate specific DNA sequences, xenobiotic responce elements, XREs. In this way the enzyme synthesis of the detoxification of both I and II phase is initiated: CYP1A1, CYP1A2, CYP1B1, CYP19, glutathione-s-transferase theta-1, GST q1, and aldo-reductase are over-regulated. In addition, the second phase of detoxification and the expression of anti-oxidant enzymes are stimulated, activating the signalling pathway Nrf2. The indole-3-carbinol modulates the metabolism of the estradiol, favors its transformation towards the 2-hydroxyestrone instead of the 16hydroxyestrone. It down-regulates estrogen-responsives genes, pS2, cathepsin-D and up-regulates breast cancer susceptibility gene 1, BRCA1. It inhibits transcription of ER-alpha and signalling pathway activated by it, 17ss-estradiol (E2)-activated ER-alpha [57]. I3C in breast cancer cells inhibits the expression of cyclin-dependent kinase-6, causes the cell cycle of mammary cancer cells to stop in phase G1, independent of estrogenic receptor signalling [58], antagonizes the expression 
of the estrogen growth-factor-1 receptor dependent insulin-like receptor-alpha and the insulin receptor-substrate-1[59]. DIM inhibits [60] TNF- $\alpha$ and TGF- $\beta$ - induced epitelial-mesenchymal transition into breast cancer cells. I3C and DIM increase the expression of p21/CDKN1A genes, cycles-dependent kinase inhibitor $1^{\circ}, \mathrm{p} 27, \mathrm{p} 53$, inhibit DNMT1 and DNMT3a. DIM inhibits histone deacetylase activity and inhibits DNA methyltransferase, modulates miRNA. It demethylates HOX 10 gene, responsible for endometrial receptivity. It increases the expression of mRNA BRCA1. It inhibits the epithelium-mesenchymal transition, EMT, and signalling pathways Notch-1 and TGF- $\beta$, countering the migration and metastatic spread of neoplastic cells. I3C down-regulates the transcriptional gene expression of the catalytic subunit of the human telomerase, hTERT [61], causing the arrest of the cell cycle of breast cancer cells. I3C prevents the loss of PTEN in cells of cervical cancer of the uterus [62] and breast cancer. It demethylates the WIF1 gene, inhibiting the carcinogenic transformation of cervical cells in the uterine being infected with Papilloma Virus, HPV. DIM activates the autophagy-related gene, ATG5 and the microtubule-associated protein light chain, LC3, by down-regulating miR-30e [63] in gastric carcinoma cells in vitro and in vivo, antagonizing its development. I3C and DIM increase the expression of p21/CDKN1A in breast cancer cells with and without estrogenic receptor positivity. The effect of I3C and its derivatives is enhanced by sulforaphane, isothiocyanate derived from sulforaphanine, or glucoraphanine, by action of myrosinase, with analogous biological, anti-inflammatory, chemo-preventive and epigenetic action $[3,9,14,16]$. Sulforaphane acts by inhibiting histone deacetylase, HDAC, activating p21, p27 and p53, sub-rule Nf-kB; in addition, similarly to I3C modulates liver detoxification, protects against the glycation process under carbonic stress, AGE formation and the expression of rAGE receptors are inhibited. Sulforaphane activates the expression of PTEN, retinoic acid recetor beta 2, RAR $\beta 2$, hTERT. It demethylates DNMT1 and DNMT3a. It activates Nrf2 and the expression of p53 and p21 The daily dose is 200-900 mg I3C and 25-450 mg DIM, 25-50 mg sulforaphan, divided into two to three doses. 
Silybum marianum

Silybum marianum [5], or Carduus marianus, is an herbaceous plant of the family of the Asteraceae, native to the European-Asian zones. An interesting phytocomplex is present in the fruit deprived of the pappus, rich in silimarin, mixture of flavolignani, in particolar silybin or silibinin A and B, isosylibin or isosilibinin A and B, silychristin A and B and silidianin. It has anti-free radicals, antioxidant, anti-inflammatory, hypocholesterol-reducing, detoxifying, cyto-protective, anti-fibrotic, immuno-modulating, regenerative, epigenetic [17], chemo-preventive [8,64]. The flavolignani manifest antioxidant action. The silymarin antagonizes lipid peroxidation. The anti-free radical action is mainly carried out by dehydrosilybin, the oxidized form of silybin. Silymarin stimulates the synthesis of the enzymes superoxidedismutase, SOD, glutathione-peroxidase, GPX, and catalase, CAT, inhibits the activation of NF-KB and to follow the COX-2, eicosanoids and inflammatory cytokines, stimulates the activity of Kuppfer cells, reduces neutrophil migration and stabilizes mastcells, inhibits $\mathrm{T}$ cells. It reduces the release of creatine kinase isoenzyme MB, CK$\mathrm{MB}$, lactate dehydrogenase, $\mathrm{LDH}$, and cardiac troponin I, cTn1. It reduces the absorption of cholesterol and promotes the reduction of cholesterolemia, VLDL, LDL and triglycerides. Silybin and its 2,3-dehydrosilybin derivative, DHS, inhibit the growth and metastatic migration of tumor cell lines by antagonizing the signaling pathways NF-kB, AP-1, induce phosphorylation of ERK1/2, EGFR, Akt and STAT3. Silybin inhibits the transformation of starry liver cells into myofibroblasts. It prevents hepatic-cellular damage and reactivates cell regeneration. Silybin activates the enzyme RNA polymerase I DNA-dependent, stimulating the synthesis of ribosomal RNA and therefore the protein synthesis of hepatocytes [5]. It counteracts lipoperoxidation, reduces the release of creatine kinase isoenzyme MB, CK-MB, lactate dehydrogenase, LDH, and cardiac troponin I, cTn1. It inhibits drug-chemo-resistance and chemo-toxicity on healthy cells. Silymarin and its derivatives inhibit organic anion transportes, OAT, ATP-binding cassettes transportes, ABC, stimulate apoptosis and inhibit the antiapoptosis of neoplastic cell lines. Silymarin inhibits histone deacetylase, HDAC, and DNMT. It inhibits cytochrome P450, in particular CYP1A1, CYP2C9, 
CYP2E1, CYP2D6, CYP3A4, glycoprotein P, the enzyme $\beta$-glucoronidase, living interactions with other molecules, drugs included. The daily dosage of dry extract of silybum marianum, titrated at 70 $\%$ in silymarin and at $30 \%$ in silybine, ranges between 100 and $300 \mathrm{mg}$, in some studies even 800 $\mathrm{mg}$, in two to three doses for three months with subsequent pause and revaluation.

\section{Quercetin}

Quercetin is a tetraoxyflavonol, an aglyconic component of various glycosides such as quercitrin and rutin. It's a secondary metabolite of several plants, natural inhibitor of the transport of polar auxin: caper, red onion, broccoli, citrus fruits, buckwheat, grape, red apple, celery, radicchio, lovage, green tea, blueberry, calendula, horse chestnut, hawthorn, chamomile, ginkgo biloba, hypericum, phylanthus, melissa, maté, moringa. It is also found among the components of propolis. The bioavailability is low and variable but is enhanced in the glycoside form compared to the aglycone. It has anti-free radicals, anti-oxidant, anti-inflammatory [8], neuro-trophic, neuroprotective, modulating hormone, anti-bacterial and anti-viral, experimental chemo-prevention with induction of apoptosis [65], inhibition of angiogenesis, inhibition of proliferation and migration of different tumor cell lines, epigenetic modulator [3,1416,17]. It manifests reducing effect the oxidized vitamin E, tocopheryl-radical, and it is scavenger of ROS. It reduces estrogen sulfotransferase, EST expressed in human mammary epithelial cells [66] and inhibits $5 \alpha$-reductase, aromatase, the enzyme $17 \beta$-hydroxysteroid dehydrogenase type 5. It inhibits 5-lipoxygenase, A2 phospholipase and the release of histamine. It reduces the activity of the 3C-like protease protein, CLpro of SARS-Cov-2 virus [67], destabilizing it. It's an epigenetic modulator agent on DNA methylation, histones, and miRNA [14,17]. It activates HAT, inhibits HDAC-1 and DNMT1. It activates the SIRT1. It inhibits acetylation of H3 and H4 by over-regulation of SIRT1. It acts on genes AMPK, p53, Akt, DBH-AS1, CDKN2A. It activates NAD+ dependent histone deacetylase SIRT1. It hypermethylates the p16 gene. It inhibits expression of TNF-induced interferon-gamma- 
inducible protein $10 \mathrm{kD}$, IP-10, and macrophage inflammatory protein 2, MMP-2, associated with inhibition of $\mathrm{CBP} / \mathrm{p} 300$ activity and phosphorylation/acetylation of histone $\mathrm{H} 3$, histone $\mathrm{H} 3$. It inhibits IP-10, interferon-gamma-inducible protein 10 and MIP-2, Macrophage inflammatory protein 2. It induces Fasl-mediated apoptosis by activating c-jun/AP-1 and activating acetylation of histone H3. It inhibits DNA-methylation at Er-beta, estrogen receptors. It inhibits p300-mediated acetylation of NF-kB resulting in inhibition of COX-2. It inhibits the methylation of the P16INK4a and RAS association domain family $1^{\circ}$ (RASSF1A) gene. It over-rules miRNA-146a. It reduces phosphorylation of Akt. It increases the activity of caspases 3, 7, 8 and Bax. It inhibits antiapoptotic proteins $\mathrm{Bcl}-\mathrm{xl}, \mathrm{Bcl}-2$. It activates the release of cytochrome $\mathrm{c}$, Cyt c, into the space between the mitochondrial membranes, after being bound to the death-receptor, initiating the formation of the aptosome and causing apoptosis intrinsically. It inhibits certain calciumphospholipid dependent kinases, PKCs, Ornithine decarboxylase, ODC, containing polyamide cell proliferation, phosphoinositid kinases, PI3K and PI4P-5K, activating cell proliferation. It causes transcriptional DHT receptor sub-regulation, dhydrotestosterone, and inhibits the activity of androgen-inducible genes. The average daily dosage is $200-500 \mathrm{mg}$. In some cases $100 \mathrm{mg}$ may be sufficient and in others the dosage is raised to $1000 \mathrm{mg}$ per day.

\section{EGCG}

EGCG is the epigagallocatechin-3-O-gallate. It's a catechin, polyphenol particularly present in the foliar bud and in the two adjacent buds of the Camellia sinensis, tea plant, of the Theaceae family. It is also present in various foods such as carobs, pistachios, plums, walnuts, hazel nuts, apples, raspberries, blackberries, moringa, avocados, peaches. The EGCG of the tea is well represented by the leaves, variously treated, in particular well concentrated in the green tea, obtained by roasting the freshly harvested leaves, subsequently rolled and lightly dried. It has a low bioavailability. EGCG manifests anti-free radical action, anti-oxidant, anti-inflammatory, chelating heavy metals, 
neuro-protective [68], endothelium-protective, inhibiting neoangiogenesis, epigenetic and chemopreventive action $[3,8,9,14,16,17,69,70]$ with activation of apoptosis, inhibition of proliferation and metastatic migration of neoplastic cell lines. It antagonizes the production of IL-6, IL-8, TNF- $\alpha$ by inhibiting the signalling pathways ERK and NF-kF. The anti-inflammatory action is also evident at the level of digestive tract. It inhibits Cox-2 signalling pathways, NF-kB, AP-1, MAPKs, STAT. It stimulates the production of nitric oxide and nhibits the release of ET-1 preventing endothelial dysfunction. It supports mnesic function, learning, attention, reduces anxiety and improbe mood tone. It has neuro-protective action favoring the expression od BDNF, activating the signalling pathways Akt, down-regulating the inflammatory pathways COX-2, iNOS, TNF- $\alpha$, IL-1, IL-6, MPTP, CD4+ CD8+ ratio. Epigallocatechin-3-O-gallate inhibits DNMT1, demethylates p16INK4a, the beta receptors of retinoid acid, activates the oncosuppressor genes p15 and p16. It inhibits the methylation of oncogenes homeobox transcription factor: CDX2, and bone morphogenic protein 2, BMP-2 in gastric carcinoma cells. It inhibits hypomethylation of DNA by UVB. It inhibits HAT, histone acetyltransferase, with inhibition of 300 and down-regulation of androgen receptors, AR. It inhibits HDAC1, increasing Bax and acetylation of p53, reactivating metalloprotease inhibitors, TIMP, especially TIMP-3, with anti-inflammatory, anti-aging and antimetastatic proliferation of tumor cell lines. It down-regulars of histone methylation. It overregulates the phosphorylation of histones. It stimulates methylation and inhibits acetylation of histone $\mathrm{H} 3 \mathrm{~K}$, resulting in subregulation of human telomerase reverse transcriptase, hTERT. It promotes the HDAC3. It upregulars miRNA-210, inhibiting cell proliferation. It increases the activity of caspase 3 and 8 and cytochrome c. It inhibits Bcl-2. It reduces expression of MMP-13 and VEGF factor. It inhibits Akt/mTOR-MAPK/ERK signalling pathways. It enhances the action of chemotherapeutics such as gemcitabine, pacilitaxel and 5-fluorouracil. It interferes with the metabolism of many drugs. The daily dosage of EGCG is $300 \mathrm{mg}$ in preparations with $40 \%$ titration. 


\section{Moringa oleifera}

Moringa oleifera, or tree of life, is a medium-sized tree of the family of the Moringaceae, native to the southern regions of the Himalayan mountain range, currently diffused in various tropical territories. Its leaves, seeds and pods are used for food. Its leaves and seeds are particularly rich in polyphenols, phenolic acids, glucosinolates and flavonoids, biologically active saponins for the well-being and health of our organism. The phytocomplex of the leave shas the maximum antioxidant power due to the high concentration of polyphenols, flavonoids and phenolic acids, the 3caffeylquinic acid, the gallic acid, the ellagic acid, flavonoids like the quercetin, the kaemferol and the catechins, of beta-carotene, chlorogenic acid, ascorbic acid, vitamin E and A and the planth ormone zeatin, glucosinolates, in particolar glucomoringina or 4-O-( $\alpha$-L-ramnopiranosil-oxi)benzylglucosinolate, from which by action of tyrosinase the isothiocyanate moringine is derived. The oil extracted from the seeds has a high oleic acid content. Moringa manifests action anti-free radicals, anti-oxidant, anti-inflammatory, hepatic-protective, digestive, fluidizing bronchial secretions, hypoglycemic [71,72,73,74], hypoliphemizing, hypotensive, neuro-protective [75], antidepressive, chemo-preventive [76], stimulating apoptosis and inhibiting the proliferation of tumor cell lines. The phytocomplex prevents lipoperoxidation, promotes the production of glutathione, increases the levels of glutathione-reductase, GR, glutathione S-transferase, GST and glutathione peroxidase, Gpx, catalase, CAT, and superoxydodismutase, SOD. It inhibits the production of TNF$\alpha$, IL-6, IL-8, IL-1 $\beta$, the activity of myoloperoxidase, MPO, the expression of the gene Re1a, correlated with the signaling NF-kB p65 in the course of inflammation, the production of iNOS, COX-2, PGE-2, nitric oxide, NO, and induces the production of IL-10 by suppressing the signalling pathways NF-kB and mitogen-activated protein kinases, MAPKs. It overrides the nuclear factor (erythroid-derived 2)-like 2, Nrf2 target genes $\mathrm{NAD}(\mathrm{P}) \mathrm{H}$, glutathione S-transferase pi-1, GSTP1, quinone oxidoreductase 1, NQO1. The phenolic glycosides 4-((2-O-acetyl- $\alpha$-Lrhamnosyloxy)benzyl) isothiocyanate, RBITC, contained in the seeds experimentally manifests anti-inflammatory action analogous to aspirin. Moringa oleifera attenuates inflammatory intestinal 
manifestations. It modulates glucose metabolism [72,73,74]: reduces blood sugar, glycosuria, hemoglobin glycata, Hba1c, and improbe glucose tolerance by inhibiting amylase and thus starch digestion, intestinal glucose absorption, slowing gastric emptying, also by action of the fibers, and stimulating the secretion of insulin. The regulatory effect on glucidic metabolism is also related to the anti-free radical action of quercetin, inhibiting glucose- 6 phosphate translocase by chlorogenic acid, with reduction of gluconeogenesis and hepatic glycogenolysis, and improving glucose tolerance by the action of moringin. Phenolic compounds, especially flavonoids, show hypolipemic activity, inhibiting pancreatic esterase cholesterol, intestinal absorption of cholesterol and increasing fecal excretion by binding to bile acids. The administration of moringa is accompanied by reduction of systolic and diastolic blood pressure by inhibiting the production of IL-2 and modulating the T-cell calcium signalling pathway. Isothiocyanates play anti-helmintic, anti-mycotic and anti-bacterial action. Moringa oleifera phytocomplex supports mnesic processes, reduces acetylcholinesterase activity, AchE. Its allyl isothiocyanates, AITC, inhibit the growth of androgenindependent prostate carcinoma cells, PC-3, induce apoptosis and cell mitosis blockage, reduce cyclin-dependent kinase 1, CDK1, protein 25B, CDC25B and CD25C, also in androgen-dependent prostate cancer cells. Isothiocyanates inhibit AKT. Benzyl isothioyanates, BITC, reduce mammalian phosphorylation target of rapamycin, mTOR, pyruvate dehydrogenase kinase, PDK, forkhead box, O3A, FOXO3A, FOXO1, phosphatidylinoside 3-kinase, PI3K, protein kinase B, AKT. Moringa oleifera extract increases the concentrations of phosphor-c-Jun N-terminal kinase, pJNK, and phosphor-extracellular signal related kinase, pERK, inhibits the expression of p65, IkB $\alpha$ and $\mathrm{p}-\mathrm{IkB} \alpha$. Isothiocyanates inhibit cytochromes $\mathrm{p} 450$, stage I detoxification, and activate stage II liver detoxification. They can therefore determine interaction with molecole such as drugs. The daily dosage of dry extract titrated in total $10 \%$ glycosides and in $40 \%$ polysaccharides is between 1.6-2.5 g. and also $5 \mathrm{~g}$. 


\section{The E.V.O.O.}

The European olea, or Olive tree, is an ever green tree of the family of the Oleaceae. The pulpy drupe, olive, is the source of an oil rich in nutritive and biologically active molecules. By mechanical action, for the first cold pressing only ripe and healthy drupes, harvested directly from the tree before falling to the ground, extra virgin olive oil is extracted: E.V.O.O. The composition of the E.V.O.O. is extremely variable in relation to the cultivars of the plant. It comprises $99 \%$ triglycerides with fatty acids, PUFA, but predominantly, MUFA, polyphenols, in particolar oleuropein, oleotyrosol, oleacein, hydroxytyrosol and tyrosol, vitamins and minerals. Among the individual molecules present were identified the oleic acids, linoleic, palmitic, stearic, caffeic, ferulic, cumaric, cinnamic, syringic, vanilic, carotenes, chlorophyll, terpenes, rutin, lignans, anthocyanins, zinc, calcium, iron and volatile substances, vitamins E and K. E.V.O.O. for its rich composition plays anti-free radicals, anti-oxidant, anti-inflammatory, hypotensive, neuro-protective, cardio-protective, chemo-preventive [76], epigenetic action [77]. It modulates lipid balance by optimizing membrane fluidity and protecting against lipoperoxidation. It reduces LDL levels, increases HDL levels. It protects the endothelium, activates vasodilation mediated flow, reduces the values of systolic and diastolic blood pressure. It subrules p38 MAPK: it inhibits the production of COX-2 iNOS and inflammatory cytokines, IL-6, and PCR. Hydroxytyrosol and tyrosol, and their derivative secoiridoid, have anti-free radicals, anti-oxidant, anti-inflammatory. E.V.O.O. intervenes on the methylation of DNA loci related to the mitochondrial metabolism of fatty acids, in the regulation of carbohydrate metabolism and glucose tolerance, with the activation of inflammatory responses. The methylation of the Cpgs cg01081346-CPT1B/CHKB-CPT1B and cg17071192GNAS/GNASAS shall be increased by the PUFA. CPT1B is related to the transformation of acylCoA into acyl-carnitine, therefore to the metabolism of fatty acids and glucose, sensitivity to insulin and cardio-vascular risk. Polyphenols down-regulate pro-atherogenic genes. Polyphenols, in particolar hydroxytyrosol, methylate DNA at the gene level for cannabinoid receptor 1, CB1, with chemo-preventive effects on the development of colon carcinoma cells. Oleuropein aglicone [78] 
reduces brain deposits of amyloid- $\beta$ fragments, inhibiting $\mathrm{pE} 3-\mathrm{A} \beta$ expression, increases histone 3 and 4 acetylase, inhibits histone deacetylase 2 expression with protective effect of neuronal synapses [78]. It inhibits the expression of HDAC4 in neoplastic cells. Oleacine blocks cell mitosis and activates apoptosis of neoplastic cell lines, by sub-regulating acetylation [79] of different class i/II histones, mRNA and proteins, with Sp1 sub-regulation. E.V.O. polyphenols inhibit the proliferation of cancer cells by inducing apoptosis via Annexin V-P assay, inhibit hypoxia-inducible factor $1 \alpha$, increasing the Bax protein and reducing $\mathrm{Bcl} 2$, modulating the signalling pathway HER2, HER 2. Polyphenols of E.V.O.O. inhibit HDAC2, HDAC3, miR-21 and miR-155, the hepitelialmesangial transformation and sub-regulate the expression of SIRT1 and weakly HDAAC1. The optimal daily dose of E.V.O.O. is $20 \mathrm{~g}$ with at least $5 \mathrm{mg}$ of hydroxytyrosol.

\section{Walnut}

Juglans regia, or Walnut, is a tree of the Juglandaceae family, native to the Middle East. It contains interesting phytocomplexes [80] in the leaves, buds, husk and seed. The seed, the kernel, edible, with very low glycemic index, have a remarkable alimentary diffusion. The kernel contains fatty acids, both saturated, FFA, monounsaturated, MUFA, and polyunsaturated, PUFA in the form of $\alpha-$ linolenic acid or ALA [81], but also arginine, melatonin, proteins, carbohydrates, vitamins, such as E, the B complex, mostly folic acid, minerals, such as potassium, phosphorus, iron, calcium, magnesium, copper, zinc, ellagic acid and EGCG. Linolenic $\alpha$ acid of nuts would have a good conversion to EPA (>10 \%) but little biotransformation in DHA [82]. From the dry seed is extracted the oil also for alimentary use. The assumption of the nuts is correlated to reduction of the values of the LDL and increase of those of the HDL, to action anti-inflammatory, cardio-vascular protector, neuro-trophic, regulating of the tone of the mood chemo-protective action [83]. The actions are related to the content in ALA, ellagic acid, EGCG, arginine and melatonin. ALA favors [84] the adequate fluidity of cell membranes, the synthesis of eicosanoids with anti-inflammatory action and 
resolving inflammation, anti-aggregant platelet and endothelial protector, epigenetic action [9], reduces genes expression of COX-1 and COX-2 and modulates genes related to the central nervous system. ALA inhibits DNMT1 and DNMT3, increasing the expression of Mecp2, Ppp1cc, Reelin, reducing that of Ppp1cb, favoring neuronal trophism, especially related to mnesic processes [85]. The ALA overrides the PPAR- $\alpha$ gene [86]. Ellagic acid and EGCG were described in the relevant chapters. Arginine promotes nitric oxide production, NO. Melatonin promotes the regularization of the sleep-wake cycle, presents hypno-inducer, glutamine antagonist, anti-oxidant, immunostimulating, anti-angiogenetic for inhibition of the production of VEGF, inhibits the synthesis of growth factor IGF-1, and EGF-R receptor, anti-proliferative neoplastic, cytodifferentiating [87]. The recommended daily intake of nuts is 3 nuts, that is about 15 grams. The walnut enhances the action of E.V.O. 
Nutrigenomic and nuclear receptors

Nuclear receptors (NR) represent a large group of proteins that function as transcription factors. Typically, a nuclear receptor is formed by three domains, related to the interaction with DNA (DBD), with a ligand (LBD) and with functional activators of transcription (AF), respectively. The RNs are linked to DNA sectors known as response elements (RE), activators and or specific inhibitors and ligands [88].

Their activation requires ligands binding and they are expressed all over the body and in all body districts, in particular gastrointestinal (GI) tract. Some of them are responsible of metabolites and hormones ligands. Some important examples include peroxisome proliferator activated receptors (PPARs) that are a big family of nuclear receptors, subdivided in PPPAR $\square, \operatorname{PPAR} \square / \square$ and PPAR $\square$, each producted by separated genes [89]. Nature ligands are fatty acids, eicosanoids and phospholipids. All of them are important for the anti-inflammatory effects in small intestine and colon and take part during the gut-brain axis signaling and interactions.

In particular, PPARs are activated by nutrient derivatives and bacteria molecules and all of them answer in different ways.

PPAR $\square$ affects on the central nervous system (CNS) working during microbiota production of glucocorticoids (GSs) and regulating expression of some cytokines, like Interleukin-22 (IL-22), antimicrobial peptides Reg3 $\square, \operatorname{Reg} 3 \square$ and calprotectin. If there is a dysbiosis in the gut there is also a deficient activity of PPAR $\square$, with an increased expression of proinflammatory cytokines and intestinal inflammation [90]. An important aspect of PPAR $\square$ function is its involvement in chronobiology, because it regulates BMAL1 and CLOCK genes transcription. Another intriguing aspect referred to PPAR $\square$ is its activity on satiety in the brain. It is important because it serves as a receptor for oleoylethanolamide (OEA) and mediates its impact on hunger and satiety, also because enterocytes in small intestine are the first cells that responds to dietary fat intake by increasing OEA production [91]. PPAR $\square / \square$ also mediates satiety signals from gut to CNS stimulating glucagon-like protein-1 (GLP-1) in the gut from the duodenum to the ilenum, where it is abudant. It promotes 
fatty acids oxidation (FAO) in adipose tissue and skeletal muscle and it is protective against obesity because it improves and stimulates energy expenditure [92]. The mostly known PPAR protein is PPAR $\square$, because it is considered the master regulator of adipogenesis [93]. Intestinal PPAR $\square$ interferes with adiposity through sympathetic nervous system (SNS) and blocks inflammation in the gut; it is important for circadian rhythm in the liver and partecipates in a balanced manner in the gut microbiota, where it can be both activaed by bacteria and regulate the intestinal and microbial makeup. PPAR $\square$ has an antiinflammatory effect regulating several signaling pathways, including p53, Bcl2, c-MYC and so on. At the end, the activation of intestinal PPAR $\square$ by bacteria metabolites or nutrients can impact adipose tissue via the nervous system. PPAR $\square$ is highly expressed in adipocytes in the gut, and at lower levels in pancreas, liver, kidney, and immune cells, and it is induced by multiple nutrients, i.e. fatty acids, glutamine, curcumin, capsaicin and so on, all of them with anti-inflammatory properties [94]. This anti-inflammatory effect is abundantly expressed by regulating some important patterns related to p53, Bcl-2, c-Myc, Cox-2, Apc/Bcatenin and NF-kB, and for all these reasons it could be considered a promising therapeutic target for contrast different type of tumors [95]. An important relationship between nuclear receptor and ligands is expressed in PPAR $\square$ and FGF21, that is involved in metabolism when it is connected to PPAR $\square$. FGF21 stimulates expression of some genes involved in lipid oxidation, ketogenesis and gluconeogenesis [96], improves leptin and insulin sensitivity and regulates glucome homeostasis. Its regulation is important for body weight reduction and energy expenditure increase, fat oxidation, lipid excretion and hepatosteatosis decrease [97]. Finally, PPAR $\square$ modulate circadian clock [98]. Another important aspect that involve the gut microbiota and nuclear receptors is linked to glucocorticoid receptors (GR), mineralcorticoid receptors (MR) and estrogen receptors (ER) action on microbiota. In particular, the relation between gut microbiota and GR is expressed by regulating the activity of $11 \square$-hydroxysteroid dehydrogenase 1 and 2 (11 $\square$-HSD), two fundamental enzymes that control the bioavailability of glucocorticoids [99] and bacterial glycerrhetic acid-like 
factors (GALFs) that is able to modulate glucorticoids availability and affinity to their respective receptors.

Additionally, microbiota regulates circadian production of glucocorticoids affecting steroid receptors activity in other multiple tissues. Estrogen receptors play a key role in reproduction, but they are also important in metabolism. Estrobolome represents a cluster of bacteria that are able to metabolize estrogens and influence their levels [100]. Gut microbiota metabolize in particular estrogen-like compounds from nutrients, i.e. daidzen (a compound of the soy) can be metabolized to O- desmethylangolesin (ODMA) and S-equol [101], that activate ER; people that are able to produce ODMA but not S- equol, are more at risk of obesity. Estrogens activity is mediated by their binding to estrogen receptor $\square$ (ER $\square$ ) and $\square$ (ER $\square$ ). They show an high affinity to for the same estrogen response elements (ERE) on DNA; they are expressed in multiple organs and various tissues, including GI tract, but only ER $\square$ is crucial for reproductive function and regulation. Infact, energy balance is mediated by ER $\square$ only.

There are strong connections between ER, MR and GR. In particular, estrogens influence MR expression and their receptors inhibits the transactivational effects of MR on different cell types [102]. Considering all the important actions of estrogen hormones and ER, their regulation in microbiota seems essential for a correct metabolism and functions in host's life.

Regarding thyroid gland and thyroid hormones, there are few direct connections between them and gut-brain axis, but thyroid hormone $(\mathrm{TH})$ is crucial for brain development and microbiota maintenance.

$\mathrm{T} 3$ and T4 are products that derived from tyroid cells that work combining aminoacid tyrosine and iodine; they differ for the number of iodine atoms. Thyroid releasing hormone (TRH) is synthetized from the hypothalamus, and it binds its receptor. Tyroid stimulating hormone (TSH) which promotes $\mathrm{TH}$ release from tyroid gland and is negatively regulated by TH. Somatostatine and dopamine inhibit TSH release and they are produced by microbiota [103]. TH links thyroid hormone receptors $\square$ and $\square$ (TR). that are expressed in different organs in different forms. TR is 
able to bind DNA and it changes its conformation facilitating corepressors separation and then promotion of gene transcription. TRs also have non genomic effects; i.e. its contribution to betacatenina stabilization and the start of the oncogenic pathway in thyroid carcinogenesis in Trbeta (PV/PV) mice, knock-in mutant mouse harboring a dominantly negative mutant thyroid hormone receptor beta [104]. Other non genomic effects, like development processes in the brain like myelination, neuronal migration and so on involve TR action. Thyroid hormone receptor beta (THRB) gene is commonly deregulated in cancers; i.e. in renal cancer, as a result of epigenetic aberrant changes, including $\mathrm{CpG}$ methylation and microRNA-dependent silencing, but probably the second one is the most abundant error type respect the first one [105]. Hypothyroidism is responsible of several health problems, like weight gain, exhaustion, neurological defects, affect mood and behaviour. Hyperthyroidism is the opposite case, in which there is an higher amount of $\mathrm{T} 3$ and $\mathrm{T} 4$ and it is caused by genetic factors or dietary iodine deficiency.

Several macro and microelements are essential for iodine hormones, like selenium. Microbiota requires selenium for some metabolic processes and it competes for the host for this microelement [106]. It was demonstrated that in some patients with tyroid issues there are also GI defects and abnormal enviroment; also autoimmune thyroid patients have athrofic gastritis and colitis [107]. Other minor nuclear receptors, like pregnane $\mathrm{X}$ receptor (PXR) and constitutive androstane nuclear receptor (CAR) are also responsible of several interactions between microbiota, liver and brain. This xenobiotic receptors use bacterial metabolites, e.g. indole and bile acids (BA), like ligands and are able to counteract inflammation, anxiety, to support lipid glucose metabolism and brain development [108]. Indole and short chain fatty acids are able to modulate also aryl hydrocarbon receptor (AHR) [109].

Regarding to FXR, secondary BAs, but also some of the primary BAs, can act as ligands for the nuclear receptor FXR (NR1H4), which is expressed in enterocytes throughout the small intestine and colon [110]. BA activation of FXR leads to subsequent alteration of the BA pool size via two FXR-dependent feedback mechanisms of hepatic BA synthesis [111]. FXR regulates the 
transcription levels of critical genes in BA synthesis, homeostasis, transport and metabolism [112], but also affects general lipid and glucose metabolism [113], as well as hepatic autophagy [114,115]. FXR binds a response element in the regulatory region of Fgf15 (a rodent ortholog to human Fgf19) and directly regulates its transcription. FGF15 protein is able to mimic insulin impact and it works like a postprandial hormone. FGF15 does not affect insulin secretion but rather mimics insulin impact [116,117]; it stimulates also hepatic protein and glycogen synthesis, and contributes to glucose metabolism. For these reasons, it is possible to highlight the microbiota-PPARalpha-FXRFGF15-gut-brain axis directly connected to BA production and activity [109] (Figure 2)

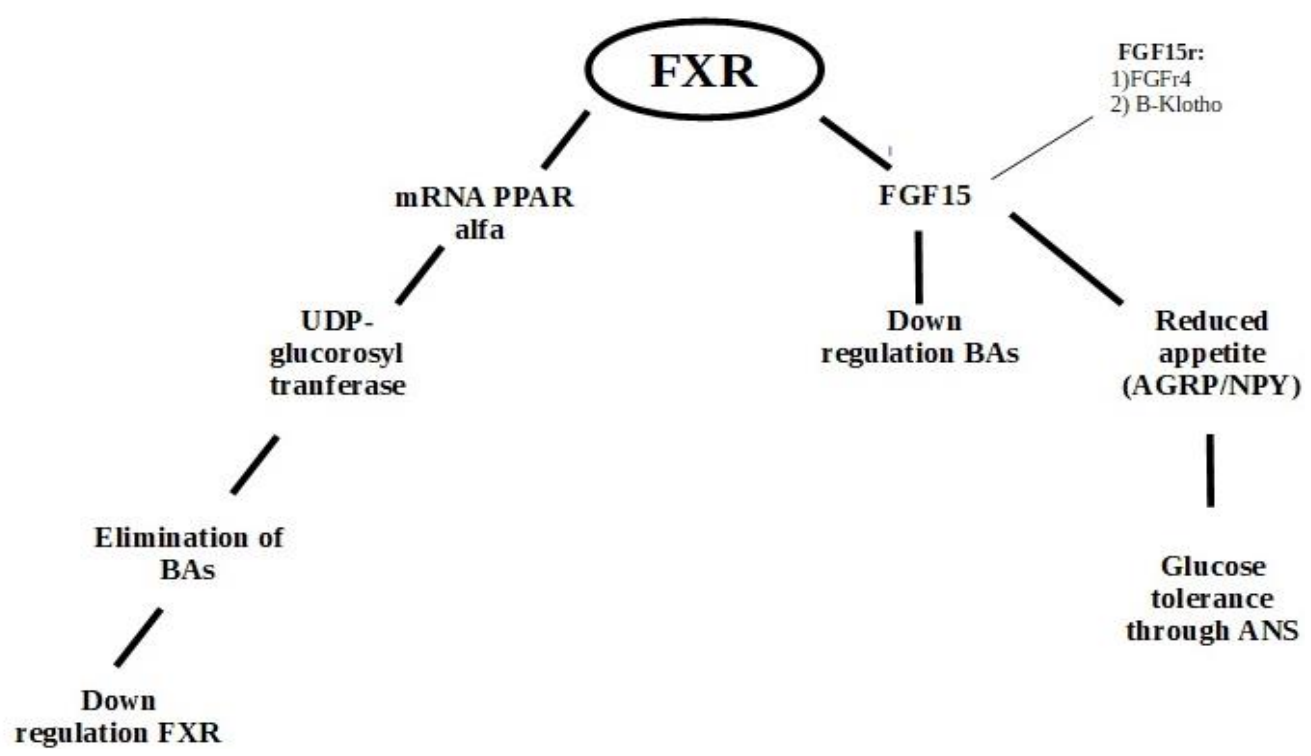

Figure 2: How FXR may modulates its effects: BAs metabolism, mimetic insulin effect and appetite.

AGRP: agouti related protein; NPY: neuropeptide Y; ANS: autonomic nervous system; FGF15r: FGF15 receptor;

At the end, one of the most important nuclear receptor, responsible of many types of metabolic processes, is vitamin D receptor (VDR). VDR links directly Vitamin D3 (cholecalciferol) producted 
by thermal isomerization of provitamin D3. Vitamin D3 is taken up by the liver and modified to prohormone calcifediol. Vitamin D2, or ergocalciferol, is present in fish, eggs, mushrooms and it is another precursor of calcifediol. The transition to calcitriol is operated by 1alpha-hydrolase (CYP27B1) in the kidneys predominantly. Other ligands of VDR are BA, curcumin, fatty acids derivatives and it is important for micronutrient (calcium, iron, selenium, zinc) homeostasis [118] expressed and it also plays a role in the immune system, because it stimulates the expression of defensins and antimicrobial peptides [119]. Regarding the brain, few data are available; we only know that vitamin D can diffuse to blood brain barrier (BBB), it is vital for brain development, neurotransmission and neuroprotection; it's deficiency is strictly linked to some diseases like Alzheimer's and Parkinson's, but the role of VDR in these diseases remained to be investigated, and its role in the gut-brain axis has not yet been established [120].

Macronutrients, micronutrients, Bile Acids and Chrononutrition

Fatty acids

It has been shown that several fatty acids have regulatory effects through the nuclear receptor kappa b (NF-kB), which contains a p50 trimer, p65 and a factor IkB [88]. When the IkB is phosphorylated, the resulting dimer moves from the cytoplasm to the nucleus, where it interacts with specific genes, whose transcription products participate in inflammation processes or are factors that promote necrosis or hyperglycemia [121]. A negative response is given when the saturated fatty acids activate NF-kB; for its part, mono and polyunsaturated fatty acids inhibit this activation, resulting in a decrease in cardiovascular disorders [122].

Carbohydrates 
Carbohydrates modulate genes through the carbohydrate response elements (ChREBP). In this way, the liver determines whether carbohydrates go towards a glycogen pathway or if enzymes necessary for lipogenesis are expressed [123]. The activation of ChREBP is promoted with high levels of carbohydrates and inactivation occurs with low levels [124]. In this sense, it has been observed that a diet rich in carbohydrates increases the expression of transcription factor XBP-1 in mice, which is why it is postulated that it has an important role in human dyslipidemia [125].

\section{Proteins}

Although proteins do not exert a direct regulatory role on genes, some amino acids regulate gene expression. Also, a low input of essential protein amino acids reduce in the synthesis of norepinephrine and cAMP, which alters protein synthesis [126]. This system works by means of a protein called CHOP, which binds with gene expression enhancers, and is activated by means of stressful stimuli such as DNA damage [127]. Furthermore, there are amino acid response elements (AARE) that are sensitive to nutrients [128]. Which, can regulate the initiation phase of protein synthesis by means of the initiation factor eIF $2 \alpha[129]$.

\section{Vitamins}

The fat-soluble vitamins A, D, E bind to RN by modulating specifically the expression of genes linked to energy metabolism [130]. Carotenoid stimulates the G-protein coupled receptors (GPCRs) and also activates genes that are related to the remodeling of the extracellular matrix by the metalloproteinase enzymes, resulting in a restructuring of the cytoskeleton [131]. Despite vitamin E is known to have antioxidant activity, in high amounts can be procarcinogenic [132]. Furthermore, the low intake of folic acid during pregnancy causes the substitution of thymine for uracil in the DNA, in addition to producing an abnormal pattern of chromatin methylations [133]. Instead, the 
adequate supply of this vitamin allows the expression of the enzyme methylenetetrahydrofolate reductase (MTHFR), which perform methylations in specific sectors of chromatin [134].

It has been observed that folate, vitamins B12, B6, C, and E, selenium, niacin, and zinc can cause alterations into the DNA that are similar to what is seen after radiation exposure. These alterations lead to the rupture of the DNA double strand, oxidative lesions, or both and so they are connect related to the development of cancer [135].

\section{Minerals}

Minerals affect the transcription of genes, increasing or decreasing their expression. For example, in the intestinal epithelium, copper interacts with clover proteins (TFF1), which, if in their homodimer state, favor the formation of tumors and copper predisposes the TFF1 protein to acquire the heterodimeric state with antitumor effect [136]. Moreover, iron and calcium have opposite effects for the expression of proteins related to carcinogenic processes [137]. Iron would favor the formation of tumors, increase the carcinogenic cytotoxicity. Calcium, instead, would inhibit it, thorugh the induction of the pentatraxin gene of the mucosa [138]. On the other hand, the moderate deficiency of copper and iron for prolonged periods causes alterations in lipid metabolism, as well as deleterious effects in the cardiovascular system [139]. Another mineral with important effects on organic physiology, is selenium. It interacts with several proteins that are regulated by this mineral [88]. It is able to modulate the progress of the cancer or to restrain it, by means of the suppression of tumors or by the expression of factors of growth of tumors, cellular invasion or adhesion, or of repair of the DNA [140]. 
Starting in 1999, it became clear that BAs serve endocrine functions in the body largely through their binding and activation of the nuclear receptor, Farnesoid X Receptor (FXR) and the plasma membrane-bile acid receptor TGR5 [141]. BAs are amphiphilic molecules with 24 carbon atoms and consist of a hydrophobic and a rigid steroid nucleus, to which are attached a hydrophilic hydroxyl group and a flexible acidic aliphatic side chain. Primary BAs are produced in the hepatocytes, while secondary BAs (SBA) are formed by modifying the primary BAs in the intestinal lumen carried on by but bacteria, i.e., by the reactions of $7 \alpha$-dehydroxylation and deconjugation of cholic acid (CA) and chenodeoxycholic acid (CDCA). The most important secondary BAs are deoxycholic acid (DCA) and lithocholic acid (LCA) [142] BAs play an important role in maintaining intestinal barrier function, as antimicrobial agents that help determine the gut microbiome structure, and as inducers of genes encoding anti-microbial peptides and lectins via FXR (FXR) [143]. Moreover, BAs regulate their own synthesis, conjugation, transport and detoxification, as well as lipid, glucose, and energy homeostasis through activation of FXR and TGR5 receptor [144]. Through activation of FXT and TGR5 receptors, bile acids regulate their own synthesis, conjugation, transport and detoxification, as well as lipid, glucose, and energy homeostasis. Furthermore, bile acids play an important role in maintaining intestinal barrier function, as antimicrobial agents that help determine the gut microbiome structure, and as inducers of genes encoding anti-microbial peptides and lectins via FXR. Others, nuclear receptor activated by BAs are liver X receptor (LXR), costitutive androstane Receptor (CAR), vitamin D receptor and pregnane X receptor (PXR). About Plasma membrane, others receptors are sphingosine-1-phospate receptor (S1PR2), muscarinic receptor M2 and M3, N-Formylmethionyl-leucyl-phenylalanine receptor fMPL and vascular endothelial growth factor receptor [145]. Microbes are responsible of BA modifications, e.g. BA deconjugation (remove of glycine or taurine conjugate) or production of oxo or keto-BA. At the end, the composition of serum bile acids returning from the gut to the liver is a mixture of free and conjugated biliary acids (CBA), secondary, and oxo and $\beta$-hydroxyl bile acids. These different types of BA are able to interact with several metabolic pattern operated by 
important genes, like Akt that enhance m-Tor activity for a cancer state progression. For this reason, a diet rich in fat induces increased bile production to aid its digestion [146]. Interesting is the capacity to BAs to regulate innate immune system, up-regulating IL10 and down-reulation proinflammatory cytochin IL6 and INF $\square$ through GPBAR1 and FXR [145].

\section{Chrononutrition}

AMP/ATP connect energy status with circadian rythm. Infact, the half-life of cytosolic dimer CRYPER is controlled by cytosolic phosphorylases. PKA phosphorylasetes CRY stimulating its elimination by proteasome [147]. Fatty acids interfere with cyrcadian clock inducing BMAIL 1 in a PPAR gamma dependent manner [98]. Resveratrol extend, as caloric restriction, to increase through SIRT1/PGC1 alfa the trascription of BMAIL1, PER1, PER 2 [148]. Caffeine is able to prolong the circadian rythm [148]. Analyzing this complex scenario it seems important to have a correct and regulate chrononutrition, because chronodistruction is responsible to some diseases development, like obesity, type 2 diabetes, cancer and so on. Night workers are more subjected to chronodistruction and disease development: a complete review from [149] analyzed several studies about circadian rhytmn and eating habits in night workers respect daily workers. In the first one they highlighted more metabolic and hormonal problems, followed by bad eating habits and psychosocial abnormalities. Some nutrients are responsible of transcription regulation of chronogenes; i.e. injected glucose in rat fibroblast reduced PER1 and PER2 transcription [109]; fatty acids are able to activate PPARG and PGC-1 alpha that induce BMAL1 transcription. [150].

\section{Nutrigenetic}

The interaction between nutrients and genetic profile

For over 20 years the Public Health burden of diet-dependent diseases resulting from poor quality diets, excess caloric intake and sedentary lifestyles, has been the main driver for nutritional 
research. Rapid developments in the life sciences, especially genetics, have created significant opportunities for nutritional science [151].

A basic concept is that the progression from a healthy phenotype to a phenotype of chronic dysfunction can be explained by changes in gene expression or by differences in the activities of proteins and enzymes, and that the components of the diet directly or indirectly regulate the expression of the genetic information.

Gene-environment studies demonstrate variability in nutrient requirements depending upon individual variations in genes affecting nutrient metabolism and transport. This study investigated whether the inclusion of genetic information to personalize a patient's diet (nutrigenetics) could improve long term weight management [152].

The Human Genome Project made the human DNA sequence available, revealing that each individual shows $99.5 \%$ genetic identity compared to any other individual randomly taken in the population. The remaining $0.5 \%$ of DNA is subject to individual variability and shows changes within the population; the sum of these differences constitutes the inter-individual variability.

This is mainly characterized by sequence variations called polymorphisms (single nucleotide substitutions SNPs), that is, the presence at a given locus of two or more alleles, present with a greater frequency $(>1 \%)$ than that which could be maintained by a mutation.

The study of inter-individual variability represents a challenge for modern medicine, especially in the perspective of being able to treat the patient in an increasingly specific and safe way, identifying the most effective therapeutic treatment. In particular, the study of polymorphic variants has become crucial in understanding the mechanisms underlying susceptibility to various multifactorial diseases, including common diseases such as diabetes, obesity, and cardiovascular diseases [153].

SNPs, represent the largest source of inter-individual variability in the genome since $0.1 \%$ of the variable portion of the sequence is responsible not only for phenotypic differences between individuals, but above all for differences in terms of predisposition and resistance to common diseases [154]. 
This number may seem almost insignificant, actually corresponds to about six million bases on the total genome.

The presence of SNPs does not in itself identify a pathology, however the SNPs can be located in regions of the genome where they determine variations in the amino acid sequence of the encoded proteins, inducing, for example, a greater or lesser protein synthesis or altering the efficiency of proteins produced.

Thanks to new reliable and sensitive genetic analysis technologies, there is sufficient experimental evidence confirming the role of SNPs in inducing the organism's susceptibility to internal and external stimuli, in terms of probabilistic estimate of the increase in risk compared to the general population.

According to localization and the possible consequences on the protein product, SNPs can be classified into: [155]

- $\quad$ cSNPs (coding region SNPs, located within the coding sequences): they can alter the amino acid sequence of the corresponding protein

- $\quad$ pSNPs (perigenic SNPs, located in non-coding regions, in the vicinity of a gene): they generally do not modify the sequence of the protein but can influence its expression

- $\quad$ iSNPs (intergenic SNPs, localized in the non-coding sequences dispersed among the genes): they generally have no consequences on the corresponding protein.

Nutrigenetics encompasses the retrospective analysis of the genetic variants of individuals that condition the clinical response to nutrients.

Therefore the main purpose of nutrigenetics consists in the identification and characterization of genes and nucleotide variants within these, which are associated with the different responses to nutrients.

This science is also referred to as "personalized nutrition", since it allows the development of a personalized diet for the genetic construction of the individual, taking into account the variability of the genes involved in the metabolism of the nutrient and its target. 
Nutrigenetics aims to identify specific nutritional needs linked to the individual genetic profile, analyzing the impact of the genetic profile on the risk of pathologies related to nutrition. The individual genotypic profile of the genes linked to metabolism will allow to identify metabolic bottlenecks and modify the supply of nutrients to restore a balanced metabolic structure [8].

Firstly, the genetic background of the individual can define the nutrient state, metabolic response, and susceptibility to diet-dependent or related health disorders. It is suggested that the science of nutrigenetics is involved in handling the mechanism by which genetic variations define the risk of individual to diseases, nutrient daily requirements, cellular metabolic response and behaviour towards the bioactive dietary components or nutritional therapy, the main target of that is to clarify the impact of the gene variability on the interaction between nutrients and diseases [156].

Polymorphisms (single nucleotide substitutions SNPs)

Up to know, have been detected thousands SNPs linked to:

- control body weight,

- $\quad$ lipid and carbohydrate metabolism,

- ability to assimilate and use vitamin D,

- detoxification processes,

- $\quad$ oxidative stress

- anti-inflammatory action

- $\quad$ pathways of glycation and methylation

Following a list of the most important:

- $\quad$ MTHFR: C677T, folate metabolism (Vit B9), VitB6 and B12 polymorphism reduces its activity with homocysteine accumulation. The 677C> $\mathrm{T}$ polymorphism in the MTHFR gene indicates reduced enzymatic activity and increased homocysteine levels, which further decrease in deficiency of the above vitamins $[157,158,159]$. 
- RAGE: G82S polymorphism, substitution of Gly (82) with Ser, it is associated with enhanced inflammatory responses, increased ligand binding, downstream signaling as well as RAGE expression [160].

- $\quad$ LCT: $13910 C>\mathrm{T}$ progressive decrease of lactase in intestinal microvilli [161].

- $\quad$ HLA-DQ2, HLA-DQ8: celiac disease. Permanent intolerance to gliadin which causes a progressive atrophy of the intestinal villi causing a picture of general intestinal malabsorption [162].

- CYP1A2: -163, decreased enzymatic activity of cytochrome P450 1A2 with consequent imbalance in the relationship between caffeine concentration and caffeine metabolites in the blood [163].

- ADH1C: Ile349Val, slow metabolization of alcohol with relative accumulation of the toxic compound acetaldehyde in the blood [164].

- ACE: I/D, nucleotide polymorphisms identified is type insertion / deletion, allele $\mathrm{I}=$ insertion, allele $\mathrm{D}=$ deletion, and this is directly associated with the plasma concentration of the enzyme itself. It has been shown that carriers of the D allele exhibit greater expression and therefore activity of the enzyme, correlated with a greater probability of developing hypertension and consequent cardiovascular complications and also leads to impaired glucose metabolism, insulin resistance and type diabetes. 2 [165].

- EPHX1: Tyr113Hys, microsomal epoxy hydrolase 1 enzyme responsible for the detoxification of Aflatoxin B1, a powerful carcinogen deriving from molds of badly preserved foodstuffs [166].

- $\quad$ NAT1, NAT2: polymorphism N-acetiltransferasi, decreased acetylation capacity of amines and hydrazines [167].

- GSTM1: I/D, polymorphism involving the enzyme Glutathione S-tranferase 1, inability to detoxify substances deriving from Cruciferae [168].

- VDR (Vitamin D Nuclear Receptor): polymorphismTaq1C $>\mathrm{T}$, associated with it, is responsible for a decrease in bone mineral density (BMD) and therefore a greater risk of bone 
fractures: there is a lower intestinal absorption of calcium. Moreover, it has been shown that some of the susceptibility loci overlap for both inflammatory bowel disease (IBD) and osteoporosis. One of the genes that may be involved in the pathogenesis of IBD as well as decreased bone mass is the vitamin D receptor (VDR) gene [169].

- $\quad$ UCP2: Rs6759366 (T;T), Rs660339(T;T): Genetic variation in the UCP2-UCP3 gene cluster may act as a modifier increasing serum lipid levels and indices of abdominal obesity, and may thereby also contribute to the metabolic aberrations observed in obesity and type 2 diabetes [170].

- MC4R: rs17782313; rs571312; gene of the melanocortin receptor associated with the regulation of body fat, food intake (eating disorders) and caloric intake. The $\mathrm{C}$ allele favors overweight. The interactions of mental stress and energy intakes with the MC4R minor allele genotype might be associated with increased risk of obesity in Korean adults. This research might identify subjects with a specific MC4R minor alleles as a human subset of people with a low metabolic tolerance for excessive energy intake, especially when under stress [171].

- $\quad$ FTO (fat mass and obesity associated): rs9939609 AA homozygous allele carries an increased risk of obesity and overweight due to increased fasting leptin concentrations. A highprotein diet is more effective than a low-calorie diet [172].

- GIP: Glucose-dependent insulinotropic polypeptide (also known as gastric inhibitory polypeptide (GIP)) and its receptor (GIPR) may link overnutrition to obesity, insulin resistance, and type 2 diabetes. A GIPR variant rs2287019 was recently associated with obesity and glucose metabolism. The T allele of GIPR rs2287019 is associated with greater improvement of glucose homeostasis in individuals who choose a low-fat, high-carbohydrate, and high-fiber diet. The POUNDS LOST trial was registered at clinical trials [173].

- PCSK1: rs6232 and rs6234/rs6235, essential role in the maturation of hormones involved in the stimulation of food intake. Located on the long arm of chromosome 5 it determines the production of insulin and glucagon. Activation defects can lead to dysfunction of these hormones and therefore to obesity and overweight [174]. 
- $\quad$ GNB3: variation c.825C> T risk of overweight and obesity [175].

- NPY: rs16139 rs16147 and rs5574 encodes a protein called neuropeptide Y (NPY), a polypeptide that performs several actions, including increasing appetite (drying effect). rs16147 T and rs16139 $\mathrm{C}$ minor alleles are associated with increased risk, whereas the minor allele $\mathrm{T}$ of the rs5574 is associated with a reduced risk of obesity [176].

- $\quad$ ADBR3: variation in codon 64 is associated with increased BMI [177].

- $\quad$ FABP2: Ala54Thr allele have a different metabolic response after weight loss than wild type non-A carriers obese, with a lack of decrease of LDL-cholesterol, glucose, insulin levels [178].

- TCF7L2: The Transcription Factor 7-Like 2 (TCF7L2) gene encodes a transcription factor involved in the expression of the glucagon and insulin receptor in pancreatic beta cells. The rs7903146 polymorphism modulates gene activity and consequently the risk of developing metabolic syndrome and type II diabetes [179].

- PLIN: variability at the PLIN1 locus is associated with variability in weight loss. Moreover, eating late is related to lower weight-loss effectiveness among carriers of the AA genotype at the PLIN1 14995A>T variant interaction of PLIN1 $\times$ food timing between the $14995 \mathrm{~A}>\mathrm{T}$ variant and timing of lunch eating for total weight loss [180].

- $\quad$ PPAR: Pro12Ala variant is significantly associated with greater insulin sensitivity [181].

- KCNJ11: Potassium channels are present in the majority of cells, where they participate in a variety of physiological responses, including the glucose-dependent release of insulin in pancreatic beta cells. rs5219 the variant determines a change in the activity of the protein that affects insulin release, resulting in a different response to blood glucose levels [182].

- IRS-1: rs2943634, alteration of the tertiary structure of the protein resulting in a decrease in its activity and phenomena related to insulin resistance with increased susceptibility to overweight and obesity in synergy with other polymorphisms [183]. 
- LEPR: rs1137101, rs8129183, the substitution of one amino acid by another can affect the functional characteristics of the receptor leading to its modified signaling capacity and resulting in various levels of leptin in circulation: leptin resistance [184].

- SCG3: rs3764220, may influence the risk of obesity through possible regulation of hypothalamic neuropeptide secretion [185].

- GHSR: rs572169, Ghrelin exerts a stimulatory effect on appetite and regulates energy homeostasis, its polymorphism it is associated with the eating behavior "overeating"[186].

- $\quad$ ACACB: this gene, plays an important role in the oxidation of fatty acids. Polymorphism rs2268388 were overrepresented in women with severe obesity, therefore the activity of acetylCoA carboxylase beta plays an important role in these disorders related to energy metabolism [187]. - ABP1: nonsynonymous polymorphisms variant alleles lead to a decreased inactivation of histamine may show altered susceptibility or a different evolution of IBD [188].

Nutrigenetic tests

Starting from individual's genetic makeup knowledge and relevant SNPs, metabolism and predisposition to develop pathologies of a single organism could be investigated.

A nutrigenetic test aimed at investigating the presence of known SNPs, will therefore be able to delineate a personalized nutritional therapeutic path in a qualitative and quantitative sense.

Here below a collection of the most significant SNPs involved in nutritional therapy:

1. Inflammaging test

2. Antiaging or oxidative stress test

3. Intolerance food test

4. Vitamin D metabolism test 


\section{Detoxification test \\ 6. Body weight}

Inflammaging test

Inflammaging refers to the connection between the processes that lead to aging and a type of chronic low-intensity inflammation: a chronic mild inflammation (low grade), persistent (chronic), which has no visible symptoms (latent) but which produces systemic effects on the whole organism [189].

Human organism produces inflammatory molecules called cytokines, these genes are closely linked with human longevity and predisposition to chronic inflammatory diseases: ACT, IL-1B, IL-6, IL-10, TNF- $\alpha[190]$.

Moreover, deficiencies in the anti-inflammatory system may also contribute to neuroinflammation. Recently, advanced methods for the analysis of genetic polymorphisms have further supported the relationship between neuroinflammatory factors and Alzheimer's disease risk because a series of polymorphisms in inflammation-related genes have been shown to be associated with Alzheimer's disease [191].

\begin{tabular}{|l|l|l|l|l|l|}
\hline Gene & SNP & RSnumber & Nucleoti & Variatio & Interpretation \\
\hline ACT & $-51 \mathrm{G}>\mathrm{T}$ & rs1884082 & $\mathrm{G}$ & $\mathrm{T}$ & TT= increased predisposition for \\
\hline IL-1B & $511 \mathrm{G}>\mathrm{A}$ & rs16944 & $\mathrm{G}$ & A & AG or AA = risk factor for \\
\hline IL-6 & 572 & rs1800796 & C & G & CG or GG = predisposition for r \\
\hline
\end{tabular}




\begin{tabular}{|c|c|c|c|c|c|}
\hline & $\mathrm{C}>\mathrm{G}$ & & & & diabetes type 2 \\
\hline & $\begin{array}{l}\text { G- } \\
174 G>C\end{array}$ & rs 1800795 & G & $\mathrm{C}$ & $\begin{array}{l}\mathrm{CG} \text { or } \mathrm{CC}=\text { risk factor for coronary } \\
\text { heart disease }\end{array}$ \\
\hline IL-10 & $\begin{array}{l}\text { G- } \\
1082 G> \\
A\end{array}$ & rs1800896 & $G$ & A & $\begin{array}{l}\mathrm{AA}=\text { high risk of cardiovascular and } \\
\text { chronic inflammatory diseases }\end{array}$ \\
\hline $\mathrm{TNF} \alpha$ & $\begin{array}{l}308 \\
G>A\end{array}$ & rs 1800629 & $G$ & A & $\begin{array}{l}\text { AG or } \mathrm{AA}=\text { increased risk of chronic } \\
\text { inflammatory diseases }\end{array}$ \\
\hline
\end{tabular}

Antiaging or Oxidative stress test

Each cell of the organism is constantly exposed to toxic action of a series of oxidizing agents generated endogenously or by forming exogenous compounds various environmental stressors (air, water, food): reactive species of oxygen (ROS) [192].

High levels of "reactive" species alter normal cellular function by interacting directly with macromolecules (proteins, lipids, nuclear and mitochondrial DNA) that make up the cellular structures, or indirectly triggering a further production and propagation of an ever great number of reactive molecules and the final result of this cascade of reactions is one dysfunction and / or cell death. To contain or mitigate the oxidative insult, it is developed in higher organisms an antioxidant defence system, the induction of which represents an adaptive response to the oxidative stress condition [193].

The Antiaging/Oxidative stress test, evaluates the potential of the antioxidant activities, responsible for the response to free radicals. 
Some polymorphisms present in specific genes can alter the production and function of antioxidant enzymes [195].

\begin{tabular}{|c|c|c|c|c|c|}
\hline Gene & SNP & RSnumber & Nucleotid & $\begin{array}{l}\text { Variatio } \\
\text { n }\end{array}$ & Interpretation \\
\hline CAT & C-262T & $\mid \begin{array}{ll}\mathrm{rs} 1001179 & \mathrm{C} \\
\mathrm{T}\end{array}$ & C & $\mathrm{T}$ & $\begin{array}{l}\mathrm{CT} \text { or } \mathrm{TT}=\text { reduced detoxifying } \\
\text { capacity }\end{array}$ \\
\hline GPX1 & P200L & rs 1050450 & $\mathrm{C}$ & $\mathrm{T}$ & $\begin{array}{l}\mathrm{CT} \text { or } \mathrm{TT}=\text { reduced detoxifying } \\
\text { capacity }\end{array}$ \\
\hline SOD3 & C760G & rs1799895 & $\mathrm{C}$ & $G$ & $\begin{array}{l}\text { CG or GG = } \\
\text { reduced detoxifying/antioxidant } \\
\text { capacity and possible cardiovascular } \\
\text { risk factor }\end{array}$ \\
\hline \multirow[t]{2}{*}{ MnSOD } & A16V & rs4880 & $\mathrm{C}$ & $\mathrm{T}$ & \multirow{2}{*}{$\begin{array}{l}\text { TC or } \mathrm{CC}=\text { reduced detoxifying } \\
\text { capacity and possible cardiovascular } \\
\text { risk factor }\end{array}$} \\
\hline & $\mathrm{T} 175 \mathrm{C}$ & rs1141718 & $\mathrm{T}$ & $\mathrm{C}$ & \\
\hline
\end{tabular}

Intolerance food test 
The majority of cases of food intolerance (15\% to $20 \%)$ are due to non-immunological causes. These causes range from pseudoallergic reactions to enzymopathies, chronic infections, and psychosomatic reactions that are associated with food intolerance, i.e. lactose intolerance.

The prevalence of true food allergy, i.e., immunologically mediated intolerance reactions, is only $2 \%$ to $5 \%$ (celiac disease ) [196].

Genomic profiling is a useful tool for assessing the organism's sensitivity or predisposition to susceptibility to substances introduced with food, in order to assure and maintain whole wellness of the organism.

Intolerance lactose test

In most human populations, the ability to digest lactose contained in milk usually disappears in childhood.

Lactose intolerance, the most common enzyme intolerance, (about $70 \%$ suffer from it of the world population), is the inability to digest the sugar present in milk.

Before to be used by the body, lactose must be broken down into two simple sugars: the glucose and galactose. To do this you need the lactase enzyme. A deficiency of this enzyme causes nonhydrolyzed lactose, unable to be digested, reaches the colon exerting an osmotic effect that causes water and electrolytes in the intestinal lumen, bacterial fermentation of sugar and formation of lactic acid and short-chain fatty acids [197].

Symptoms are dose-dependent: major is the amount of lactose ingested, the more evident are the symptoms.

In European-derived populations, lactase activity frequently persists into adulthood SNPs in the gene encoding lactase (LCT) (C/T-13910, A/G -22018) are associated with the ability to digest milk as adults (lactase persistence) in Europeans and Africans [198,199]. 
The genotypic variant CC / GG associated with a lower transcription of the gene correlates with the lactose intolerance phenotype.

\begin{tabular}{|l|l|l|l|l|l|}
\hline Gene & SNP & RSnumber & Nucleotid & Variatio & Interpretation \\
\hline \multirow{2}{*}{ LCT } & -13910 T-C & rs4988235 & T & C & CC = Lactose intolerant \\
\cline { 2 - 7 } & $-22018 \quad$ A- & rs182549 & A & G & GG= Lactose intolerant \\
\hline
\end{tabular}

Intolerance gluten test

Celiac disease is an autoimmune disease, induced by gluten, responsible for serious and lasting damage to the mucosa of the small intestine.

Numerous studies report that celiac disease is frequently associated with the presence of specific genes of the HLA System, encoding the heterodimers DQ2 and DQ8 [200].

In the HLA class II system of celiacs, haplotype DQ2 is present in $90 \%$ of cases, while celiacs not DQ2 are mostly DQ8. In particular, the HLA-DQ2 and DQ8 haplotype (encoded by the allelic combination DQA1 * 0201, DQA1 * 03 and DQB1 * 02) is present in 98\% of Northern European celiacs.

HLA genetic analysis is a susceptibility test that evaluates the probability of getting sick relative to that of the general population. 
A genetic test is important to evaluate any family predisposition and decide in the case of positivity to proceed with in-depth analysis for confirmation [201]. 


\begin{tabular}{|c|c|c|c|c|c|}
\hline Gene & SNP & RSnumber & Nucleotid & $\begin{array}{l}\text { Variatio } \\
\text { n }\end{array}$ & Interpretation \\
\hline DR type 4 & HLA DQ8 & rs7454108 & $G$ & A & $\begin{array}{l}\text { GA or } \mathrm{AA}=\text { predisposition to } \\
\text { Celiac Disease, to investigate further }\end{array}$ \\
\hline \multirow[t]{3}{*}{ DR type 7} & \multirow[t]{3}{*}{$\begin{array}{l}\text { HLA DQ } \\
2.5\end{array}$} & rs2395182 & $G$ & $\mathrm{~T}$ & $\begin{array}{l}\text { GT or TT = predisposition to Celiac } \\
\text { Disease, to investigate further }\end{array}$ \\
\hline & & rs7775228 & A & $G$ & $\begin{array}{l}\text { AG or } \mathrm{GG}=\text { predisposition to } \\
\text { Celiac Disease, to investigate further }\end{array}$ \\
\hline & & rs4713586 & A & G & $\begin{array}{l}\text { AG or } \mathrm{GG}=\text { predisposition to } \\
\text { Celiac Disease, to investigate further }\end{array}$ \\
\hline
\end{tabular}

Intolerance histamin test

Histamine intolerance results from a disequilibrium of accumulated histamine and the capacity for histamine degradation. Histamine is a biogenic amine that occurs to various degrees in many foods. In healthy persons, dietary histamine can be rapidly detoxified by amine oxidases, whereas persons with low amine oxidase activity are at risk of histamine toxicity. Diamine oxidase (DAO) is the main enzyme for the metabolism of ingested histamine. It has been proposed that DAO, when functioning as a secretory protein, may be responsible for scavenging extracellular histamine after mediator release. Conversely, histamine N-methyltransferase, the other important enzyme inactivating histamine, is a cytosolic protein that can convert histamine only in the intracellular space of cells. An impaired histamine degradation based on reduced DAO activity and the resulting 
histamine excess may cause numerous symptoms mimicking an allergic reaction. The ingestion of histamine-rich food or of alcohol or drugs that release histamine or block DAO may provoke diarrhea, headache, rhino-conjunctival symptoms, asthma, hypotension, arrhythmia, urticaria, pruritus, flushing, and other conditions in patients with histamine intolerance. Symptoms can be reduced by a histamine-free diet or be eliminated by antihistamines. However, because of the multifaceted nature of the symptoms, the existence of histamine intolerance has been underestimated, and further studies based on double-blind, placebo-controlled provocations are needed. In patients in whom the above mentioned symptoms are triggered by the corresponding substances and who have a negative diagnosis of allergy or internal disorders, histamine intolerance should be considered as an underlying mechanism [202,203].

Genetic polymorphisms for histamine-metabolizing enzymes are responsible for inter individual variation in histamine metabolism and are associated with diverse diseases. Initial reports on polymorphisms of histamine-related genes including those coding for the enzymes histidine decarboxylase (HDC), diamine oxidase (ABP1) and histamine N-methyltransferase (HNMT), as well as histamine receptor genes, often have pointed to polymorphisms that occur with extremely low frequencies or that could not be verified by later studies. In contrast, common and functionally significant polymorphisms recently described have been omitted in many association studies. In this review we analyze allele frequencies, functional and clinical impact and interethnic variability on histamine-related polymorphisms [188]. 


\begin{tabular}{|l|l|l|l|l|l|}
\hline Gene & SNP & RSnumber & Nucleotid & Variatio & Interpretation \\
\hline \multirow{3}{*}{ HDC } & Glu644Asp & rs2073440 & Q & D & \\
\cline { 2 - 7 } & Thr31Met & rs17740607 & T & M & \\
\hline \multirow{2}{*}{ HNMT } & Thr105Ile & rs1801105 & T & I & \\
\hline \multirow{3}{*}{ ABP1 } & Thr16Met & rs10156191 & T & M & \\
\cline { 2 - 7 } & Ser332Phe & rs1049742 & S & F & \\
\cline { 2 - 7 } & His645Asp & rs1049793 & H & D & \\
\cline { 2 - 7 } & G4586T & rs2052129 & G & T & \\
\hline
\end{tabular}

Intolerance nickel test

Nickel is a ubiquitous trace element and it occurs in soil, water, air and of the biosphere.

Nickel is the commonest cause of metal allergy. Nickel allergy is a chronic and recurring skin problem; females are affected more commonly than males.

Nickel is present in most of the dietary items and food is considered to be a major source of nickel exposure for the general population. Nickel content in food may vary considerably from place to place due to the difference in nickel content of the soil. However, certain foods are routinely high in nickel content. Nickel in the diet of a nickel-sensitive person can provoke dermatitis. Careful 
selection of food with relatively low nickel concentration can bring a reduction in the total dietary intake of nickel per day [204].

Nickel is also a micronutrient essential for proper functioning of the human body, as it increases hormonal activity and is involved in lipid metabolism.

Large doses of nickel or prolonged contact with it could cause a variety of side effects. Harmfull effects, the population of people allergic to nickel is growing [205].

FLG codes for filaggrin, the main component of keratoyalin granules of the human epidermis and is essential for the formation and hydration of the stratum corneum. There partial or total loss of filaggrin gene expression causes large disturbances of the skin barrier, including an increase in skin dryness (xerosis cutaneous) and a reduced formation of the stratum corneum (ichthyosis), as well as an important one susceptibility to allergens entering the skin. The 2282 del 4 deletion results in an increased sensitivity of the skin to allergens and in particular to nickel [206].

TNF $\alpha$ encodes tumor necrosis factor $\alpha$, a cytokine produced mainly in macrophages, involved in systemic inflammation and a member of a group of cytokines which stimulate the acute phase reaction. Among the main biological functions of TNF $\alpha$ is the stimulation of the production of IL-1, IL-6 and chemokines. If the A allele is present on TNF $\alpha$ tumor necrosis factor $\alpha$ is overproduced and inflammatory processes are system favourites [207]. 


\begin{tabular}{|l|l|l|l|l|l|}
\hline Gene & SNP & RSnumber & Nucleotid & Variation & Interpretation \\
\hline FLG & $2282 \mathrm{del} 4$ & rs558269137 & NO Del & Del & Del4bp/ Del4bp = probable \\
nickel intolerance
\end{tabular}

Intolerance sulphites test

Sulphites are widely used as preservative and antioxidant additives in the food and pharmaceutical industries. Topical, oral or parenteral exposure to sulphites has been reported to induce a range of adverse clinical effects in sensitive individuals, ranging from dermatitis, urticaria, flushing, hypotension, abdominal pain and diarrhoea to life-threatening anaphylactic and asthmatic reactions. Exposure to the sulphites arises mainly from the consumption of foods and drinks that contain these additives.

In addition to episodic and acute symptoms, sulphites may also contribute to chronic skin and respiratory symptoms. To date, the mechanisms underlying sulphite sensitivity remain unclear, although a number of potential mechanisms have been proposed. Physicians should be aware of the range of clinical manifestations of sulphite sensitivity, as well as the potential sources of exposure. Minor modifications to diet or behaviour lead to excellent clinical outcomes for sulphite-sensitive individuals [208]. 


\begin{tabular}{|c|c|c|c|c|c|}
\hline Gene & SNP & RSnumber & Nucleotid & $\begin{array}{l}\text { Variatio } \\
\text { n }\end{array}$ & Interpretation \\
\hline \multirow{4}{*}{ SUOX } & Q364X & - & $\mathrm{C}$ & & $\begin{array}{l}\text { TT o } \mathrm{CT}=\text { possible increased risk of } \\
\text { sulphite accumulation and } \\
\text { neurotoxicity }\end{array}$ \\
\hline & S370S & rs773115 & $G$ & C & $\begin{array}{l}\mathrm{CC} \text { o } \mathrm{GC}=\text { possible increased risk of } \\
\text { sulphite accumulation and } \\
\text { neurotoxicity }\end{array}$ \\
\hline & S370Y & - & $\mathrm{C}$ & A & $\begin{array}{l}\text { AA o } \mathrm{CA}=\text { possible increased risk } \\
\text { of sulphite accumulation and } \\
\text { neurotoxicity }\end{array}$ \\
\hline & $\begin{array}{l}\text { Cod 381del } \\
\text { TAGA }\end{array}$ & & & & $\begin{array}{l}\text { Del cod } 381=\text { possible increased risk } \\
\text { of sulphite accumulation and } \\
\text { neurotoxicity }\end{array}$ \\
\hline \multirow[t]{2}{*}{ CBS } & C699T & rs234706 & $\mathrm{C}$ & $\mathrm{T}$ & $\begin{array}{l}\mathrm{TT}=\text { possible prevention factor for } \\
\text { cardiovascular events }- \text { high } \\
\text { sensitivity to folic acid activity } \\
\mathrm{CC}=\text { possible risk factor for } \\
\text { cardiovascular events }\end{array}$ \\
\hline & T1080C & rs1801181 & $\mathrm{T}$ & $\mathrm{C}$ & $\mathrm{CC}=$ possible prevention factor for \\
\hline
\end{tabular}




\begin{tabular}{|l|l|l|l} 
cardiovascular events $\quad$ high \\
sensitivity to folic acid activity \\
TT=possible risk factor for \\
cardiovascular events
\end{tabular}

VIT D metabolism test

Endogenous provitamin D, with exposure to ultraviolet light, is converted to Vitamin D3.

This form is activated and made biologically available through hydroxylation in the liver and in the kidneys, which lead to the production of 1.25 D3 dihydroxyvitamine.

This hormone, interacting with VDR receptors, activates the transcription of some genes that will produce proteins responsible for regulating calcium levels in the blood.

The mechanisms of calcium homeastasis are 3:

- $\quad$ intestinal absorption

- $\quad$ resorption at the level of the renal tubules

- $\quad$ activation of osteoclasts that reabsorb the bone matrix

The absence of Vitamin D results in a decrease in bone mass due to decreased calcium absorption.

VDR gene variability is relevant in the aging process and emphasizes the role of the VDR genetic background in determining healthy aging [209]. 


\begin{tabular}{|c|c|c|c|c|c|}
\hline Gene & SNP & RSnumber & Nucleotid & $\begin{array}{l}\text { Variatio } \\
\text { n }\end{array}$ & Interpretation \\
\hline \multirow{3}{*}{ VDR } & $\begin{array}{l}\text { Fok1 (ATG } \\
\text {-ACG } \\
\text { codon 1) }\end{array}$ & rs2228570 & $\mathrm{C}$ & $\mathrm{T}$ & $\begin{array}{l}\mathrm{TT}=\text { possible predisposition to } \\
\text { decrease in bone density }\end{array}$ \\
\hline & $\begin{array}{l}\text { BsmI (A-G } \\
\text { introne } 8)\end{array}$ & rs 1544410 & A & G & $\begin{array}{l}\mathrm{AA}=\text { possible reduced absorption of } \\
\text { calcium in the intestine } \\
\mathrm{GG}=\text { possible protection factor } \\
\text { against loss of bone density }\end{array}$ \\
\hline & $\begin{array}{l}\text { TaqI }(\mathrm{T}-\mathrm{C} \\
\text { esone 9) }\end{array}$ & rs731236 & $\mathrm{T}$ & $\mathrm{C}$ & $\begin{array}{l}\mathrm{C}=\text { possible risk factor for } \\
\text { osteoporosis }\end{array}$ \\
\hline
\end{tabular}

Detoxification test

The human body is exposed to a wide array of xenobiotics during lifetime, from food components to environmental toxins to pharmaceuticals, and has developed complex enzymatic mechanisms to detoxify these substances. 
Human detoxification systems is a two steps pathway termed Phase I and Phase II detoxification, respectively

The Phase I detoxification system, composed mainly of the cytochrome P450 supergene family of enzymes, is generally the first enzymatic defence against foreign compounds.

Phase II conjugation reactions generally follow Phase I activation, resulting in a xenobiotic that has been transformed into a water-soluble compound that can be excreted through urine or bile.

Mono-functional inducers, such as polycyclic hydrocarbons from cigarette smoke and aryl amines from charbroiled meats, result in dramatic induction of the Cyp1A1 and Cyp1A2 enzymes, leading to a substantial increase in Phase I activity, these activities may lead to an uncoupling of the Phase I and Phase II balance of activity and, therefore, a higher level of reactive intermediates, which can cause damage to DNA, RNA, and proteins.

The multifunctional inducers include many of the flavonoid molecules (for example, ellagic acid) found in fruits and vegetables that induce several Phase II enzymes while decreasing Phase I activity. In general, this increase in Phase II supports better detoxification in an individual and helps to promote and maintain a healthy balance between Phase I and Phase II activities.

These detoxification mechanisms exhibit significant individual variability, and are affected by environment, lifestyle, and genetic influences [210].

\begin{tabular}{|l|l|l|l|l|l|}
\hline Gene & SNP & RSnumber & Nucleotid & Variatio & Interpretation \\
\hline CYP1A2 & $* 1 \mathrm{~F} * 1 \mathrm{~A}$ & rs762551 & C & A & $* 1 \mathrm{~F} / * 1 \mathrm{~F}=$ rapid metabolizer- \\
& & & & & ergogenic effect (AA) \\
\hline
\end{tabular}




\begin{tabular}{|c|c|c|c|c|c|}
\hline & & & & & $\begin{array}{l}* 1 \mathrm{~F} / * 1 \mathrm{~A} \text { or } * 1 \mathrm{~A} / 1 \mathrm{~A}=\text { slow } \\
\text { metabolizer of caffeine }- \text { no } \\
\text { ergogenic effect }(\mathrm{AC} \text { or } \mathrm{CC})\end{array}$ \\
\hline \multirow{2}{*}{ EPHX1 } & Y113H & rs 1051740 & $\mathrm{~T}$ & $\mathrm{C}$ & $\begin{array}{l}\mathrm{TC} \text { o } \mathrm{CC}=\text { possible reduced } \\
\text { detoxifying and antioxidant capacity }\end{array}$ \\
\hline & R139H & rs2234922 & A & $G$ & $\begin{array}{l}\text { AG o } G G=\text { possible reduced } \\
\text { detoxifying and antioxidant capacity }\end{array}$ \\
\hline
\end{tabular}

Body weight

Obesity, a complex condition with serious medical, psychological and social consequences, affects millions of people across the world [211].

The pathophysiology of obesity is influenced by several factors such as candidate genes and their expression, single nucleotide polymorphisms, proteins, metabolic pathways and their perturbations due to mutations, nutrition, exercise, gut microbes, and diseases, e.g. hypothyroidism [212].

Multiple DNA polymorphisms/genes have been shown to be strongly associated with obesity, typically in populations of European descent [213].

Adipose tissue is central to the regulation of energy balance; the adipose tissue storage is influenced by environmental and genetic factors. The environmental influence generally depends on the individual's life-style, for instance, food intake and physical activity. Some studies have indicated that certain single nucleotide polymorphisms (SNPs) are related to food intake, energy expenditure and the development of obesity [214]. 


\begin{tabular}{|l|l|l|l|l|l|}
\hline Gene & SNP & RSnumber & Nucleotid & Variatio & Interpretation \\
\hline PPARG & P12A & rs1801282 & C & G & G (GC o GG)= possible \\
\hline NPY & L7P & rs16139 & T & C & C (CT o CC) = possible \\
\hline Leptin & 2548 & rs7799039 & G & A & AA= possible predisposition to \\
\hline
\end{tabular}

\section{Conclusion}

The future of genetics and epigenetics applied to food is important, because new technologies focused on food require the intervention of new professionals from other fields of science, who understand the importance of biotechnology and genetics. On the other hand, thanks to technological advances which can be applied in clinical approach it will be possible to guide patients to personalized nutrition and lifestyle, in pathology and in prevention. Furthermore the contribution of the different omic sciences as well as the creation of several gene banks, has allowed to increase the existing information pool on biological molecules analyzed by multidisciplinary teams, which can be used also for integrated clinical approach. 
NOTES:

1)HOLOBIONT: term introduced in 1991 by Lynn Mangulis, biologist who formulated the theory of endosymbiosis. It indicates the whole of the host organism/microorganisms ecosystem present in it. HOLOGENOME: the genome of the holobiont. 
2)UNIFIED FIELD QUANTUM THEORY: theory of modern physics, according to which the various manifestations of the Universe are the natural expression of a single field, with a single law unifying gravity and electromagnetism. Albert Einstien spent many years researching "unified field theory".

3)CENTRAL DOGMA OF MOLECULAR BIOLOGY: dogma enunciated by Francis Crick (Nobel Prize winner for medicine in 1962) for which genetic information presents a unidirectional flow, from nucleic acids of DNA to protein synthesis, that is that the gene contains in the DNA the information for the synthesis of specific polypeptic chains: "once the information is inserted in a protein it is no longer able to go back" (Francis Crick).

4)EPIGENOME: the set of changes, specific for each cell, of DNA expression, without alterations of the sequence in nucleic acids of DNA.

5)EPISTEMOLOGY OF COMPLEXITY: epistemology is a term coined by the Scottish philosopher James Frederick Ferrier (1854): it is a branch of philosophy that examines the methodological bases of scientific knowledge.

6)EPIGENETICS: term coined by Conrad Hal Waddington. the science that studies the epigenomes.

7)EPIDRUGS: o epigentic drugs: epigenetic-curative chemical agents. 
8)PHYTOCHEMICALS: molecules naturally present in plants, without proven nutritional action, but with beneficial effects on health. PHYTONUTRIENTS: molecules naturally present in plants with a nutritional action for our organism.

9)ALLELOPATHY: inhibition of the growth of other plants mediated by specific plant molecules.

10)PHYTOALEXIN: (from the Greek,"in aid of the plant") low molecular weight antimicrobial compounds synthesized by plants and accumulated in them following the attack by microorganisms" Paxton 1981

\section{References}

1)Romero-Cortes, T.; Lopez-Perez, A.; Toledo, K.M., Perez-Espana, V.H.; Aparicio-Burgos, J.E.; Cuervo-Parra, J.A. Nutrigenomics and nutrigenetics in functional food. Int. J. of Bio-res and Stress Manag 2018, 9(6), pp. 661-672.

2) Clementi, F.; Fumagalli, G.; Farmacologia generale e molecolare, Italia, 2016, EDRA

3) Taormina, G.; Mirisola, M.G. Longevity: epigenetic and biomolecular aspects. Biomol Concepts. 2015 Apr;6(2):105-117. doi: 10.1515/bmc-2014-0038.

4) Stein, R.A. Epigenetic therapies - a new direction in clinical medicine. Int J Clin Pract. 2014 Jul;68(7):802-811. doi: 10.1111/ijcp.12436.

5) Mazzanti, G.; Dell'Agli, M.; Izzo, A. Farmacognosia e Fitoterapia-Basi farmacologiche e aspetti applicativi - Italy - Piccin $\mathbf{2 0 2 0 .}$

6) Cicero, A.F.C. coadiutori Alessandro Colletti, A.; Francesco Di Pierro, F. 2019 SiNutScripta Manent Trattato Italiano di Nutraceutica clinica.

7) Ding, S.; Jiang, H.; Fang, J. Regulation of Immune Function by Polyphenols. J Immunol Res. 2018 Apr 12;2018:1264074. doi: 10.1155/2018/1264074. 
8) Galimberti, D.; Girado, G.B.; Calabrese, V.; Gelli, A.; Govoni, S. “ Nutrigenomica ed epigenetica - Dalla Biologia alla clinica” - 2017 -EDRA

9) Bishop, K.S.; Ferguson, L.R. The interaction between epigenetics, nutrition and the development of cancer. Nutrients. 2015 Jan 30;7(2):922-947. doi: 10.3390/nu7020922.

10) Origlia, C. Bioavailability Enanchers Advanced Therapies Terapia d'Avanguardia. anno VII-n.13-2018 Nuova Ipsa Editore

11) Origlia, C. "Nutriterapia adattogena. Fosfatidilserina e Curcumina nella modulazione cortisolica della reazione da stress”- Omeopatia Oggi, Anno 27, n. 58, settembre 2017.

12) Origlia, C. «Il Re delle Spezie, Piper Nigrum, e la Scienza dei Bioenanchersi» Omeopatia Oggi Anno 28, n. 59, febbraio 2018.

13) Hassan, F.U.; Rehman M.S.; Khan, M.S; Ali, M.A; Javed, A.; Nawaz, A.; Yang, C. Curcumin as an Alternative Epigenetic Modulator: Mechanism of Action and Potential Effects. Front Genet. 2019 Jun 4;10:514. doi: 10.3389/fgene.2019.00514.

14) Arora, I.; Sharma, M., Tollefsbol, T.O. Combinatorial Epigenetics Impact of Polyphenols and Phytochemicals in Cancer Prevention and Therapy. Int J Mol Sci. 2019 Sep 14;20(18):4567. doi: 10.3390/ijms20184567.

15) Azad, G.K.; Thomar, R.S. Epigenetics of Curcumin: A Gifted Dietary Therapeutics Compound - J Carcinog Mutagen 2015, page 1-6.

16) Shankar, S.; Kumar, D.; Srivastava, R.K. Epigenetic modifications by dietary phytochemicals: implications for personalized nutrition. Pharmacol Ther. 2013 Apr;138(1):1-17. doi: 10.1016/j.pharmthera.2012.11.002.

17) Pan, M.H.; Lai, C.S.; Wu, J.C.; Ho, C.T. Epigenetic and disease targets by polyphenols. Curr Pharm Des. 2013;19(34):6156-6185. doi: 10.2174/1381612811319340010.

18) www.salute.gov.it

19) Docente Guida: Prof. Francesco Paolo Mancino-Coordinatore: Prof. Carmelo Bruno BruniCandidata: Dr. ssa Paola Iannelli-"Caratterizzazione degli effetti biologici del resveratrolo, un 
potenziale nutraceutico per la prevenzione delle malattie cronico-degenerative"-AA 2006/2007Università degli Studi di Napoli “Federico II"-Scuola di Dottorato in Medicina MolecolareDottorato di Ricerca in Genetica e Medicina Molecolare XIX ciclo

20) Moscato, A.; Restani, P.; Di Lorenzo, C. Il LICOPENE - un carotenoide dalle promettenti proprietà salutistiche - Natural 1, settembre 2017

21) Calabrese, D. Relazione “Il licopene come prodotto nutraceutico e funzionale” Università degli Studi Mediterranea di Reggio Calabria. Anno accademico 2012/2013, culture erbacee Nutraceutiche (6CFU)

22) Popescu, G.D.A.; Scheau, C.; Badarau, I.A.; Dumitrache, M.D.; Caruntu, A., Scheau, A.E.; Costache, D.O.; Costache, R.S.; Constantin, C.; Neagu, M.; Caruntu, C.; The Effects of Capsaicin on Gastrointestinal Cancers. Molecules. 2020 Dec 28;26(1):94. doi: 10.3390/molecules26010094.

23) Sivasangari, K.; Rajan, K.E. Standardized Bacopa monnieri Extract Ameliorates Learning and Memory Impairments through Synaptic Protein, Neurogranin, Pro-and Mature BDNF Signaling, and HPA Axis in Prenatally Stressed Rat Offspring. Antioxidants (Basel). 2020 Dec 4;9(12):1229. doi: 10.3390/antiox9121229.

24) Preethi, J.; Singh, H.K.; Rajan, K.E. Possible Involvement of Standardized Bacopa monniera Extract (CDRI-08) in Epigenetic Regulation of reelin and Brain-Derived Neurotrophic Factor to Enhance Memory. Front Pharmacol. 2016 Jun 27;7:166. doi: 10.3389/fphar.2016.00166.

25) Khan, N.; Syed, D.N.; Ahmad, N.; Mukhtar, H. Fisetin: a dietary antioxidant for health promotion. Antioxid Redox Signal. 2013 Jul 10;19(2):151-162. doi: 10.1089/ars.2012.4901.

26) Yousefzadeh, M.J.; Zhu, Y.; McGowan, S.J.; Angelini, L.; Fuhrmann-Stroissnigg, H.; Xu, M.; Ling, Y.Y., Melos, K.I.; Pirtskhalava, T.; Inman, C.L.; McGuckian, C.; Wade, E.A.; Kato, J.I.; Grassi, D., Wentworth, M.; Burd, C.E.; Arriaga, E.A.; Ladiges, W.L.; Tchkonia, T.; Kirkland, J.L.; Robbins, P.D.; Niedernhofer, L.J. Fisetin is a senotherapeutic that extends health and lifespan. EBioMedicine. 2018 Oct;36:18-28. doi: 10.1016/j.ebiom.2018.09.015. 
27) Maher, P. Protective effects of fisetin and other berry flavonoids in Parkinson's disease. Food Funct. 2017 Sep 20;8(9):3033-3042. doi: 10.1039/c7fo00809k.

28) Grynkiewicz, G.; Demchuk, O.M. New Perspectives for Fisetin. Front Chem. 2019 Oct 30;7:697. doi: 10.3389/fchem.2019.00697.

29) Busch, C.; Burkard, M.; Leischner, C.; Lauer, U.M.; Frank, J.; Venturelli, S. Epigenetic activities of flavonoids in the prevention and treatment of cancer. Clin Epigenetics. 2015 Jul 10;7(1):64. doi: 10.1186/s13148-015-0095-z.

30) Klimaszewska-Wiśniewska, A.; Grzanka, D.; Czajkowska, P.; Hałas-Wiśniewska, M.; Durślewicz, J.; Antosik, P.; Grzanka, A.; Gagat, M. Cellular and molecular alterations induced by low dose fisetin in human chronic myeloid leukemia cells. Int J Oncol. 2019 Dec;55(6):1261-1274. doi: 10.3892/ijo.2019.4889.

31) Maher, P.; Dargusch, R.; Ehren, J.L.; Okada, S.; Sharma, K.; Schubert, D. Fisetin lowers methylglyoxal dependent protein glycation and limits the complications of diabetes. PLoS One. 2011;6(6):e21226. doi: 10.1371/journal.pone.0021226.

32) Kim, H.J.; Kim, S.H.; Yun, J.M. Fisetin inhibits hyperglycemia-induced proinflammatory cytokine production by epigenetic mechanisms. Evid Based Complement Alternat Med. 2012; 2012:639469. doi: 10.1155/2012/639469.

33) Liang, Y.; Kong, D.; Zhang, Y.; Li, S.; Li, Y.; Ramamoorthy, A.; Ma, J. Fisetin Inhibits Cell Proliferation and Induces Apoptosis via JAK/STAT3 Signaling Pathways in Human Thyroid TPC 1 Cancer Cells-Biotechnology and Bioprocess Engineering 25, 197-205(2020)

34) Li, Y.; Jia, S.; Dai, W. Fisetin Modulates Human Oral Squamous Cell Carcinoma Proliferation by Blocking PAK4 Signaling Pathways-Drug Design, Development and Therapy, Volume 1430 August 2019.

35) Wu, P.Y.; Lyu, J.L.; Liu, Y.J.; Chien, T.Y.; Hsu, H.C.; Wen, K.C.; Chiang, H.M. Fisetin Regulates Nrf2 Expression and the Inflammation-Related Signaling Pathway to Prevent UVB- 
Induced Skin Damage in Hairless Mice. Int J Mol Sci. 2017 Oct 10;18(10):2118. doi: 10.3390/ijms 18102118 .

36) Abedini, M.R.; Erfanian, N.; Nazem, H., Jamali, S., Hoshyar, R. Anti-proliferative and apoptotic effects of Ziziphus Jujube on cervical and breast cancer cells. Avicenna J Phytomed. 2016 Mar-Apr;6(2):142-148.

37) Tahergorabi, Z.; Abedini, M.R.; Mitra, M.; Fard, M.H.; Beydokhti, H. "Ziziphus jujuba": A red fruit with promising anticancer activities. Pharmacogn Rev. 2015 Jul-Dec;9(18):99-106. doi: $10.4103 / 0973-7847.162108$.

38) Vahedi, F.; Fathi Najafi, M.; Bozari, K. Evaluation of inhibitory effect and apoptosis induction of Zyzyphus Jujube on tumor cell lines, an in vitro preliminary study. Cytotechnology. 2008 Feb;56(2):105-111. doi: 10.1007/s10616-008-9131-6.

39) Park, S.H.; Kang, Y.H. Dietary ellagic acid suppresses atherosclerotic lesion formation and vascular inflammation in apoE-deficience mice -Tge FASEB Journal/Volume 27, Issue S1/ p. 861.23-861.23 Nutrition- First published: 01 April 2013

40) Lembo, S.; Balato, A.; Di Caprio, R.; Cirillo, T.; Giannini, V.; Gasparri, F.; Monfrecola, G. The modulatory effect of ellagic acid and rosmarinic acid on ultraviolet-B-induced cytokine/chemokine gene expression in skin keratinocyte (HaCaT) cells. Biomed Res Int. 2014; 2014:346793. doi: 10.1155/2014/346793.

41) He, X.M.; Zhou, Y.Z.; Sheng, S.; Li, J.J.; Wang, G.Q.; Zhang, F. Ellagic Acid Protects Dopamine Neurons via Inhibition of NLRP3 Inflammasome Activation in Microglia. Oxid Med Cell Longev. 2020 Nov 19;2020:2963540. doi: 10.1155/2020/2963540.

42) Li, T.M.; Chen, G.W.; Su, C.C.; Lin, J.G.; Yeh, C.C.; Cheng, K.C.; Chung, J.G. Ellagic acid induced p53/p21 expression, G1 arrest and apoptosis in human bladder cancer T24 cells. Anticancer Res. 2005 Mar-Apr;25(2A):971-979. 
43) Aslan, A.; Beyaz, S.; Gok O.; Erman, O. The effect of ellagic acid on caspase-3/bcl-2/Nrf2/NF-kB/TNF- $\alpha / C O X-2$ gene expression product apoptosis pathway: a new approach for muscle damage therapy. Mol Biol Rep. 2020 Apr;47(4):2573-2582. doi: 10.1007/s11033-020-05340-7.

44) Kowshik, J.; Giri, H.; Kishore, T.K.; Kesavan, R.; Vankudavath, R.N.; Reddy, G.B.; Dixit, M.; Nagini, S. Ellagic acid inhibits VEGF/VEGFR2, PI3K/Akt and MAPK signaling cascades in the hamster cheek pouch carcinogenesis model. Anticancer Agents Med Chem. 2014;14(9):1249-1260. doi: 10.2174/1871520614666140723114217.

45) van Breemen, R.B.; Tao, Y.; Li, W. Cyclooxygenase-2 inhibitors in ginger (Zingiber officinale). Fitoterapia. 2011 Jan;82(1):38-43. doi: 10.1016/j.fitote.2010.09.004.

46) de Lima, R.M.T.; Dos Reis, A.C.; de Menezes, A.P.M.; Santos, J.V.O.; Filho, J.W.G.O.; Ferreira, J.R.O.; de Alencar, M.V.O.B.; da Mata, A.M.O.F.; Khan, I.N.; Islam, A.; Uddin, S.J.; Ali, E.S.; Islam, M.T.; Tripathi, S.; Mishra, S.K.; Mubarak, M.S; Melo-Cavalcante, A.A.C. Protective and therapeutic potential of ginger (Zingiber officinale) extract and [6]-gingerol in cancer: A comprehensive review. Phytother Res. 2018 Oct;32(10):1885-1907. doi: 10.1002/ptr.6134

47) Li, Y.; Pham, V.; Bui, M.; Song, L.; Wu, C.; Walia, A.; Uchio, E.; Smith-Liu, F.; Zi, X. Rhodiola rosea L.: an herb with anti-stress, anti-aging, and immunostimulating properties for cancer chemoprevention. Curr Pharmacol Rep. 2017 Dec;3(6):384-395. doi: 10.1007/s40495-0170106-1.

48) Li, R.; Wang, S.; Li, T.; Wu, L.; Fang, Y.; Feng, Y.; Zhang, L.; Chen, J.; Wang, X. Salidroside Protects Dopaminergic Neurons by Preserving Complex I Activity via DJ-1/Nrf2Mediated Antioxidant Pathway. Parkinsons Dis. 2019 May 16;2019:6073496. doi: $10.1155 / 2019 / 6073496$.

49) Hwang, J.W.; Oh, J.H.; Yoo, H.S.; Lee, Y.W.; Cho, C.K.; Kwon, K.R.; Yoon, J.H.; Park, J.; Her, S.; Lee, Z.W.; Jang, I.S.; Choi, J.S. Mountain ginseng extract exhibits anti-lung cancer activity by inhibiting the nuclear translocation of NF- $\kappa B$. Am J Chin Med. 2012;40(1):187-202. doi: 10.1142/S0192415X12500152. 
50) Zhao, L.; Shou, H.; Chen, L.; Gao, W.; Fang, C.; Zhang, P. Effects of ginsenoside Rg3 on epigenetic modification in ovarian cancer cells. Oncol Rep. 2019 Jun;41(6):3209-3218. doi: 10.3892/or.2019.7115.

51) Liu, W.; Yang, B.; Yang, L., Kaur, J.; Jessop, C.; Fadhil, R.; Good, D.; Ni, G.; Liu, X.; Mosaiab, T.; Yi, Z.; Wei, M.Q.; Therapeutic Effects of Ten Commonly Used Chinese Herbs and Their Bioactive Compounds on Cancers. Evid Based Complement Alternat Med. 2019 Sep 15;2019:6057837. doi: 10.1155/2019/6057837.

52) Yang, Q.; Wang, P.; Cui, J.; Wang, W.; Chen, Y.; Zhang, T. Panax notoginseng saponins attenuate lung cancer growth in part through modulating the level of Met/miR-222 axis. $\mathrm{J}$ Ethnopharmacol. 2016 Dec 4;193:255-265. doi: 10.1016/j.jep.2016.08.040.

53) Gomes, M.B.; Negrato, C.A. Alpha-lipoic acid as a pleiotropic compound with potential therapeutic use in diabetes and other chronic diseases. Diabetol Metab Syndr. 2014 Jul 28;6(1):80. doi: 10.1186/1758-5996-6-80.

54) Lei, L.; Zhu, Y.; Gao, W.; Du, X.; Zhang, M.; Peng, Z.; Fu, S.; Li, X.; Zhe, W.; Li, X.; Liu, G. Alpha-lipoic acid attenuates endoplasmic reticulum stress-induced insulin resistance by improving mitochondrial function in HepG2 cells. Cell Signal. 2016 Oct;28(10):1441-1450. doi: 10.1016/j.cellsig.2016.06.024.

55) Dinicola, S.; Proietti, S.; Cucina, A.; Bizzarri, M.; Fuso, A. Alpha-Lipoic Acid Downregulates IL-1 $\beta$ and IL-6 by DNA Hypermethylation in SK-N-BE Neuroblastoma Cells. Antioxidants (Basel). 2017 Sep 26;6(4):74. doi: 10.3390/antiox6040074.

56) Arambašić, J.; Mihailović, M.; Uskoković, A.; Dinić, S.; Grdović, N.; Marković, J.; Poznanović, G.; Bajec, D.; Vidaković, M. Alpha-lipoic acid upregulates antioxidant enzyme gene expression and enzymatic activity in diabetic rat kidneys through an O-GlcNAc-dependent mechanism. Eur J Nutr. 2013 Aug;52(5):1461-1473. doi: 10.1007/s00394-012-0452-z. 
57) Meng, Q.; Yuan, F.; Goldberg, I.D.; Rosen, E.M.; Auborn, K.; Fan, S. Indole-3-carbinol is a negative regulator of estrogen receptor-alpha signaling in human tumor cells. J Nutr. 2000 Dec;130(12):2927-2931. doi: 10.1093/jn/130.12.2927.

58) Cover, C.M.; Hsieh, S.J.; Tran, S.H.; Hallden, G.; Kim, G.S.; Bjeldanes, L.F., Firestone, G.L. Indole-3-carbinol inhibits the expression of cyclin-dependent kinase-6 and induces a G1 cell cycle arrest of human breast cancer cells independent of estrogen receptor signaling. $\mathrm{J}$ Biol Chem. 1998 Feb 13;273(7):3838-3847. doi: 10.1074/jbc.273.7.3838.

59) Marconett, C.N.; Singhal, A.K.; Sundar, S.N. Firestone GL. Indole-3-carbinol disrupts estrogen receptor-alpha dependent expression of insulin-like growth factor-1 receptor and insulin receptor substrate-1 and proliferation of human breast cancer cells. Mol Cell Endocrinol. 2012 Nov 5;363(1-2):74-84. doi: 10.1016/j.mce.2012.07.008.

60) Lee, J. 3,3'-Diindolylmethane Inhibits TNF- $\alpha$ - and TGF- $\beta$-Induced Epithelial-Mesenchymal Transition in Breast Cancer Cells. Nutr Cancer. 2019;71(6):992-1006. doi: 10.1080/01635581.2019.1577979.

61) Marconett, C.N.; Sundar, S.N.; Tseng, M.; Tin, A.S.; Tran, K.Q.; Mahuron, K.M.; Bjeldanes, L.F.; Firestone, G.L. Indole-3-carbinol downregulation of telomerase gene expression requires the inhibition of estrogen receptor-alpha and Sp1 transcription factor interactions within the hTERT promoter and mediates the G1 cell cycle arrest of human breast cancer cells. Carcinogenesis. 2011 Sep;32(9):1315-1323. doi: 10.1093/carcin/bgr116.

62) Qi, M.; Anderson, A.E.; Chen, D.Z.; Sun, S.; Auborn, K.J. Indole-3-carbinol prevents PTEN loss in cervical cancer in vivo. Mol Med. 2005 Jan-Dec;11(1-12):59-63. doi: 10.2119/200600007.Auborn.

63) Ye, Y.; Fang, Y.; Xu, W.; Wang, Q.; Zhou, J.; Lu, R. 3,3'-Diindolylmethane induces antihuman gastric cancer cells by the miR-30e-ATG5 modulating autophagy. Biochem Pharmacol. 2016 Sep 1;115:77-84. doi: 10.1016/j.bcp.2016.06.018. 
64) Delmas, D.; Xiao, J.; Vejux, A.; Aires, V. Silymarin and Cancer: A Dual Strategy in Both in Chemoprevention and Chemosensitivity. Molecules. 2020 Apr 25;25(9):2009. doi: 10.3390/molecules25092009.

65) Yang, J.X.; Chaudhry, M.T.; Yao, J.Y.; Wang, S.N.; Zhou, B.; Wang, M.; Han, C.Y.; You, Y.; Li, Y. Effects of phyto-oestrogen quercetin on productive performance, hormones, reproductive organs and apoptotic genes in laying hens. J Anim Physiol Anim Nutr (Berl). 2018 Apr;102(2):505-513. doi: 10.1111/jpn.12778.

66) Otake, Y.; Nolan, A.L.; Walle, U.K.; Walle, T. Quercetin and resveratrol potently reduce estrogen sulfotransferase activity in normal human mammary epithelial cells. J Steroid Biochem Mol Biol. 2000 Jul-Aug;73(5):265-270. doi: 10.1016/s0960-0760(00)00073-x.

67) Abian, O.; Ortega-Alarcon, D.; Jimenez-Alesanco, A.; Ceballos-Laita, L.; Vega, S.; Reyburn, H.T.; Rizzuti, B.; Velazquez-Campoy, A. Structural stability of SARS-CoV-2 3CLpro and identification of quercetin as an inhibitor by experimental screening. Int J Biol Macromol. 2020 Dec 1;164:1693-1703. doi: 10.1016/j.ijbiomac.2020.07.235.

68) Malar, D.S.; Prasanth, M.I.; Brimson, J.M.; Sharika, R.; Sivamaruthi, B.S.; Chaiyasut, C.; Tencomnao, T. Neuroprotective Properties of Green Tea (Camellia sinensis) in Parkinson's Disease: A Review. Molecules. 2020 Aug 27;25(17):3926. doi: 10.3390/molecules25173926.

69) Deb, G.; Shankar, E.; Thakur, V.S.; Ponsky, L.E.; Bodner, D.R.; Fu, P.; Gupta, S. Green tea-induced epigenetic reactivation of tissue inhibitor of matrix metalloproteinase-3 suppresses prostate cancer progression through histone-modifying enzymes. Mol Carcinog. 2019 Jul;58(7):1194-1207. doi: 10.1002/mc.23003.

70) Yuasa, Y.; Nagasaki, H.; Akiyama, Y.; Hashimoto, Y.; Takizawa, T.; Kojima, K.; Kawano, T.; Sugihara, K.; Imai, K.; Nakachi, K. DNA methylation status is inversely correlated with green tea intake and physical activity in gastric cancer patients. Int J Cancer. 2009 Jun 1;124(11):26772682. doi: 10.1002/ijc.24231. 
71) Nova, E.; Redondo-Useros, N.; Martínez-García, R.M.; Gómez-Martínez, S.; Díaz-Prieto, L.E.; Marcos, A. Potential of Moringa oleifera to Improve Glucose Control for the Prevention of Diabetes and Related Metabolic Alterations: A Systematic Review of Animal and Human Studies. Nutrients. 2020 Jul 10;12(7):2050. doi: 10.3390/nu12072050.

72) Haber, S.L.; McMahon, R.P.; Barajas, J.; Hayes, A.R.; Hussein, H. Effects of Moringa oleifera in patients with type 2 diabetes. Am J Health Syst Pharm. 2020 Oct 30;77(22):1834-1837. doi: 10.1093/ajhp/zxaa255.

73) Vargas-Sánchez, K.; Garay-Jaramillo, E.; González-Reyes, R.E. Effects of Moringa oleifera on Glycaemia and Insulin Levels: A Review of Animal and Human Studies. Nutrients. 2019 Dec 2;11(12):2907. doi: 10.3390/nu11122907.

74) Taweerutchana, R.; Lumlerdkij, N.; Vannasaeng, S.; Akarasereenont, P.; Sriwijitkamol, A. Effect of Moringa oleifera Leaf Capsules on Glycemic Control in Therapy-Nä̈ve Type 2 Diabetes Patients: A Randomized Placebo Controlled Study. Evid Based Complement Alternat Med. 2017; 2017:6581390. doi: 10.1155/2017/6581390.

75) Igado, O.O.; Olopade, J.O.A. Review on the Possible Neuroprotective Effects of Moringa Oleifera Leaf Extract. Niger J Physiol Sci. 2017 Mar 6;31(2):183-187.

76) Juli, G.; Oliverio, M., Bellizzi, D., Gallo Cantafio, M.E.; Grillone, K.; Passarino, G.; Colica, C.; Nardi, M.; Rossi, M., Procopio, A.; Tagliaferri, P., Tassone, P.; Amodio, N. Anti-tumor Activity and Epigenetic Impact of the Polyphenol Oleacein in Multiple Myeloma. Cancers (Basel). 2019 Jul 16;11(7):990. doi: 10.3390/cancers11070990.

77) Arpón, A. Milagro, F.I.; Razquin, C.; Corella, D.; Estruch, R.; Fitó, M; Marti, A; MartínezGonzález, M.A.; Ros, E.; Salas-Salvadó, J.; Riezu-Boj, J.I.; Martínez, J.A. Impact of Consuming Extra-Virgin Olive Oil or Nuts within a Mediterranean Diet on DNA Methylation in Peripheral White Blood Cells within the PREDIMED-Navarra Randomized Controlled Trial: A Role for Dietary Lipids. Nutrients. 2017 Dec 23;10(1):15. doi: 10.3390/nu10010015. 
78) Luccarini, I.; Grossi, C.; Rigacci, S.; Coppi, E.; Pugliese, A.M.; Pantano, D.; la Marca, G.; Ed Dami, T., Berti, A.; Stefani, M., Casamenti, F. Oleuropein aglycone protects against pyroglutamylated-3 amyloid- $\beta$ toxicity: biochemical, epigenetic and functional correlates. Neurobiol Aging. 2015 Feb;36(2):648-63. doi: 10.1016/j.neurobiolaging.2014.08.029.

79) Mansouri, N.; Alivand, M.R.; Bayat, S.; Khaniani, M.S.; Derakhshan, S.M. The hopeful anticancer role of oleuropein in breast cancer through histone deacetylase modulation. J Cell Biochem. 2019 Oct;120(10):17042-17049. doi: 10.1002/jcb.28965.

80) Kou, X.; Li, B.; Olayanju, J.B.; Drake, J.M.; Chen, N. Nutraceutical or Pharmacological Potential of Moringa oleifera Lam. Nutrients. 2018 Mar 12;10(3):343. doi: 10.3390/nu10030343.

81) Petrović-Oggiano, G.; Debeljak-Martačić, J.; Ranković, S.; Pokimica, B.; Mirić, A.; Glibetić, M.; Popović, T. The Effect of Walnut Consumption on n-3 Fatty Acid Profile of Healthy People Living in a Non-Mediterranean West Balkan Country, a Small Scale Randomized Study. Nutrients. 2020 Jan 10;12(1):192. doi: 10.3390/nu12010192.

82) Lane, K.; Derbyshire, E.; Li, W.; Brennan, C. Bioavailability and potential uses of vegetarian sources of omega-3 fatty acids: a review of the literature. Crit Rev Food Sci Nutr. 2014;54(5):572-579. doi: 10.1080/10408398.2011.596292.

83) Tsoukas, M.A.; Ko, B.J.; Witte, T.R.; Dincer, F.; Hardman, W.E.; Mantzoros, C.S. Dietary walnut suppression of colorectal cancer in mice: Mediation by miRNA patterns and fatty acid incorporation. J Nutr Biochem. 2015 Jul;26(7):776-783. doi: 10.1016/j.jnutbio.2015.02.009.

84) Behavioral, Genetic, and Epigenetic Central Register Supplementation With Alpha-linoleic Acid in Humans - Cochrane Central Register of Controlled Trialshttps://clinicaltrials.gov/show/NCT01634776, 2012 I added to CENTRAL: 31 May 2018 I 2018 Issue 5

85) He, F.; Lupu, D.S.; Niculescu, M.D. Perinatal $\alpha$-linolenic acid availability alters the expression of genes related to memory and to epigenetic machinery, and the Mecp2 DNA 
methylation in the whole brain of mouse offspring. Int J Dev Neurosci. 2014 Aug;36:38-44. doi: 10.1016/j.ijdevneu.2014.05.006.

86) Ebrahimi, M.; Rajion, M.A.; Meng, G.Y.; Farjam, A.S.; Oskoueian, E.; Jafari, S. Diet high in $\alpha$-linoleic acid up-regulate PPAR- $\alpha$ gene expression in the liver of goats - Electronic Journal of Biotechnology, Volume 18, Issue 3, May 2015, Pages 210-214

87) Lissoni, P. -“Principi di PSICONEUROENDOCRINOIMMUNOLOGIA CLINICA”- Italia, Natur Editore, 2006.

88) Sanhueza, J., Valenzuela, A.B. Nutrigenómica: Revelando los aspectos moleculares de una nutricion personalizada - 2012, Revista Chilena de Nutricion - 39, 71-85.

89) Manoharan, I.; Suryawanshi, A.; Hong, Y.; Ranganathan, P.; Shanmugam, A.; Ahmad, S.; Swafford, D.; Manicassamy, B.; Ramesh, G.; Koni, P.A.; Thangaraju, M.; Manicassamy, S. Homeostatic PPARa Signaling Limits Inflammatory Responses to Commensal Microbiota in the Intestine. J Immunol. 2016 Jun 1;196(11):4739-4749. doi: 10.4049/jimmunol.1501489.

90) Nuclear Receptors Nomenclature Committee A unified nomenclature system for the nuclear receptor superfamily. Cell. 1999, 97, pp. 161-163.

91) Fu, J.; Gaetani, S.; Oveisi, F.; Lo Verme, J.; Serrano, A.; Rodríguez De Fonseca, F.; Rosengarth, A.; Luecke, H.; Di Giacomo, B.; Tarzia, G.; Piomelli, D. Oleylethanolamide regulates feeding and body weight through activation of the nuclear receptor PPAR-alpha. Nature. 2003 Sep 4;425(6953):90-93. doi: 10.1038/nature01921.

92) Doktorova, M.; Zwarts, I.; Zutphen, T.V.; Dijk, T.H.V.; Bloks, V.W.; Harkema, L.; Bruin, A.; Downes, M.; Evans, R.M.; Verkade, H.J.; Jonker, J.W. Intestinal PPAR $\delta$ protects against dietinduced obesity, insulin resistance and dyslipidemia. Sci Rep. 2017 Apr 12;7(1):846. doi: 10.1038/s41598-017-00889-z.

93) Anghel, S.I.; Wahli, W. Fat poetry: a kingdom for PPAR gamma. Cell Res. 2007 Jun;17(6):486-511. doi: 10.1038/cr.2007.48. 
94) Marion-Letellier, R.; Déchelotte, P.; Iacucci, M.; Ghosh, S. Dietary modulation of peroxisome proliferator-activated receptor gamma. Gut. 2009 Apr;58(4):586-593. doi: 10.1136/gut.2008.162859.

95) Cerbone, A.; Toaldo, C.; Laurora, S.; Briatore, F.; Pizzimenti, S.; Dianzani, M.U.; Ferretti, C.; Barrera, G. 4-Hydroxynonenal and PPARgamma ligands affect proliferation, differentiation, and apoptosis in colon cancer cells. Free Radic Biol Med. 2007 Jun 1;42(11):1661-1670. doi: 10.1016/j.freeradbiomed.2007.02.009.

96) Liang, Q.; Zhong, L.; Zhang, J.; Wang, Y., Bornstein, S.R.; Triggle, C.R.; Ding, H.; Lam, K.S.; Xu, A. FGF21 maintains glucose homeostasis by mediating the cross talk between liver and brain during prolonged fasting. Diabetes. 2014 Dec;63(12):4064-4075. doi: 10.2337/db14-0541.

97) Kharitonenkov, A.; Shiyanova, T.L.; Koester, A.; Ford, A.M.; Micanovic, R.; Galbreath, E.J.; Sandusky, G.E.; Hammond, L.J.; Moyers, J.S.; Owens, R.A.; Gromada, J.; Brozinick, J.T.; Hawkins, E.D.; Wroblewski, V.J.; Li, D.S.; Mehrbod, F.; Jaskunas, S.R; Shanafelt, A.B. FGF-21 as a novel metabolic regulator. J Clin Invest. 2005 Jun;115(6):1627-1635. doi: 10.1172/JCI23606.

98) Chen, L.; Yang, G. PPARs Integrate the Mammalian Clock and Energy Metabolism. PPAR Res. 2014; 2014:653017. doi: 10.1155/2014/653017.

99) Seckl, J.R. 11beta-hydroxysteroid dehydrogenases: changing glucocorticoid action. Curr Opin Pharmacol. 2004 Dec;4(6):597-602. doi: 10.1016/j.coph.2004.09.001.

100) Plottel, C.S.; Blaser, M.J. Microbiome and malignancy. Cell Host Microbe. 2011 Oct 20;10(4):324-335. doi: 10.1016/j.chom.2011.10.003.

101) Frankenfeld, C.L.; Atkinson, C.; Wähälä, K.; Lampe, J.W. Obesity prevalence in relation to gut microbial environments capable of producing equol or O-desmethylangolensin from the isoflavone daidzein. Eur J Clin Nutr. 2014 Apr;68(4):526-530. doi: 10.1038/ejcn.2014.23.

102) Barrett Mueller, K.; Lu, Q.; Mohammad, N.N.; Luu, V.; McCurley, A.; Williams, G.H.; Adler, G.K.; Karas, R.H.; Jaffe, I.Z. Estrogen receptor inhibits mineralocorticoid receptor 
transcriptional regulatory function. Endocrinology. 2014 Nov;155(11):4461-4472. doi: 10.1210/en.2014-1270.

103) Rodriguez, F.; Jolin, T. The role of somatostatin and/or dopamine in basal and TRHstimulated TSH release in food-restricted rats. Acta Endocrinol (Copenh). 1991 Aug;125(2):186191. doi: 10.1530/acta.0.1250186.

104) Guigon, C.J.; Zhao, L.; Lu, C., Willingham, M.C.; Cheng, S.Y. Regulation of beta-catenin by a novel nongenomic action of thyroid hormone beta receptor. Mol Cell Biol. 2008 Jul;28(14):4598-4608. doi: 10.1128/MCB.02192-07.

105) Wojcicka, A.; Piekielko-Witkowska, A.; Kedzierska, H.; Rybicka, B.; Poplawski, P.; Boguslawska, J. Master A, Nauman A. Epigenetic regulation of thyroid hormone receptor beta in renal cancer. PLoS One. 2014 May 21;9(5):e97624. doi: 10.1371/journal.pone.0097624.

106) Lavu, R.V.; Van De Wiele, T.; Pratti, V.L.; Tack, F.; Du Laing, G. Selenium bioaccessibility in stomach, small intestine and colon: Comparison between pure Se compounds, Se-enriched food crops and food supplements. Food Chem. 2016 Apr 15;197(Pt A):382-387. doi: 10.1016/j.foodchem.2015.08.001.

107) Cindoruk, M.; Tuncer, C.; Dursun, A.; Yetkin, I.; Karakan, T.; Cakir, N.; Soykan, I. Increased colonic intraepithelial lymphocytes in patients with Hashimoto's thyroiditis. J Clin Gastroenterol. 2002 Mar;34(3):237-239. doi: 10.1097/00004836-200203000-00008.

108) Litwa, E.; Rzemieniec, J.; Wnuk, A.; Lason, W.; Krzeptowski, W.; Kajta, M. RXR 2 , PXR and CAR xenobiotic receptors mediate the apoptotic and neurotoxic actions of nonylphenol in mouse hippocampal cells. J Steroid Biochem Mol Biol. 2016 Feb;156:43-52. doi: 10.1016/j.jsbmb.2015.11.018.

109) Duszka, K.; Wahli, W. Enteric Microbiota-Gut-Brain Axis from the Perspective of Nuclear Receptors. Int J Mol Sci. 2018 Jul 28;19(8):2210. doi: 10.3390/ijms19082210.

110) Inagaki, T.; Moschetta, A.; Lee, Y.K.; Peng, L.; Zhao, G.; Downes, M., Yu, R.T.; Shelton, J.M.; Richardson, J.A.; Repa, J.J.; Mangelsdorf, D.J.; Kliewer, S.A. Regulation of antibacterial 
defense in the small intestine by the nuclear bile acid receptor. Proc Natl Acad Sci U S A. 2006 Mar 7;103(10):3920-3925. doi: 10.1073/pnas.0509592103.

111) Kim, I.; Ahn, S.H.; Inagaki, T.; Choi, M.; Ito, S; Guo, G.L.; Kliewer, S.A.; Gonzalez, F.J. Differential regulation of bile acid homeostasis by the farnesoid $X$ receptor in liver and intestine. $\mathbf{J}$ Lipid Res. 2007 Dec;48(12):2664-2672. doi: 10.1194/jlr.M700330-JLR200.

112) Makishima, M.; Okamoto, A.Y.; Repa, J.J.; Tu, H; Learned, R.M.; Luk, A.; Hull, M.V.; Lustig, K.D.; Mangelsdorf, D.J.; Shan, B. Identification of a nuclear receptor for bile acids. Science. 1999 May 21;284(5418):1362-1365. doi: 10.1126/science.284.5418.1362.

113) Nguyen, A.; Bouscarel, B. Bile acids and signal transduction: Role in glucose homeostasis. Cell Signal. 2008;20:2180-2197.

114) Lee, J.M.; Wagner, M.; Xiao, R.; Kim, K.H.; Feng, D.; Lazar, M.A.; Moore, D.D. Nutrientsensing nuclear receptors coordinate autophagy. Nature. 2014 Dec 4;516(7529):112-115. doi: 10.1038/nature13961.

115) Seok, S.; Fu, T.; Choi, S.E.; Li, Y.; Zhu, R.; Kumar, S.; Sun, X.; Yoon, G.; Kang, Y.; Zhong, W.; Ma, J.; Kemper, B.; Kemper, J.K. Transcriptional regulation of autophagy by an FXRCREB axis. Nature. 2014 Dec 4;516(7529):108-111. doi: 10.1038/nature13949.

116) Lundåsen, T.; Gälman, C.; Angelin, B.; Rudling, M. Circulating intestinal fibroblast growth factor 19 has a pronounced diurnal variation and modulates hepatic bile acid synthesis in man. J Intern Med. 2006 Dec;260(6):530-536. doi: 10.1111/j.1365-2796.2006.01731.x.

117) Lin, B.C.; Wang, M. Blackmore, C.; Desnoyers, L.R.; Liver-specific activities of FGF19 require Klotho beta. J Biol Chem. 2007 Sep 14;282(37):27277-27284. doi: 10.1074/jbc.M704244200.

118) Haussler, M.R.; Haussler, C.A.; Bartik, L.; Whitfield, G.K.; Hsieh, J.C.; Slater, S.; Jurutka, P.W. Vitamin D receptor: molecular signaling and actions of nutritional ligands in disease prevention. Nutr Rev. 2008 Oct;66(10 Suppl 2):S98-112. doi: 10.1111/j.1753-4887.2008.00093.x. 
119) Su, D.; Nie, Y.; Zhu, A.; Chen, Z.; Wu, P.; Zhang, L.; Luo, M.; Sun, Q.; Cai, L.; Lai, Y.; Xiao, Z.; Duan, Z.; Zheng, S.; Wu, G.; Hu, R.; Tsukamoto, H.; Lugea, A.; Liu, Z.; Pandol, S.J.; Han, Y.P. Vitamin D Signaling through Induction of Paneth Cell Defensins Maintains Gut Microbiota and Improves Metabolic Disorders and Hepatic Steatosis in Animal Models. Front Physiol. 2016 Nov 15;7:498. doi: 10.3389/fphys.2016.00498.

120) Evatt, M.L.; Delong, M.R.; Khazai, N.; Rosen, A.; Triche, S.; Tangpricha, V. Prevalence of vitamin d insufficiency in patients with Parkinson disease and Alzheimer disease. Arch Neurol. 2008 Oct;65(10):1348-52. doi: 10.1001/archneur.65.10.1348.

121) De Martin, R.; Hoeth, M.; Hofer-Warbinek, R.; Schmid, J.A. The transcription factor NFkappa $B$ and the regulation of vascular cell function. Arterioscler Thromb Vasc Biol. 2000 Nov;20(11):E83-8. doi: 10.1161/01.atv.20.11.e83.

122) Bellido, C.; López-Miranda, J.; Blanco-Colio, L.M.; Pérez-Martínez, P.; Muriana, F.J.; Martín-Ventura, J.L.; Marín, C.; Gómez, P., Fuentes, F.; Egido, J.; Pérez-Jiménez, F. Butter and walnuts, but not olive oil, elicit postprandial activation of nuclear transcription factor kappaB in peripheral blood mononuclear cells from healthy men. Am J Clin Nutr. 2004 Dec;80(6):1487-1491. doi: 10.1093/ajcn/80.6.1487.

123) Yamashita, H.; Takenoshita, M.; Sakurai, M.; Bruick, R.K.; Henzel, W.J.; Shillinglaw, W.; Arnot, D.; Uyeda, K. A glucose-responsive transcription factor that regulates carbohydrate metabolism in the liver. Proc Natl Acad Sci U S A. 2001 Jul 31;98(16):9116-9121. doi: 10.1073/pnas.161284298.

124) Fukasawa, M.; Ge, Q.; Wynn, R.M.; Ishii, S.; Uyeda, K. Coordinate regulation/localization of the carbohydrate responsive binding protein (ChREBP) by two nuclear export signal sites: discovery of a new leucine-rich nuclear export signal site. Biochem Biophys Res Commun. 2010 Jan 8;391(2):1166-1169. doi: 10.1016/j.bbrc.2009.11.115. 
125) Lee, A.H.; Scapa, E.F.; Cohen, D.E.; Glimcher, L.H. Regulation of hepatic lipogenesis by the transcription factor XBP1. Science. 2008 Jun 13;320(5882):1492-1496. doi: 10.1126/science. 1158042 .

126) Zhang, P.; McGrath, B.C.; Reinert, J.; Olsen, D.S.; Lei, L.; Gill, S.; Wek, S.A., Vattem, K.M.; Wek, R.C.; Kimball. S.R.; Jefferson, L.S.; Cavener, D.R. The GCN2 eIF2alpha kinase is required for adaptation to amino acid deprivation in mice. Mol Cell Biol. 2002 Oct;22(19):66816688. doi: 10.1128/mcb.22.19.6681-6688.2002.

127) Luethy, J.D.; Holbrook, N.J. Activation of the gadd153 promoter by genotoxic agents: a rapid and specific response to DNA damage. Cancer Res. 1992 Jan 1;52(1):5-10.

128) Jousse, C.; Averous, J.; Bruhat, A.; Carraro, V.; Mordier, S.; Fafournoux, P. Amino acids as regulators of gene expression: molecular mechanisms. Biochem Biophys Res Commun. 2004 Jan 9;313(2):447-452. doi: 10.1016/j.bbrc.2003.07.020.

129) Kimball, S.R.; Jefferson, L.S. Amino acids as regulators of gene expression. Nutr Metab (Lond). 2004 Aug 17;1(1):3. doi: 10.1186/1743-7075-1-3.

130) Wise, C.; Kaput, J. A strategy for analyzing gene-nutrient interactions in type 2 diabetes. J Diabetes Sci Technol. 2009 Jul 1;3(4):710-721. doi: 10.1177/193229680900300416.

131) Razny, U.; Polus, A.; Kiec-Wilk, B.; Wator, L.; Hartwich, J.; Stachura, J.; Tomaszewska, R.; Dyduch, G.; Laidler, P.; Schmitz, G.; Goralczyk, R.; Wertz, K.; Riss, G.; Franssen-van Hal, N.L.; Keijer, J.; Dembinska-Kiec, A. Angiogenesis in Balb/c mice under beta-carotene supplementation in diet. Genes Nutr. 2010 Mar;5(1):9-16. doi: 10.1007/s12263-009-0160-3.

132) Birringer, M.; Drogan, D.; Brigelius-Flohe, R. Tocopherols are metabolized in HepG2 cells by side chain omega-oxidation and consecutive beta-oxidation. Free Radic Biol Med. 2001 Jul 15;31(2):226-232. doi: 10.1016/s0891-5849(01)00574-3.

133) Ma, J.; Stampfer, M.J.; Giovannucci, E.; Artigas, C.; Hunter, DJ.; Fuchs, C.; Willett, W.C.; Selhub, J.; Hennekens, C.H.; Rozen, R. Methylenetetrahydrofolate reductase polymorphism, dietary interactions, and risk of colorectal cancer. Cancer Res. 1997 Mar 15;57(6):1098-1102. 
134) Kim, Y.I. Folate and carcinogenesis: evidence, mechanisms, and implications. J Nutr Biochem. 1999 Feb;10(2):66-88. doi: 10.1016/s0955-2863(98)00074-6.

135) Sales, N.M.; Pelegrini, P.B.; Goersch, M.C. Nutrigenomics: definitions and advances of this new science. J Nutr Metab. 2014; 2014:202759. doi: 10.1155/2014/202759.

136) Tosco, A.; Monti, M.C.; Fontanella, B.; Montefusco, S.; D’Andrea, L.; Ziaco, B.; Baldantoni, D.; Rio, M.C.; Marzullo, L. Copper binds the carboxy-terminus of trefoil protein 1 (TFF1), favoring its homodimerization and motogenic activity. Cell Mol Life Sci. 2010 Jun;67(11):1943-55. doi: 10.1007/s00018-010-0309-7.

137) Sesink, A.L.; Termont, D.S.; Kleibeuker, J.H.; Van der Meer, R. Red meat and colon cancer: dietary haem-induced colonic cytotoxicity and epithelial hyperproliferation are inhibited by calcium. Carcinogenesis. 2001 Oct;22(10):1653-1659. doi: 10.1093/carcin/22.10.1653.

138) van der Meer-van Kraaij, C.; Kramer, E.; Jonker-Termont, D.; Katan, M.B.; van der Meer, R.; Keijer, J. Differential gene expression in rat colon by dietary heme and calcium. Carcinogenesis. 2005 Jan;26(1):73-79. doi: 10.1093/carcin/bgh288.

139) Tosco, A.; Fontanella, B.; Danise, R.; Cicatiello, L.; Grober, O.M.; Ravo, M.; Weisz, A.; Marzullo, L. Molecular bases of copper and iron deficiency-associated dyslipidemia: a microarray analysis of the rat intestinal transcriptome. Genes Nutr. 2010 Mar;5(1):1-8. doi: 10.1007/s12263009-0153-2.

140) Davis, C.D.; Milner, J. Frontiers in nutrigenomics, proteomics, metabolomics and cancer prevention. Mutat Res. 2004 Jul 13;551(1-2):51-64. doi: 10.1016/j.mrfmmm.2004.01.012.

141) Staels, B.; Fonseca, V.A. Bile acids and metabolic regulation: mechanisms and clinical responses to bile acid sequestration. Diabetes Care. 2009 Nov;32 Suppl 2(Suppl 2):S237-45. doi: $10.2337 / \mathrm{dc} 09-\mathrm{S} 355$.

142) Šarenac, T.M.; Mikov, M. Bile Acid Synthesis: From Nature to the Chemical Modification and Synthesis and Their Applications as Drugs and Nutrients. Front Pharmacol. 2018 Sep 25;9:939. doi: 10.3389/fphar.2018.00939. 
143) Ridlon, J.M.; Harris, S.C.; Bhowmik, S.; Kang, D.J.; Hylemon, P.B. Consequences of bile salt biotransformations by intestinal bacteria. Gut Microbes. 2016;7(1):22-39. doi: 10.1080/19490976.2015.1127483.

144) Chiang, J.Y. Bile acid metabolism and signaling. Compr Physiol. 2013 Jul;3(3):1191-1212. doi: 10.1002/cphy.c120023.

145) Fiorucci, S.; Biagioli, M.; Zampella, A.; Distrutti, E. Bile Acids Activated Receptors Regulate Innate Immunity. Front Immunol. 2018 Aug 13;9:1853. doi: 10.3389/fimmu.2018.01853.

146) Magaway, C.; Kim, E.; Jacinto, E. Targeting mTOR and Metabolism in Cancer: Lessons and Innovations. Cells. 2019 Dec 6;8(12):1584. doi: 10.3390/cells8121584.

147) Merbitz-Zahradnik, T.; Wolf, E. How is the inner circadian clock controlled by interactive clock proteins?: Structural analysis of clock proteins elucidates their physiological role. FEBS Lett. 2015 Jun 22;589(14):1516-1529. doi: 10.1016/j.febslet.2015.05.024.

148) Oike, H.; Kobori, M. Resveratrol regulates circadian clock genes in Rat-1 fibroblast cells. Biosci Biotechnol Biochem. 2008 Nov;72(11):3038-3040. doi: 10.1271/bbb.80426.

149) Mohd Azmi, N.A.S.; Juliana, N.; Mohd Fahmi Teng, N.I.; Azmani, S.; Das, S.; Effendy, N. Consequences of Circadian Disruption in Shift Workers on Chrononutrition and their Psychosocial Well-Being. Int J Environ Res Public Health. 2020 Mar 19;17(6):2043. doi: 10.3390/ijerph17062043.

150) Hirota, T.; Okano, T.; Kokame, K.; Shirotani-Ikejima, H.; Miyata, T.; Fukada, Y. Glucose down-regulates Perl and Per2 mRNA levels and induces circadian gene expression in cultured Rat1 fibroblasts. J Biol Chem. 2002 Nov 15;277(46):44244-44251. doi: 10.1074/jbc.M206233200.

151) Williams, C.M.; Ordovas, J.M.; Lairon, D.; Hesketh, J.; Lietz, G.; Gibney, M.; van Ommen, B. The challenges for molecular nutrition research 1: linking genotype to healthy nutrition. Genes Nutr. 2008 Jul;3(2):41-49. doi: 10.1007/s12263-008-0086-1. 
152) Arkadianos, I.; Valdes, A.M.; Marinos, E.; Florou, A.; Gill, R.D.; Grimaldi, K.A. Improved weight management using genetic information to personalize a calorie controlled diet. Nutr J. 2007 Oct 18;6:29. doi: 10.1186/1475-2891-6-29.

153) Novelli e Giardina, 2003 RT-ICAR-NA-2013-6 Novembre 2013

154) Levy, S.; Sutton, G.; Ng, P.C.; Feuk, L.; Halpern, A.L.; Walenz, B.P.; Axelrod, N.; Huang, J.; Kirkness, E.F., Denisov, G.; Lin, Y.; MacDonald, J.R.; Pang, A.W.; Shago, M.; Stockwell, T.B.; Tsiamouri, A.; Bafna, V.; Bansal, V.; Kravitz, S.A.; Busam, D.A.; Beeson, K.Y.; McIntosh, T.C.; Remington, K.A.; Abril, J.F.; Gill, J.; Borman, J.; Rogers, Y.H.; Frazier, M.E.; Scherer, S.W.; Strausberg. R.L.; Venter, J.C. The diploid genome sequence of an individual human. PLoS Biol. 2007 Sep 4;5(10):e254. doi: 10.1371/journal.pbio.0050254.

155) Mozzoni, P.; De Palma, G.; Scotti, E.; Capelletti, M.; Mutti, A. Characterization of GSTM3 polymorphism by real-time polymerase chain reaction with LightCycler. Anal Biochem. 2004 Jul 1;330(1):175-177. doi: 10.1016/j.ab.2004.03.006.

156) Gregori, D.; Foltran, F., Verduci, E., Ballali, S., Franchin, L., Ghidina, M., Halpern, G.M.; Giovannini, M. A genetic perspective on nutritional profiles: do we still need them? J Nutrigenet Nutrigenomics. 2011;4(1):25-35. doi: 10.1159/000322569.

157) Bailey, L.B.; Gregory, J.F. 3rd. Polymorphisms of methylenetetrahydrofolate reductase and other enzymes: metabolic significance, risks and impact on folate requirement. J Nutr. 1999 May;129(5):919-922. doi: 10.1093/jn/129.5.919.

158) Ashfield-Watt P.A.; Pullin, C.H.; Whiting, J.M.; Clark, Z.E.; Moat, S.J.; Newcombe, R.G.; Burr, M.L.; Lewis, M.J.; Powers, H.J.; McDowell, I.F. Methylenetetrahydrofolate reductase 677C-$>T$ genotype modulates homocysteine responses to a folate-rich diet or a low-dose folic acid supplement: a randomized controlled trial. Am J Clin Nutr. 2002 Jul;76(1):180-6. doi: 10.1093/ajcn/76.1.180.

159) Tsang, B.L.; Devine, O.J.; Cordero, A.M.; Marchetta, C.M.; Mulinare, J.; Mersereau, P.; Guo, J.; Qi, Y.P.; Berry, R.J.; Rosenthal, J.; Crider, K.S.; Hamner, H.C. Assessing the association 
between the methylenetetrahydrofolate reductase (MTHFR) $677 C>T$ polymorphism and blood folate concentrations: a systematic review and meta-analysis of trials and observational studies. Am J Clin Nutr. 2015 Jun;101(6):1286-1294. doi: 10.3945/ajcn.114.099994.

160) Rowisha, M.; El-Batch, M.; El Shikh, T.; El Melegy, S.; Aly, H. Soluble receptor and gene polymorphism for AGE: relationship with obesity and cardiovascular risks. Pediatr Res. 2016 Jul;80(1):67-71. doi: 10.1038/pr.2016.55.

161) Schirru, E.; Corona, V.; Usai-Satta, P., Scarpa, M.; Oppia, F.; Loriga, F., Cucca, F., De Virgiliis, S., Rossino, R.; Macis, M.D.; Jores, R.D.; Congia, M. Genetic testing improves the diagnosis of adult type hypolactasia in the Mediterranean population of Sardinia. Eur J Clin Nutr. 2007 Oct;61(10):1220-1225. doi: 10.1038/sj.ejen.1602638.

162) Medrano, L.M.; Dema, B.; López-Larios, A.; Maluenda, C.; Bodas, A.; López-Palacios, N.; Figueredo, M.Á.; Fernández-Arquero, M.; Núñez, C. HLA and celiac disease susceptibility: new genetic factors bring open questions about the HLA influence and gene-dosage effects. PLoS One. 2012; 7(10):e48403. doi: 10.1371/journal.pone.0048403.

163) Palatini, P.; Ceolotto, G.; Ragazzo, F.; Dorigatti, F.; Saladini, F.; Papparella, I.; Mos, L.; Zanata, G.; Santonastaso, M. CYP1A2 genotype modifies the association between coffee intake and the risk of hypertension. J Hypertens. 2009 Aug;27(8):1594-1601. doi: 10.1097/HJH.0b013e32832ba850.

164) Martínez, C.; Galván, S.; Garcia-Martin, E.; Ramos, M.I.; Gutiérrez-Martín, Y.; Agúndez, J.A. Variability in ethanol biodisposition in whites is modulated by polymorphisms in the ADH1B and ADH1C genes. Hepatology. 2010 Feb;51(2):491-500. doi: 10.1002/hep.23341.

165) Giner, V.; Poch, E.; Bragulat, E., Oriola, J.; González, D.; Coca, A.; De La Sierra, A. Renin-angiotensin system genetic polymorphisms and salt sensitivity in essential hypertension. Hypertension. 2000 Jan;35(1 Pt 2):512-517. doi: 10.1161/01.hyp.35.1.512. 
166) Hassett, C.; Aicher, L.; Sidhu, J.S.; Omiecinski, C.J. Human microsomal epoxide hydrolase: genetic polymorphism and functional expression in vitro of amino acid variants. Hum Mol Genet. 1994 Mar;3(3):421-428. doi: 10.1093/hmg/3.3.421.

167) Hein, D.W. Molecular genetics and function of NAT1 and NAT2: role in aromatic amine metabolism and carcinogenesis. Mutat Res. 2002 Sep 30;506-507:65-77. doi: 10.1016/s00275107(02)00153-7.

168) Palli, D.; Masala, G.; Peluso, M.; Gaspari, L.; Krogh, V.; Munnia, A.; Panico, S.; Saieva, C.; Tumino, R.; Vineis, P.; Garte, S. The effects of diet on DNA bulky adduct levels are strongly modified by GSTM1 genotype: a study on 634 subjects. Carcinogenesis. 2004 Apr;25(4):577-584. doi: 10.1093/carcin/bgh033.

169) Szymczak-Tomczak, A.; Krela-Kaźmierczak, I.; Kaczmarek-Ryś, M.; Hryhorowicz, S.; Stawczyk-Eder, K.; Szalata, M.; Skrzypczak-Zielińska, M.; Łykowska-Szuber, L.; Eder, P.; Michalak, M.; Dobrowolska, A.; Słomski, R. Vitamin D receptor (VDR) TaqI polymorphism, vitamin D and bone mineral density in patients with inflammatory bowel diseases. Adv Clin Exp Med. 2019 Jul;28(7):955-960. doi: 10.17219/acem/97376.

170) Oktavianthi, S.; Trimarsanto, H.; Febinia, C.A.; Suastika, K.; Saraswati, M.R.; Dwipayana, P.; Arindrarto, W.; Sudoyo, H.; Malik, S.G. Uncoupling protein 2 gene polymorphisms are associated with obesity. Cardiovasc Diabetol. 2012 Apr 25;11:41. doi: 10.1186/1475-2840-11-41.

171) Park, S.; Daily, J.W.; Zhang, X.; Jin, H.S.; Lee, H.J.; Lee, Y.H. Interactions with the MC4R rs17782313 variant, mental stress and energy intake and the risk of obesity in Genome Epidemiology Study. Nutr Metab (Lond). 2016 May 21;13:38. doi: 10.1186/s12986-016-0096-8.

172) Saliba, L.F.; Reis, R.S.; Brownson, R.C.; Hino, A.A.; Tureck, L.V.; Valko, C.; de Souza, R.L.; Furtado-Alle, L. Obesity-related gene ADRB2, ADRB3 and GHRL polymorphisms and the response to a weight loss diet intervention in adult women. Genet Mol Biol. 2014 Mar;37(1):15-22. doi: $10.1590 / \mathrm{s} 1415-47572014000100005$. 
173) Qi, Q.; Bray, G.A.; Hu, F.B.; Sacks, F.M.; Qi, L. Weight-loss diets modify glucosedependent insulinotropic polypeptide receptor rs2287019 genotype effects on changes in body weight, fasting glucose, and insulin resistance: the Preventing Overweight Using Novel Dietary Strategies trial. Am J Clin Nutr. 2012 Feb;95(2):506-513. doi: 10.3945/ajcn.111.025270.

174) Nead, K.T.; Li, A.; Wehner, M.R.; Neupane, B.; Gustafsson, S.; Butterworth, A.; Engert, J.C.; Davis, A.D.; Hegele, R.A.; Miller, R.; den Hoed, M.; Khaw, K.T.; Kilpeläinen, T.O.; Wareham, N.; Edwards, T.L.; Hallmans, G.; Varga, T.V.; Kardia, S.L.; Smith, J.A.; Zhao, W.; Faul, J.D.; Weir, D.; Mi, J.; Xi, B.; Quinteros, S.C.; Cooper, C.; Sayer, A.A.; Jameson, K.; Grøntved, A.; Fornage, M.; Sidney, S.; Hanis, C.L.; Highland, H.M.; Häring, H.U.; Heni, M.; Lasky-Su, J.; Weiss, S.T.; Gerhard, G.S.; Still, C.; Melka, M.M.; Pausova, Z.; Paus, T.; Grant, S.F.; Hakonarson, H.; Price, R.A.; Wang, K.; Scherag, A; Hebebrand, J.; Hinney, A; BioBank Japan, AGEN-BMI, GIANT Consortium.; Franks, P.W.; Frayling, T.M.; McCarthy, M.I.; Hirschhorn, J.N.; Loos, R.J.; Ingelsson, E.; Gerstein, H.C.; Yusuf, S.; Beyene, J.; Anand. S.S.; Meyre, D. Contribution of common non-synonymous variants in PCSK1 to body mass index variation and risk of obesity: a systematic review and meta-analysis with evidence from up to 331175 individuals. Hum Mol Genet. 2015 Jun 15;24(12):3582-3594. doi: 10.1093/hmg/ddv097.

175) Li, H.L.; Zhang, Y.J.; Chen, X.P.; Luo, J.Q.; Liu, S.Y.; Zhang, Z.L. Association between GNB3 c.825C > T polymorphism and the risk of overweight and obesity: A meta-analysis. Meta Gene. 2016 Mar 18;9:18-25. doi: 10.1016/j.mgene.2016.03.002.

176) Zain, S.M.; Mohamed, Z.; Jalaludin, M.Y.; Fauzi, F.; Hamidi, A.; Zaharan, N.L. Comprehensive evaluation of the neuropeptide-Y gene variants in the risk of obesity: a case-control study and meta-analysis. Pharmacogenet Genomics. 2015 Oct;25(10):501-510. doi: 10.1097/FPC.0000000000000164.

177) Daghestani, M.; Daghestani, M.; Daghistani, M.; Eldali, A., Hassan, Z.K.; Elamin, M.H.; Warsy, A. ADRB3 polymorphism rs4994 (Trp64Arg) associates significantly with bodyweight 
elevation and dyslipidaemias in Saudis but not rs1801253 (Arg389Gly) polymorphism in ARDB1. Lipids Health Dis. 2018 Mar 27;17(1):58. doi: 10.1186/s12944-018-0679-7.

178) de Luis, D.A.; Izaola, O.; de la Fuente, B.; Primo, D.; Romero, E. Role of Fatty AcidBinding Protein 2 Ala54Thr Genotype on Weight Loss and Cardiovascular Risk Factors after a High-Protein/Low-Carbohydrate versus a Standard Hypocaloric Diet during 9 Months. Ann Nutr Metab. 2015;67(2):81-86. doi: 10.1159/000438947.

179) Liu, X.H.; Xie, C.G.; An, Y.; Zhang, X.X.; Wu, W.B. Meta-analysis of the association between the rs7903146 polymorphism at the TCF7L2 locus and type 2 diabetes mellitus susceptibility. Genet Mol Res. 2015 Dec 14;14(4):16856-16862. doi: 10.4238/2015.December.14.12.

180) Garaulet, M.; Vera, B.; Bonnet-Rubio, G.; Gómez-Abellán, P.; Lee, Y.C.; Ordovás, J.M. Lunch eating predicts weight-loss effectiveness in carriers of the common allele at PERILIPIN1: the ONTIME (Obesity, Nutrigenetics, Timing, Mediterranean) study. Am J Clin Nutr. 2016 Oct;104(4):1160-1166. doi: 10.3945/ajcn.116.134528.

181) Buzzetti, R.; Petrone, A.; Ribaudo, M.C.; Alemanno, I.; Zavarella, S., Mein, C.A.; Maiani, F.; Tiberti, C.; Baroni, M.G.; Vecci, E., Arca, M.; Leonetti, F.; Di Mario, U. The common PPARgamma2 Pro12Ala variant is associated with greater insulin sensitivity. Eur J Hum Genet. 2004 Dec;12(12):1050-1054. doi: 10.1038/sj.ejhg.5201283.

182) Baturin, AK.; Sorokina, E.; Pogozheva, AV.; Peskova, EV.; Makurina, ON.; Tutelyan, VA. The study of the association of polymorphism rs5219 gene KCNJ11 with obesity and the risk of type 2 diabetes among residents of the Moscow Region. Vopr Pitan. 2015;84(2):4-9. Russian.

183) Povel, C.M.; Boer, J.M.; Onland-Moret, N.C.; Dollé, M.E.; Feskens, E.J.; van der Schouw, Y.T. Single nucleotide polymorphisms (SNPs) involved in insulin resistance, weight regulation, lipid metabolism and inflammation in relation to metabolic syndrome: an epidemiological study. Cardiovasc Diabetol. 2012 Oct 29;11:133. doi: 10.1186/1475-2840-11-133. 
184) Gajewska, J.; Kuryłowicz, A.; Mierzejewska, E; Ambroszkiewicz, J.; Chełchowska, M.; Weker, H.; Puzianowska-Kuźnicka, M. Complementary Effects of Genetic Variations in LEPR on Body Composition and Soluble Leptin Receptor Concentration after 3-Month Lifestyle Intervention in Prepubertal Obese Children. Nutrients. 2016 May 27;8(6):328. doi: 10.3390/nu8060328.

185) Tanabe, A.; Yanagiya, T.; Iida, A.; Saito, S.; Sekine, A.; Takahashi, A.; Nakamura, T.; Tsunoda, T.; Kamohara, S.; Nakata, Y.; Kotani, K.; Komatsu, R.; Itoh, N.; Mineo, I.; Wada, J.; Funahashi, T.; Miyazaki, S.; Tokunaga, K.; Hamaguchi, K.; Shimada, T.; Tanaka, K.; Yamada, K.; Hanafusa, T.; Oikawa, S.; Yoshimatsu, H.; Sakata, T.; Matsuzawa, Y.; Kamatani, N.; Nakamura, Y.; Hotta, K. Functional single-nucleotide polymorphisms in the secretogranin III (SCG3) gene that form secretory granules with appetite-related neuropeptides are associated with obesity. J Clin Endocrinol Metab. 2007 Mar;92(3):1145-1154. doi: 10.1210/jc.2006-1808.

186) Gueorguiev, M.; Lecoeur, C.; Meyre, D.; Benzinou, M.; Mein, C.A.; Hinney, A.; Vatin. V.; Weill, J.; Heude, B.; Hebebrand, J.; Grossman, A.B.; Korbonits, M.; Froguel, P. Association studies on ghrelin and ghrelin receptor gene polymorphisms with obesity. Obesity (Silver Spring). 2009 Apr;17(4):745-54. doi: 10.1038/oby.2008.589.

187) Riancho, J.A.; Vázquez, L.; García-Pérez, M.A.; Sainz, J.; Olmos, J.M.; Hernández, J.L.; Pérez-López, J.; Amado, J.A.; Zarrabeitia, M.T.; Cano, A.; Rodríguez-Rey, J.C. Association of ACACB polymorphisms with obesity and diabetes. Mol Genet Metab. 2011 Dec;104(4):670-6. doi: 10.1016/j.ymgme.2011.08.013.

188) García-Martín, E.; Ayuso, P.; Martínez, C., Blanca, M.; Agúndez, J.A. Histamine pharmacogenomics. Pharmacogenomics. 2009 May;10(5):867-883. doi: 10.2217/pgs.09.26

189) Franceschi, C.; Capri, M.; Monti, D.; Giunta, S.; Olivieri, F.; Sevini, F.; Panourgia, M.P.; Invidia, L.; Celani, L.; Scurti, M.; Cevenini, E.; Castellani, G.C.; Salvioli, S. Inflammaging and anti-inflammaging: a systemic perspective on aging and longevity emerged from studies in humans. Mech Ageing Dev. 2007 Jan;128(1):92-105. doi: 10.1016/j.mad.2006.11.016. 
190) Capri. M.; Salviol, S.; Sevini, F.; Valensin, S.; Celani, L.; Monti, D.; Pawelec, G.; De Benedictis, G.; Efstathios, S.; Franceschi, C. The Genetics of Human Longevity, Annals of the NY Academy of Science 2006 May;1067:252-63. - Ann N Y Acad Sci. 2006 May;1067:252-263.

191) Su, F.; Bai, F.; Zhang, Z. Inflammatory Cytokines and Alzheimer's Disease: A Review from the Perspective of Genetic Polymorphisms. Neurosci Bull. 2016 Oct;32(5):469-480. doi: $10.1007 / \mathrm{s} 12264-016-0055-4$.

192) Giudice, A.; Montella, M. Activation of the Nrf2-ARE signaling pathway: a promising strategy in cancer prevention. Bioessays. 2006 Feb;28(2):169-181. doi: 10.1002/bies.20359.

193) Da Costa, L.A.; Badawi, A.; El-Sohemy, A. Nutrigenetics and modulation of oxidative stress. Ann Nutr Metab. 2012;60 Suppl 3:27-36. doi: 10.1159/000337311.

194) Hernández-Guerrero, C.; Parra-Carriedo, A.; Ruiz-de-Santiago, D.; Galicia-Castillo, O.; Buenrostro-Jáuregui, M.; Díaz-Gutiérrez, C. Genetic polymorphisms of antioxidant enzymes CAT and SOD affect the outcome of clinical, biochemical, and anthropometric variables in people with obesity under a dietary intervention. Genes Nutr. 2018 Jan 8;13:1. doi: 10.1186/s12263-017-05902.

195) Atanasovska Velkovska, M.; Goričar, K.; Blagus, T.; Dolžan, V.; Cvenkel, B. Association of Genetic Polymorphisms in Oxidative Stress and Inflammation Pathways with Glaucoma Risk and Phenotype. J Clin Med. 2021 Mar 9;10(5):1148. doi: 10.3390/jcm10051148.

196) Zopf, Y.; Baenkler, H.W.; Silbermann, A.; Hahn, E.G.; Raithel, M. The differential diagnosis of food intolerance. Dtsch Arztebl Int. 2009 May;106(21):359-369; quiz 369-370; 4 p following 370. doi: 10.3238/arztebl.2009.0359.

197) Delacour, H.; Leduc, A.; Louçano-Perdriat, A., Plantamura, J.; Ceppa F. Diagnosis of genetic predisposition for lactose intolerance by high resolution melting analysis. Ann Biol Clin (Paris). 2017 Feb 1;75(1):67-74. English. doi: 10.1684/abc.2016.1210. 
198) Bersaglieri, T.; Sabeti, P.C.; Patterson, N.; Vanderploeg, T.; Schaffner, S.F.; Drake, J.A.; Rhodes, M.; Reich, D.E.; Hirschhorn, J.N. Genetic signatures of strong recent positive selection at the lactase gene. Am J Hum Genet. 2004 Jun;74(6):1111-1120. doi: 10.1086/421051

199) Tishkoff, S.A.; Reed, F.A.; Ranciaro, A.; Voight, B.F.; Babbitt, C.C.; Silverman, J.S.; Powell, K.; Mortensen, H.M.; Hirbo, J.B.; Osman, M.; Ibrahim, M.; Omar, S.A.; Lema, G.; Nyambo, T.B.; Ghori, J.; Bumpstead, S.; Pritchard, J.K.; Wray, G.A.; Deloukas, P. Convergent adaptation of human lactase persistence in Africa and Europe. Nat Genet. 2007 Jan;39(1):31-40. doi: $10.1038 /$ ng 1946 .

200) Stanković, B.; Radlović, N.; Leković, Z.; Ristić, D.; Radlović, V.; Nikčević, G.; Kotur, N.; Vučićević, K.; Kostić, T.; Pavlović, S., Zukic, B. HLA genotyping in pediatric celiac disease patients. Bosn J Basic Med Sci. 2014 Aug 16;14(3):171-176. doi: 10.17305/bjbms.2014.3.28.

201) Hill, I.D.; Dirks, M.H.; Liptak, G.S.; Colletti, R.B.; Fasano, A.; Guandalini, S., Hoffenberg, E.J., Horvath, K.; Murray, J.A.; Pivor, M.; Seidman, E.G. North American Society for Pediatric Gastroenterology, Hepatology and Nutrition. Guideline for the diagnosis and treatment of celiac disease in children: recommendations of the North American Society for Pediatric Gastroenterology, Hepatology and Nutrition. J Pediatr Gastroenterol Nutr. 2005 Jan;40(1):1-19. doi: 10.1097/00005176-200501000-00001.

202) Maintz, L.; Novak, N. Histamine and histamine intolerance. Am J Clin Nutr. 2007 May;85(5):1185-1196. doi: 10.1093/ajen/85.5.1185.

203) Agúndez, J.A.; Ayuso, P.; Cornejo-García, J.A.; Blanca, M.; Torres, M.J.; Doña, I.; Salas, M., Blanca-López, N.; Canto, G.; Rondon, C.; Campo, P.; Laguna, J.J.; Fernández, J.; Martínez, C., García-Martín, E. The diamine oxidase gene is associated with hypersensitivity response to nonsteroidal anti-inflammatory drugs. PLoS One. 2012;7(11):e47571. doi: 10.1371/journal.pone.0047571.

204) Sharma, A.D. Relationship between nickel allergy and diet. Indian J Dermatol Venereol Leprol. 2007 Sep-Oct;73(5):307-312. doi: 10.4103/0378-6323.35733. 
205) Zdrojewicz, Z.; Popowicz, E.; Winiarski, J. Nickel - role in human organism and toxic effects. Pol Merkur Lekarski. 2016 Aug;41(242):115-118. Polish.

206) Müller, S.; Marenholz, I.; Lee, Y.A.; Sengler, C.; Zitnik, S.E.; Griffioen, R.W.; Meglio, P.; Wahn, U.; Nickel, R. Association of Filaggrin loss-of-function-mutations with atopic dermatitis and asthma in the Early Treatment of the Atopic Child (ETAC) population. Pediatr Allergy Immunol. 2009 Jun;20(4):358-361. doi: 10.1111/j.1399-3038.2008.00808.x.

207) Colagiovanni, A.; Di Renzo, L.; Sarlo, F.; Schiavino, D.; De Lorenzo, A. Role of TNFalpha polymorphism in patients with nickel allergy: a marker of susceptibility to contact polysensitization. Eur Rev Med Pharmacol Sci. 2016 Jun;20(12):2663-2666.

208) Vally, H.; Misso, N.L.; Madan, V. Clinical effects of sulphite additives. Clin Exp Allergy. 2009 Nov;39(11):1643-1651. doi: 10.1111/j.1365-2222.2009.03362.x.

209) Gussago, C.; Arosio, B.; Guerini, F.R.; Ferri, E.; Costa, A.S.; Casati, M.; Bollini, E.M.; Ronchetti, F.; Colombo, E., Bernardelli, G.; Clerici, M.; Mari, D. Impact of vitamin D receptor polymorphisms in centenarians. Endocrine. 2016 Aug;53(2):558-64. doi: 10.1007/s12020-0160908-7.

210) Liska, D.J. The detoxification enzyme systems. Altern Med Rev. 1998 Jun;3(3):187-98.

211) Pontzer, H.; Raichlen, D.A.; Wood, B.M.; Mabulla, A.Z.; Racette, S.B.; Marlowe, F.W. Hunter-gatherer energetics and human obesity. PLoS One. 2012;7(7):e40503. doi: 10.1371/journal.pone.0040503.

212) Turnbaugh, P.J.; Gordon, J.I. The core gut microbiome, energy balance and obesity. J Physiol. 2009 Sep 1;587(Pt 17):4153-4158. doi: 10.1113/jphysiol.2009.174136.

213) Tan, L.J.; Zhu, H.; He, H., Wu, K.H.; Li, J., Chen, X.D.; Zhang, J.G.; Shen, H.; Tian, Q.; Krousel-Wood, M.; Papasian, C.J.; Bouchard, C; Pérusse, L; Deng ,H.W. Replication of 6 obesity genes in a meta-analysis of genome-wide association studies from diverse ancestries. PLoS One. 2014 May 30;9(5):e96149. doi: 10.1371/journal.pone.0096149. 
214) Jagannadham, J.; Jaiswal, H.K.; Agrawal, S.; Rawal, K. Comprehensive Map of Molecules Implicated in Obesity. PLoS One. 2016 Feb 17;11(2):e0146759. doi: 10.1371/journal.pone.0146759. 